DOCUMENTO DE TRABAJO

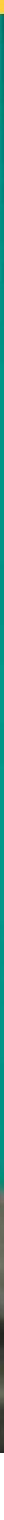

Políticas REDD+

\title{
y los medios de comunicación
}

Caso de estudio en el Perú

Javier Perla Alvarez

Daniela Freundt Montero

Eduardo Burga Barrantes

Talía Postigo Takahashi

Mary Menton 



\section{Políticas REDD+ y los medios de comunicación}

\section{Caso de estudio en el Perú}

Javier Perla Alvarez

Libélula Comunicación Ambiente y Desarrollo

Daniela Freundt Montero

Libélula Comunicación Ambiente y Desarrollo

Eduardo Burga Barrantes

Libélula Comunicación Ambiente y Desarrollo

Talía Postigo Takahashi

Libélula Comunicación Ambiente y Desarrollo

Mary Menton

CIFOR 
Documento de Trabajo 101

(C) 2012 Center for International Forestry Research

Todos los derechos reservados

Perla Alvarez, J., Freundt Montero, D., Burga Barrantes, E., Postigo Takahashi, T., Menton, M. 2012 Políticas REDD+ y los medios de comunicación: Caso de estudio en el Perú. Documento de Trabajo 101. CIFOR, Bogor, Indonesia.

Fotografías: Gerhard Buttner

CIFOR

Jl. CIFOR, Situ Gede

Bogor Barat 16115

Indonesia

$\mathrm{T}+62(251) 8622-622$

$\mathrm{F}+62(251) 8622-100$

E cifor@cgiar.org

\section{cifor.org}

Cualquier opinión vertida en este documento es de los autores. No refleja necesariamente las opiniones de CIFOR, de las instituciones para las que los autores trabajan o de los financiadores.

Libélula Comunicación, Ambiente y Desarrollo: La empresa se enfoca en temas técnicos, políticos, sociales, financieros y legales, así como de negociaciones internacionales, en el marco de la temática ambiental y de cambio climático en particular. Elabora, implementa, monitorea y evalúa proyectos de inversión en ámbitos ambientales, comunicacionales, educativos y de desarrollo. Recurre a una amplia gama de herramientas como la publicidad y el trabajo de prensa, el diseño participativo de campañas mediante la investigación social o la planificación de la comunicación, enfocándose en potenciar los objetivos institucionales o del proyecto.

Para más información entrar a: www.libelula.com.pe 


\section{Índice}

Abreviaciones

Agradecimientos viii

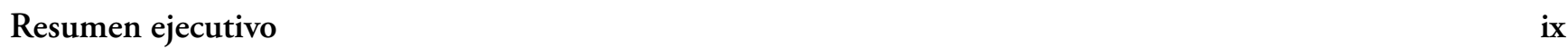

1 Introducción: DesenREDDando REDD 1

2 REDD+ en el Perú: ¿¿País de bosques significa país de REDD? 3

3 Los medios de comunicación en el Perú

3.1 Los impactos de los medios de comunicación en los tomadores de decisiones 5

3.2 Los medios más importantes en el Perú $\quad 6$

4 Metodología del estudio 9

4.1 Selección de diarios y artículos $\quad 9$

4.2 Enfoque del marco de medios 11

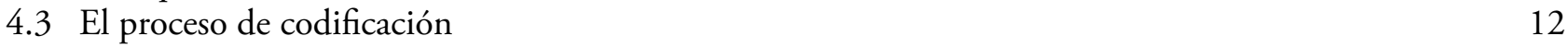

4.4 Entrevistas 13

4.5 Análisis de las 3Es: Efectividad, Eficiencia, Equidad 15

5 Resultados y análisis de la codificación de noticias $\quad 18$

5.1 Incidencia de artículos en los diarios seleccionados: Evaluación del Nivel $1 \quad 18$

5.2 Análisis de los artículos en el Nivel 2 y $3 \quad 28$

6 Conclusiones y recomendaciones $\quad 38$

$\begin{array}{llr}7 & \text { Bibliografía } & 40\end{array}$ 


\section{Lista de cuadros y figuras}

\section{Cuadros}

1 Nivel de confianza en instituciones no estatales 5

2 Tiraje promedio diario de los principales periódicos a nivel nacional $\quad 7$

3 Características de lectores de tres diarios en Lima

4 Categorías que describen el Tipo de Marco 12

5 Periodistas del estudio a nivel nacional entrevistados 14

6 Expertos en REDD y personas vinculadas a la temática ambiental entrevistados $\begin{array}{ll}\text { en el estudio de nivel nacional } & 15\end{array}$

7 Madre de Dios: miembros de los medios de comunicación entrevistados $\quad 15$

8 Madre de Dios: expertos en REDD y personas vinculadas a la temática $\begin{array}{ll}\text { ambiental entrevistados } & 16\end{array}$

9 San Martín: miembros de los medios de comunicación entrevistados 16

10 San Martín: expertos en REDD y personas vinculadas a la temática ambiental entrevistados

11 Las 3Es (Efectividad, Eficiencia, Equidad) 17

12 Ranking de los diarios según la percepción de los entrevistados, versus la incidencia $\begin{array}{ll}\text { real de artículos } & 20\end{array}$

13 Ranking de los diarios regionales según la percepción de los entrevistados 26

Figuras

1 Desenlace de REDD a nivel nacional e internacional 4

2 Traslape de noticias con las palabras clave analizadas a nivel nacional 18

3 Frecuencia de aparición de artículos de diarios de alcance nacional mencionando 19

4 Frecuencia de noticias por diario de alcance nacional, de acuerdo a grupo mayor de palabras clave

5 Número de artículos hallados por diario de alcance nacional para "REDD", "deforestación evitada", "reducción de emisiones + deforestación"; y "cambio climático + bosques"

6 Frecuencia de cobertura por año y por diario de alcance nacional, para "REDD", "deforestación evitada" y "reducción de emisiones + deforestación"

7 Frecuencia de cobertura por diario de alcance nacional y por trimestre, para "REDD", "deforestación evitada" y "reducción de emisiones + deforestación"

8 Frecuencia de cobertura por año y por diario de alcance nacional, para "cambio climático + bosques"

9 Frecuencia de cobertura por trimestre y por diario de alcance nacional, para "cambio climático + bosques"

10 Frecuencia de aparición de artículos por diario regional, mencionando

11 Frecuencia de noticias por diario regional, de acuerdo a grupo mayor de palabras clave

12 Número de artículos hallados por diario regional para "REDD", "deforestación evitada", "reducción de emisiones + deforestación"; y "cambio climático + bosques" 
13 Frecuencia de cobertura por año y por diario regional, para "cambio climático + bosques"

14 Frecuencia de artículos de diarios de alcance nacional, por autor, para "REDD", "deforestación evitada" y "reducción de emisiones + deforestación"

15 Frecuencia de artículos de diarios de alcance nacional por autor, para "cambio climático + bosques"

16 Frecuencia de artículos por autor en diarios regionales, para "REDD", "deforestación evitada" y "reducción de emisiones + deforestación"

17 Frecuencia de artículos por autor en diarios regionales, para "cambio climático + bosques"

18 Evolución de la categoría de los marcos primarios por año, para "REDD", "deforestación evitada" y "reducción de emisiones + deforestación"

19 Número de artículos por año por nivel, para "REDD", "deforestación evitada" y "reducción de emisiones + deforestación"

20 Metatópicos identificados para "REDD", "deforestación evitada" y "reducción de emisiones + deforestación"

21 Tópicos identificados para "REDD", "deforestación evitada" y "reducción de emisiones + deforestación"

22 Representación organizacional de los defensores, para "REDD", "deforestación evitada" y "reducción de emisiones + deforestación"

23 Evaluación del futuro de REDD por parte de defensores, por año, para "REDD", "deforestación evitada" y "reducción de emisiones + deforestación"

24 Evaluación del futuro de REDD por parte de los defensores, por organización, para "REDD", "deforestación evitada", y "reducción de emisiones + deforestación"

25 Prioridades de los defensores para resultados de REDD, para "REDD", "deforestación evitada" y "reducción de emisiones + deforestación"

26 Prioridades de los defensores según la representación organizacional, para "REDD", "deforestación evitada" y "reducción de emisiones + deforestación" 


\section{Abreviaciones}

3Es

3Es+

ACCA

AFP

AIDER

AIDESEP

AMPA

AP

APECO

ARA

CAMDE PERÚ

CEDISA

CI

CIFOR

CIMA

CMNUCC

COP

COSUDE

CPN

DAR

DGCCDRH

DGFFS

DPA

EFE

F\&R

FAO

FCPF

FEPROCAN

FERIAM

FIP

FONAM

G1

G2

G8

GCS

GEI

GTZ
Eficiencia, Efectividad y Equidad

Eficiencia, Efectividad, Equidad y otros beneficios

Asociación para la Conservación de la Cuenca Amazónica

Agencia Francesa de Prensa

Asociación para la Investigación y el Desarrollo Integral

Asociación Interétnica de Desarrollo de la Selva Peruana

Amazónicos por la Amazonía

Associated Press

Asociación Peruana para la Conservación de la Naturaleza

Autoridad Regional Ambiental

Conservación Ambiental y Desarrollo en el Perú

Centro de Desarrollo e Investigación de la Selva Alta

Conservación Internacional

Centro para la Investigación Forestal Internacional

Centro de Conservación, Investigación y Manejo de Áreas Naturales

Convención Marco de las Naciones Unidas sobre el Cambio Climático

Conferencia de las Partes de la Convención Marco de Naciones Unidas sobre el Cambio Climático

Agencia Suiza para el Desarrollo y la Cooperación

Cadena Peruana de Noticias

Derecho, Ambiente y Recursos Naturales

Dirección General de Cambio Climático, Desertificación y Recursos Hídricos

Dirección General Forestal y de Fauna Silvestre

Agencia Alemana de Noticias

Agencia Internacional de Noticias en Español

Actividades de Forestación y Reforestación

Organización de las Naciones Unidas para la Alimentación y la Agricultura

Fondo Cooperativo para el Carbono de los Bosques

Federación de Productores Castañeros y Madereros

Federación Regional e Indígena Awajún del Alto Mayo

Programa de Inversión Forestal

Fondo Nacional del Ambiente

Noticias del Grupo 1 (relacionadas con REDD)

Noticias del Grupo 2 (relacionadas con cambio climático y bosques)

Grupo de los 8

Estudio Comparativo Global sobre REDD

Gases de efecto invernadero

Agencia de Cooperación Técnica Alemana 
IPCC

ISUR

JICA

KfW

LNM

MADERACRE

$\mathrm{MdD}$

MDL

MINAG

MINAM

MRV

NAMA

NORAD

OEI

ONG

ORDEPISAN

PCM

PNCBMCC

PROFONANPE

PRONAMI

RED

REDD

REDD+/REDD Plus

RPP

SM

TNC

TNP

UNAMAD

USAID

WWF
Panel Intergubernamental de Cambio Climático

Interoceánica Sur

Agencia de Cooperación Internacional del Japón

Banco Alemán de Desarrollo

Lineamientos Nacionales de Mitigación

Maderera Río Acre

Madre de Dios

Mecanismos de Desarrollo Limpio

Ministerio de Agricultura

Ministerio del Ambiente

Medición, Reporte y Verificación

Medidas de Mitigación Nacionalmente Apropiadas

Agencia Noruega de Cooperación para el Desarrollo

Organización de Estados Iberoamericanos

Organización No Gubernamental

Oficina Regional de Desarrollo de los Pueblos Indígenas de San Martín

Presidencia del Consejo de Ministros

Programa Nacional de Conservación de Bosques para la Mitigación del

Cambio Climático

Fondo de Promoción de las Áreas Naturales Protegidas

Programa Nacional de Mitigación

Reducción de emisiones por deforestación

Reducción de emisiones por deforestación y degradación de los bosques

Reducción de emisiones por deforestación y degradación de los bosques, la función de la conservación, la gestión sostenible de los bosques y el aumento de las reservas de carbono

Radio Programas del Perú

San Martín

The Nature Conservancy

Televisión Nacional del Perú

Universidad Nacional Amazónica de Madre de Dios

Agencia de los Estados Unidos para el Desarrollo Internacional

World Wildlife Fund for Nature (Fondo Mundial para la Naturaleza) 


\section{Agradecimientos}

Para la elaboración del presente documento se contó con el apoyo de diferentes profesionales que con su conocimiento y experiencia enriquecieron el informe, a quienes queremos agradecerles por su gentil contribución. Entre ellos se encuentran Bertha Alvarado de la DGFFS del MINAG, Elvira Gómez de la DGCCDRH del MINAM, Julia Justo del FONAM, Alberto Paniagua del PROFONANPE, Roberto Persivale de Asesorandes, José Luis Alzamora de Bioforest, Juan José Rodríguez de TNC, Eddy Mendoza de CI, Lucía Ruiz, Cinthia Mongylardi y Walter Aguirre del CIMA, Alonso Castro y Carlos Sánchez de AIDER, Hugo Che Piu y Tania García de DAR, Bruno Sanguinetti del Consorcio Madre de Dios, Nelson Kroll de MADERACRE, Andrea Chávez de la Universidad de la Florida en el Consorcio Madre de Dios, Mishari García y José Mamani de la UNAMAD, Oscar Macedo y Claudio Delgado del Gobierno Regional de Madre de Dios, Jaime Semizo de ISUR, Juan Flores de Bosques Amazónicos, Melina Panduro de Candela Perú, Pastor Vidal de la Asociación de Despachadores de Producto Forestal de Madre de Dios, Víctor Zambrano del Comité de Gestión de la Reserva Nacional Tambopata, Augusto Mulanovich de ACCA, Iván Cárdenas de FEPROCAM, Pedro Casanova de la Federación Agraria de Madre de Dios, William Moreno de CAMDE Perú, Alex Juárez de APECO, Elías Peas de FERIAM, Segundo Cahuas de ORDEPISAN, Karina Pinasco de AMPA, Karla Mendoza de la Mesa REDD de Madre de Dios, Silvia Reátegui y Sebastián Inoñam de ARA, Jessica Untama, Mario Ríos y Miguel Alva del Gobierno Regional de San Martín, Martha del Castillo de CEDISA, Jessica Quipas de la Municipalidad Provincial de San Martín, José Armas de la Universidad César Vallejo, Gonzalo Pajares y Claudia Izaguirre de Perú 21, Francisco Ínsua de
Expreso, Nelly Luna, Mariella Balbi, Carlos Batalla e Iana Málaga de El Comercio, Roberto Ochoa de La República, José Cevallos de Don Jaque, Leonidas Tito de El Observador, Grimaldo Taboada de Mi Frontera, Lenin Quevedo de Voces, Marco Carrillo de Ahora, Julio García de Hoy, David Mejía de Inforegión y del programa radial Ciudadano al Día, José Huamaní del programa televisivo Telepuerto al Día, Alonso Paz del programa radial Noticiero de la Una y del programa televisivo Intercambio, Julio Blanco de Radio Popular, Biblioteca de la UNAMAD y a la Biblioteca Municipal de Madre de Dios.

El estudio es parte del componente de políticas del Estudio Comparativo Global de REDD de CIFOR (GCS, http://www.forestsclimatechange. org/global-comparative-study-on-redd.html), liderado por Maria Brockhaus. Los métodos utilizados en el estudio se basan en el protocolo para el análisis de los medios desarrollado por el programa COMPON (Comparing Climate Change Policy Networks, http://compon.org/) financiado por la Fundación Nacional de Ciencias (NSF) y liderado por Jeffrey Broadbent de la Universidad de Minnesota. Agradecemos el apoyo de la Agencia Noruega de Cooperación en Desarrollo (NORAD), la Agencia Australiana para el Desarrollo Internacional (AUSAID), la Comisión Europea, y del Departamento de Desarrollo Internacional del Reino Unido (DfID).

Finalmente, un especial agradecimiento al equipo técnico de CIFOR que nos acompañó en el proceso de elaboración del presente estudio y revisión de versiones anteriores, María Brockhaus, Gabriela Ramírez, Mónica di Gregorio, Christine Padoch, Peter Cronkleton y Kaisa Korhonen-Kurki. 


\section{Resumen ejecutivo}

En los últimos años, el papel de los bosques frente al cambio climático ha sido un tema de gran interés durante las negociaciones de la Convención Marco de las Naciones Unidas sobre Cambio Climático (CMNUCC). En 2005, nació el discurso sobre el potencial de evitar la deforestación (y luego en seguida la degradación forestal), como una herramienta de mitigación. Desde entonces, Perú ha sido uno de los países que más participa en las fases iniciales de REDD (reducción de emisiones por deforestación y degradación forestal). Como un país piloto en varias iniciativas internacionales de preparación para la implementación ("readiness"), Perú viene apoyando un enfoque anidado y una variedad de iniciativas subnacionales de REDD están en marcha en el país. Sin embargo, mientras que hay actores y expertos bien enterados en el tema, no está claro hasta qué punto las discusiones han llegado a un público mayor.

En este estudio, hemos evaluado la representación de REDD en periódicos nacionales y subnacionales del país para entender mejor los mensajes que llegan a los lectores peruanos. Al nivel nacional, encontramos apenas 33 artículos sobre REDD en 8 periódicos nacionales: El Comercio, Perú 21, Gestión, Expreso, La República, La Razón, El Peruano y Trome. Expandiendo la búsqueda a cambio climático y bosques, encontramos 203 noticias. Al encontrar esta baja cobertura en la prensa nacional, elegimos dos departamentos del país donde se encuentran el mayor número de proyectos REDD y mayores avances en las fases de preparación, San Martín (Voces y Ahora) y Madre de Dios (Don Jaque y El Observador). Pero, de nuevo, encontramos únicamente 10 artículos sobre REDD, y 10 más al ampliar la búsqueda a cambio climático y bosques.

En los periódicos regionales, todos los artículos mencionaron REDD pero no trataron el tema con profundidad suficiente para poder evaluar los marcos y enfoques temáticos. En los periódicos nacionales, 26 artículos llegaron a discutir REDD con mayor profundidad. La mayoría de ellos son optimistas sobre REDD (58\%). Mientras que hay una estimativa de 41 proyectos REDD en el país, $74 \%$ de las noticias tratan de temas internacionales. Los temas centrales de los artículos fueron mayormente políticos o de ecología y los actores principales fueron las ONG ambientales. Los enfoques están distribuidos casi igualmente entre los cobeneficios (26\%), la equidad (26\%), la eficiencia (21\%), y la efectividad (16\%) de REDD. Aunque REDD se creó en base a la premisa de mitigación del cambio climático, para los cuales la eficiencia y efectividad son las preocupaciones más relevantes, la equidad y los cobeneficios son los temas centrales en el Perú: los derechos de pueblos indígenas, la reducción de la pobreza, y la conservación de biodiversidad salen como los temas más relevantes para la cobertura del tema y como prioridades nacionales. 



\section{Introducción: DesenREDDando REDD}

Desde los orígenes de las negociaciones en la CMNUCC (Convención Marco de las Naciones Unidas sobre Cambio Climático), los bosques siempre han sido un tema controversial. Durante la COP3 (Conferencia de las Partes), en 1997, la decisión fue establecer el Protocolo de Kioto donde se excluían las absorciones y emisiones de GEI de los bosques. Los argumentos, entre otros, fueron que la mayor superficie de bosque del mundo se encuentra en el hemisferio norte, especialmente en países desarrollados y con alto potencial de absorción de GEI y que incluir créditos de bosques podría inundar el mercado con certificados de carbono baratos y fáciles de comercializar. Esto podría dificultar el desarrollo de otros proyectos de reducción de emisiones (Inwent et al., 2009); y que podría ser sumamente complicado desarrollar un sistema de Medición, Reporte y Verificación (MRV) para los GEI del bosque. En la COP7 de 2001 (los Acuerdos de Marrakech) las Partes acordaron la inclusión de las actividades de forestación y reforestación ( $F \& R$ ) en los Mecanismos de Desarrollo Limpio (MDL), pero no profundizaron en cuanto a la reglamentación que debía regir dichos proyectos. En la COP9 (Milán) las Partes adoptaron las definiciones y modalidades para las actividades de F\&R en el MDL durante el primer período de compromiso. En Montreal (COP11), se tomó la decisión de incluir la reducción de emisiones de GEI mediante deforestación evitada en países en desarrollo, a la que en ese momento se le denominó RED. Luego de eso y a través de sucesivas decisiones de la COP, se fueron incluyendo otros temas como la degradación del bosque, la conservación, el manejo forestal sostenible, el mantenimiento de las reservas de carbono, lo que actualmente se denomina REDD+ o REDD Plus (Inwent et al., 2009). Actualmente, se sigue negociando la mejor forma de cómo REDD+ funcionaría, asegurando que países desarrollados, en vías de desarrollo, con iniciativas tempranas, con sólidos y débiles sistemas de gobernanza forestal, están conformes y pueden participar. Los acuerdos y decisiones avanzan a un ritmo pausado, tal como la complejidad del tema lo requiere. La discusión continúa.
En principio, la reducción de las emisiones de gases de efecto invernadero derivadas de la deforestación y degradación forestal (REDD) está basada en 2 ideas principales. La primera: las emisiones de este sector en los países en desarrollo son responsables de más o menos el 20\% del total de las emisiones de gases de efecto invernadero (GEI) generadas anualmente a nivel mundial. La segunda: si generamos un sistema para premiar (ya sea con un enfoque de créditos o de fondos) a personas, comunidades, proyectos y/o países que reducen las emisiones GEI de los bosques, esto podría reducir significativamente las emisiones, con bajos costos y en un periodo corto de tiempo, a la vez que contribuye con la reducción de la pobreza y el desarrollo sostenible.

Aclarar los detalles de REDD implicará un proceso no necesariamente sencillo, en el cual se requiere que los países se pongan de acuerdo en cómo se enfocará REDD en términos de formulación de niveles de referencia, sistemas de MRV, no permanencia, escala (nacional, subnacional), distribución de beneficios, financiamiento, entre otros complejos temas. Mientras que las negociaciones internacionales siguen sin llegar a un consenso sobre estos detalles, los países están avanzando con el proceso de "readiness" (o preparación para la implementación de REDD). Este proceso de "readiness" involucra formulación de políticas públicas forestales y la creación de discursos sobre estos temas. Si bien en el Perú se cuenta con un grupo de profesionales bien capacitados en temas REDD, no está claro hasta dónde llega el entendimiento del mismo por parte de los políticos y el público en general.

Un actor importante en la formulación de la opinión pública sobre estas políticas se encuentra en los medios de comunicación y su relación con la sociedad civil y los tomadores de decisiones. Los medios de comunicación son un instrumento que cumple dos funciones claras: por un lado sirve para informar y comunicar masivamente diferentes hechos y noticias; y por el otro sirve como fuente de información para las distintas personas, grupos $\mathrm{u}$ 
organizaciones que los utilizan con el fin de conocer lo que sucede a su alrededor (Sandoval et al., 1990). De acuerdo con Muñoz (2011), los medios de comunicación cumplen la función de ser "motores de transmisión del pensamiento", ya que gracias a ellos "se han generado un sinnúmero de cambios sociales relevantes en la sociedad moderna, por lo que la idea de posicionar temas políticos y sociales como necesidad social está supeditada a la construcción de mensajes y entrega de información a través de ellos".

Desde finales de la década de los 60 hasta principios de los ańos 70 se generó una nueva fase en el estudio del impacto de los medios de comunicación masivos en la opinión pública, donde se destacó el poder que tienen para resaltar ciertos temas y crear marcos de interpretación de los diferentes eventos. Los medios tienen la capacidad de influir en los pensamientos y conocimientos de las personas, y de guiar los discursos, sean políticos o no. Milburn (1991) resalta la capacidad de los medios de comunicación para "definir los temas acerca de los cuales una sociedad debe pensar y debatir a cada momento, para atraer la mirada pública hacia determinados asuntos mientras otros son dejados de lado, al tiempo que brindan los estándares y parámetros a partir de los cuales los sucesos serán comprendidos, explicados y analizados". Complementando esta opinión, McCombs (2004) afirma que los medios de comunicación cumplen un rol tan importante en el sistema informativo global que la mayoría de los conocimientos que poseen las personas sobre distintos temas no proviene de experiencias personales, sino de los medios de comunicación. Un conocido periodista peruano menciona que los medios de comunicación sirven para poner en agenda diferentes temas, ya sean de interés público o de quienes manejan la información, ya que es muy común que los distintos grupos de presión (político, económico, o de otra índole) sean dueños de medios de comunicación (Vargas, 2010).

Es en este contexto que se evidencia la importancia del presente estudio, promovido por CIFOR en el marco del proyecto global de investigación comparativa sobre las actividades de demostración de la primera generación de REDD y las iniciativas nacionales de REDD (GCS-REDD). Este estudio facilita entender la situación del discurso de los medios en el Perú sobre temas ambientales (específicamente en bosques y REDD) y posiblemente ayude a identificar oportunidades $y$ desafíos clave que se tendrán que abordar en el futuro a corto plazo.

Después de una breve introducción al contexto nacional de REDD en el Perú, este estudio examina los medios de comunicación en el país y presenta un análisis de los discursos sobre REDD en los periódicos nacionales, así como estudios de caso en dos regiones subnacionales (San Martín y Madre de Dios). 


\section{REDD+ en el Perú: ¿País de bosques significa país de REDD?}

A nivel nacional se hace evidente el alto potencial forestal, siendo Perú el segundo país con mayor extensión de bosques en América Latina, los que cubren el $60 \%$ de su territorio. El país posee 39 millones de hectáreas de bosques aptos para la extracción de madera, sin embargo, aún no se ha desarrollado una actividad forestal apropiada, lo que se refleja en que el sector forestal representa apenas entre el $1 \%$ y el $4 \%$ del PBI nacional. La cobertura de bosques naturales se encuentra principalmente en la Amazonía, mientras que los bosques secos de la costa representan actualmente menos del $1 \%$ de la cobertura boscosa nacional (MINAM, 2010).

En el Perú, la principal fuente de emisiones de GEI es la conversión de bosques y pasturas debido a la deforestación de la Amazonía, lo cual representa el 47,5\% del total de emisiones nacionales. La deforestación nacional entre los años 1990 y 2000, ha sido aproximadamente 150000 hectáreas por ańo (MINAM, 2010). Los factores que conducen a la deforestación incluyen: la agricultura de roza y quema, la extracción de leńa y sobre pastoreo en la sierra, la agricultura a gran escala y plantaciones forestales, limpia de bosques para cultivar coca y construcción de pistas de aterrizaje ilegales, pastoreo de ganado, desarrollo de carreteras e infraestructura en la Amazonía, así como el aumento de la demanda por la tierra y los recursos debido al crecimiento demográfico (PCM, 2008).

El camino del Perú para evaluar la factibilidad de la implementación de REDD+ se inició con algunas iniciativas importantes, entre las que destacan:

(1) estudios puntuales sobre la determinación del carbono en los principales usos de suelo, y estudios de línea base de secuestro de carbono y esquema de pagos por servicios ambientales; (2) un Grupo REDD Perú formado en el 2008 con varias organizaciones participantes (del gobierno, ONG, empresas privadas, comunidades nativas, etc.); y (3) la iniciativa del país (junto a otros países latinoamericanos como Paraguay, México, Argentina, Honduras, Chile y Panamá), de expresar a la CMNUCC su interés por un enfoque denominado Enfoque Anidado ("Nested Approach") (SBSTA, 2008).
Paralelamente, desde el año 2008, el Perú viene impulsando una serie de acciones enfocadas en explorar las oportunidades de una economía baja en carbono y a mitigar los gases de efecto invernadero. En ese sentido, se vienen validando los Lineamientos Nacionales de Mitigación al Cambio Climático con el Grupo Técnico de Mitigación y Mecanismo de Desarrollo Limpio (MDL), de la Comisión Nacional de Cambio Climático, así como a nivel regional (Loreto, San Martin, La Libertad, Junín, Arequipa y Lima). A nivel del Grupo Técnico se ha aceptado que en los Lineamientos Nacionales de Mitigación (LNM) se incluyan los del PRONAMI (que están en la misma línea que las NAMA), los cuales consisten en una serie de actividades realizadas a nivel nacional, regional o sectorial. Estas iniciativas promueven el desarrollo sostenible, reducen las emisiones, aumentan la absorción o captura por los sumideros de gases de efecto invernadero; todo esto implementado y apoyado por la tecnología, financiamiento y capacidades que pueda proveer el país por sí mismo y los países desarrollados ya sea de manera bilateral o multilateral. Los LNM sugieren seis PRONAMI para los siguientes sectores: forestal y usos del suelo, agrícola, residuos sólidos, energía, transporte e industrial.

\section{El 27 de julio de 2011, el gobierno del Perú hizo} llegar a la Secretaria Ejecutiva de la Convención Marco de las Naciones Unidas sobre Cambio Climático una comunicación en la cual reiteraba su firme voluntad de fortalecer la acción colectiva para mitigar el cambio climático a través del desarrollo de una economía de crecimiento sostenible baja en carbono, para lo cual realizaría las siguientes acciones voluntarias, de acuerdo a los principios y provisiones de la Convención (MINAM, 2011):

1. Emisiones netas declinantes y equivalentes a cero en la categoría Uso del Suelo, Cambios en el Uso del Suelo y Silvicultura

2. Modificación de la matriz energética nacional a fin de que las energías renovables no convencionales y la hidroenergía representen en conjunto por lo menos el $40 \%$ de la energía consumida en el país 


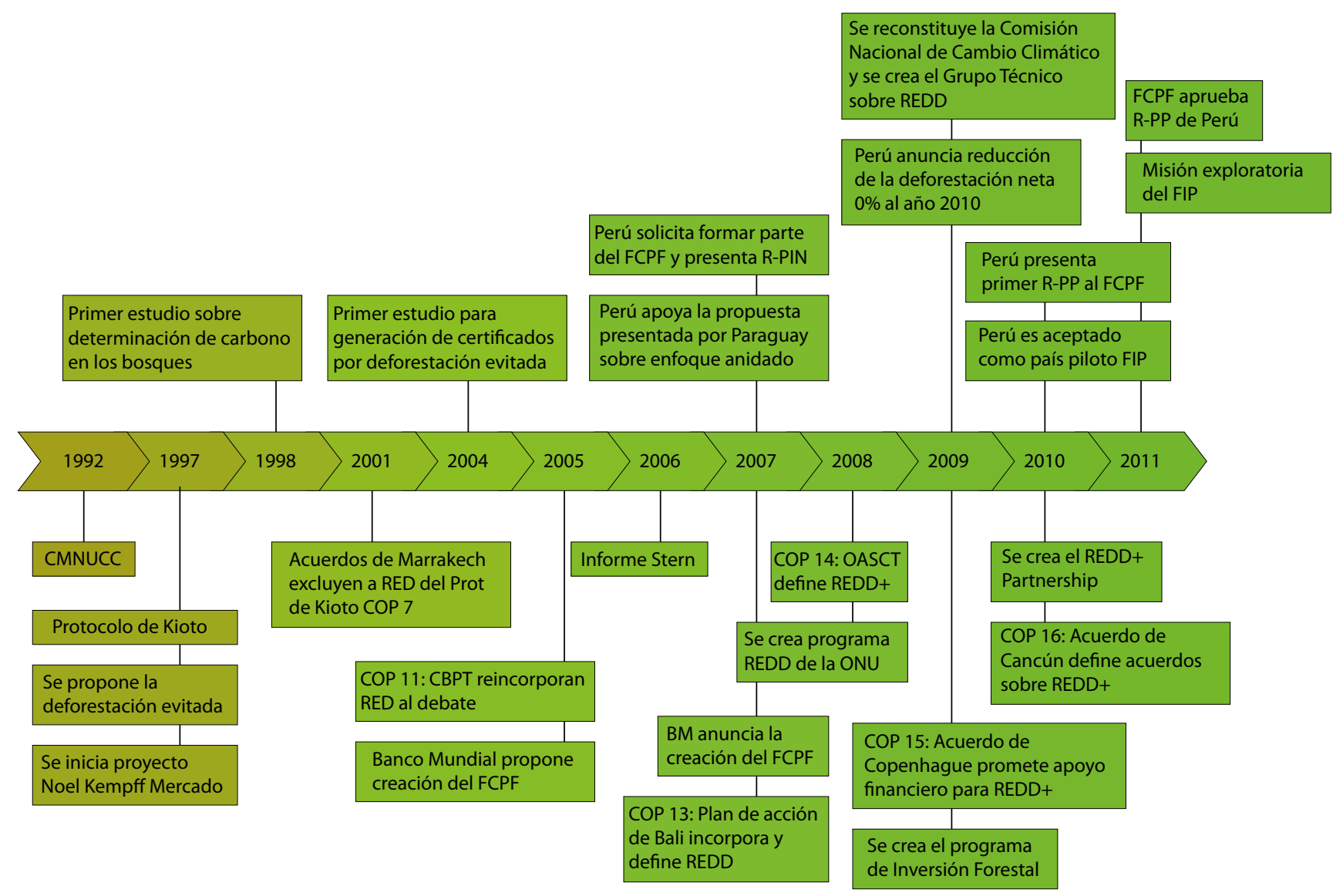

Figura 1. Desenlace de REDD a nivel nacional e internacional

Fuente: DAR, 2011

3. Captura y uso de metano proveniente de la disposición adecuada de residuos urbanos

Estos compromisos internacionales posiblemente promuevan esquemas para reducir las emisiones provenientes de la deforestación, lo que podría promover a su vez nuevas iniciativas REDD tanto privadas como estatales.

Mientras la discusión internacional de cambio climático en temas legales, políticos, técnicos y financieros sobre REDD continúa, a nivel nacional se cuenta con una agenda propia para REDD para la formulación e implementación de la estrategia nacional. Actualmente, se cuenta con fondos comprometidos para la etapa de preparación y desarrollo de iniciativas en REDD+, entre ellos destacan el FIP ${ }^{1}$, el FCPF², fondos de empresas privadas, cooperación bilateral (e.g. KfW, USAID) y fundaciones privadas (e.g. Fundación Gordon y Betty Moore), entre otras (DAR, 2011).

No necesariamente todos los actores involucrados en el proceso nacional de REDD tienen una opinión compartida, pero muchos identifican estas iniciativas, ante el problema de la deforestación, como una oportunidad para el país, no sólo para mitigar las emisiones, sino para mejorar economías locales, promover la inversión privada y preservar servicios ambientales. Sin embargo, algunos actores, más notablemente AIDESEP (Asociación Interétnica para el Desarrollo de la Selva Peruana) han presentado declaraciones y cartas al gobierno para expresar sus preocupaciones frente a REDD y los riesgos evidentes en su implementación.

1 Fondo de Inversión Forestal.

2 Fondo Cooperativo del Carbono Forestal. 


\section{Los medios de comunicación en el Perú}

En el presente capítulo se dará una breve explicación de la importancia de los medios de comunicación en el Perú, y en las dos regiones evaluadas en el presente estudio. Luego, se hará un recuento de cuáles son y cuál es su alcance.

\subsection{Los impactos de los medios de comunicación en los tomadores de decisiones}

Como se mencionó anteriormente, los medios de comunicación sirven por un lado como instrumentos de difusión de información y por el otro como fuentes de conocimiento. Es a través de los medios que se logra influir en los pensamientos de las personas y guiar sus discursos.

Según un estudio sobre el nivel de confianza de la población en las instituciones de Lima y Callao publicado por la Universidad de Lima (2007), al momento de analizar la confianza en instituciones no estatales, los distintos medios de prensa ocupan puestos importantes. Como se puede ver en el cuadro 1, la prensa radial ocupa el segundo puesto, mientras que la prensa televisiva el quinto y la prensa escrita el sexto puesto en la lista, todas por encima de ONG (en noveno lugar) y de los partidos políticos, que ocupan el último puesto en el cuadro. Cabe resaltar que para el caso de la prensa escrita, el número de personas que respondieron no tener confianza en esta institución superó a los que indicaron sí confiar, con $47,8 \%$ para el primer grupo versus $46,8 \%$ para el segundo.

De las entrevistas realizadas se desprende que en líneas generales, los periodistas consideran que los medios son los que generan las opiniones y acciones de los tomadores de decisiones ya que establecen la agenda de los principales hechos que ocurren en el Perú para ser tratados y tomados en cuenta. Son, a la vez, los que a través de la difusión de información priorizan la gravedad de los distintos temas y establecen una reacción inmediata en los principales actores que toman las decisiones. "Los medios son el vehículo de la información que los tomadores de decisiones quieren transmitir. Hay una tendencia de la gente a no creer en lo oficial, entonces necesitan de los medios para entender la información y la verdad", afirma Gonzalo Pajares, periodista del diario Perú 21.

Cuadro 1. Nivel de confianza en instituciones no estatales

\begin{tabular}{lccccc}
\hline Institución & $\begin{array}{c}\text { Sí confía } \\
\%\end{array}$ & $\begin{array}{c}\text { No confía } \\
\%\end{array}$ & $\begin{array}{c}\text { No sabe } \\
\%\end{array}$ & $\begin{array}{c}\text { No contesta } \\
\%\end{array}$ & $\begin{array}{c}\text { Índice de confianza } \\
\%\end{array}$ \\
\hline Universidades privadas & 74,3 & 18,9 & 6,5 & 0,3 & $+59,4$ \\
Prensa radial & 71,1 & 24,6 & 3,8 & 0,5 & $+48,6$ \\
Iglesia Católica & 72,7 & 25,5 & 1,6 & 0,2 & $+48,0$ \\
Bancos & 63,5 & 32,8 & 3,6 & 0,2 & $+31,8$ \\
Prensa televisiva & 59,9 & 35,5 & 3,7 & 1,0 & $+25,6$ \\
Prensa escrita & 46,8 & 47,8 & 4,1 & 1,3 & $-1,1$ \\
Empresa de telecomunicaciones & 44,4 & 50,7 & 4,5 & 0,3 & $-6,6$ \\
Gremios empresariales & 39,7 & 45,6 & 13,2 & 1,4 & $-6,8$ \\
ONG & 35,2 & 51,9 & 12,2 & 0,6 & $-19,2$ \\
Clubes de fútbol & 36,9 & 55,7 & 6,3 & 1,1 & $-20,2$ \\
Centrales sindicales de trabajadores & 34,7 & 56,9 & 7,9 & 0,6 & $-24,2$ \\
Partidos políticos & 10,6 & 87,1 & 1,9 & 0,4 & $-78,2$ \\
\hline
\end{tabular}

Fuente: Grupo de Opinión Pública de la Universidad de Lima, 2007 
Para Alberto Paniagua, director de PROFONANPE, "los medios cumplen un rol bien importante de difusión y de creación de un estado de discusión, que genera que los tomadores de decisiones anden con cuidado en sus decisiones. Temas como la minería ilegal, derechos de los nativos, los transgénicos, etc., los medios los han puesto en la agenda pública, antes de su discusión, con la intención de generar políticas públicas". Los medios tienen una gran fuerza en la sociedad e influencian sobre las opiniones del público ya que son, en muchos casos, la principal fuente de información de la población.

Es así que los medios de comunicación en el país (y en el mundo) juegan un rol sumamente importante y decisivo para la propagación de información y para la toma de decisiones en varios niveles. Los aspectos vinculados a la temática ambiental (como REDD+ por ejemplo) no escapan de esta realidad y es justamente la evaluación de los discursos que se dan actualmente en distintos diarios a nivel nacional lo que permitirá entender y evaluar la información que se está propagando actualmente sobre REDD+. Todo esto facilitará la comprensión de quiénes son los actores clave a nivel nacional e internacional, cuáles son las posiciones más evidentes y cuáles los temas más tratados, entre otros.

\subsection{Los medios más importantes en el Perú}

Como en todos los países del mundo, en el Perú los medios de comunicación juegan un rol decisivo, tanto para la vida cultural como política. A nivel nacional existen medios que tienen un tratamiento serio y veraz, y durante las últimas décadas han surgido otros más bien de baja calidad y credibilidad, más baratos y accesibles al ciudadano de menores recursos. Estos diarios se denominan "prensa chicha", y se caracterizan por ser de dudosa reputación y tener un estilo de redacción sumamente vulgar (Cappellini, 2004).

Según Bruno Sanguinetti, Gerente del Consorcio Madre de Dios, se deben tener en cuenta las diferencias que existen entre la televisión, la radio, los medios impresos y el Internet, ya que cada uno tiene códigos definidos y orientaciones hacia ciertos públicos. Según Sanguinetti, y muchos otros entrevistados, la radio es la que llega a la población masiva y es la que más se utiliza en el país por su funcionalidad y accesibilidad.
A continuación, se describirá los principales medios de comunicación en el Perú, Madre de Dios y San Martín.

\subsubsection{Prensa escrita: diarios}

En el Perú existen 73 diarios en las principales ciudades a nivel nacional, siendo Lima la sede de muchos de ellos. En la capital se distribuyen un total de 25 diarios entre los que figuran diarios de todo tipo: de economía, deportes, sensacionalistas, etc. Dentro de los diarios de nivel nacional vale la pena destacar a El Comercio, fundado en 1839, considerado el diario de mayor trayectoria y seriedad. Otros diarios importantes a nivel nacional (en función a datos de las encuestadoras nacionales y mediciones de lectoría) clasificados según los temas que tratan son: (1) informativos "serios": Correo, Expreso, Gestión, La República, Perú 21 y El Peruano (el diario oficial del Gobierno); (2) deportivos: Bocón, Líbero, Depor; (3) sensacionalistas moderados: Ojo y El Men; (4) chichas: Ajá, El Chino, Extra, El Popular y Trome (Cappellini, 2004).

La mayoría de diarios en el país se encuentran asociados a grupos, teniéndose por ejemplo el Grupo El Comercio, de tendencias centro derechas, dueño de los diarios El Comercio, Perú 21, Trome, Gestión, Depor y Publimetro; EPENSA, al que pertenecen Ojo, Ajá, Correo, y El Bocón, que tiene una tendencia más liberal y de oposición; o el Grupo La República, con diarios como La República, El Popular, y Libero, de inclinaciones de centro derecha y ligeramente socialista.

En el cuadro 2 se detalla el tiraje promedio por día para los principales diarios del país durante el año 2010, ordenándolos de forma descendente.

Según un estudio realizado en la ciudad de Lima por la Compañía Peruana de Estudios de Mercado y Opinión Pública (CPI, 2010), hay diferencias importantes entre los lectores de tres de los periódicos incluidos en el estudio, Trome, Comercio, y Perú 21. Como se puede ver en el cuadro 3 , si se analizan los diarios evaluados en el estudio, que a su vez son parte del presente estudio, se puede apreciar lo siguiente: El Comercio y Perú 21 cuentan con una mayoría de lectores pertenecientes al sector $\mathrm{A} / \mathrm{B}$, mientras que los lectores de Trome son mayoritariamente del Sector D/E. Tanto Trome como Perú 21 cuentan con una 
Cuadro 2. Tiraje promedio diario de los principales periódicos a nivel nacional

\begin{tabular}{llc}
\hline$N^{\circ}$ & Diario & Tiraje diario promedio \\
\hline 1 & Trome & 1824676 \\
2 & Ojo & 526052 \\
3 & El Comercio & 467619 \\
4 & Perú 21 & 293432 \\
5 & El Popular & 225865 \\
6 & Correo & 197732 \\
7 & Depor & 190903 \\
8 & Ajá & 182089 \\
9 & El Bocón & 153386 \\
10 & Libero & 128442 \\
11 & La República & 94363 \\
12 & Todo Sport & 56963 \\
13 & El Men & 53040 \\
14 & El Chino & 50289 \\
15 & Gestión & 50086 \\
16 & La Razón & 49804 \\
\hline
\end{tabular}

mayoría de lectores de sexo masculino, mientras que El Comercio cuenta con un porcentaje mayor de lectores de sexo femenino. La mayoría de lectores de Trome se encuentran entre los 15 y 25 ańos, mientras que el Comercio cuenta con lectores de entre 26 y 37, y Perú 21 son mayores a 51 años. La mayoría de lectores de Trome cuentan con grado de estudios de nivel secundaria, mientras que los lectores de El Comercio y Perú 21 tienen nivel superior. Para Trome y Perú 21, la mayoría de sus lectores son trabajadores independientes, mientras que los lectores de El Comercio son empleados.

Los diarios de provincias, si bien tienen un tiraje muy pequeńo comparado a los diarios de cobertura nacional, son la voz de las ciudades del interior del país, y se debe tener en cuenta que son de gran importancia para cada localidad (DePerú, 2011).

Para el caso de Madre de Dios, son tres los diarios que tienen una circulación relativamente importante: Don Jaque que se difunde de lunes a sábado y tiene un tiraje de 1500 ejemplares por día; El Observador, que circula también los mismos días (pero hay épocas donde se paraliza su difusión) y que tiene un tiraje de 1000 diarios por día; y el Diario Internacional Mi Frontera que se emite una vez al mes.
Cuadro 3. Características de lectores de tres diarios en Lima

\begin{tabular}{|c|c|c|c|}
\hline Categoría & $\begin{array}{c}\text { TROME } \\
\%\end{array}$ & $\begin{array}{c}\text { COMERCIO } \\
\%\end{array}$ & $\begin{array}{l}\text { PERÚ } \\
21 \% \\
\end{array}$ \\
\hline \multicolumn{4}{|l|}{$\begin{array}{l}\text { Nivel Socio } \\
\text { Económico }^{\text {a }}\end{array}$} \\
\hline$A / B$ & 14,8 & 52,1 & 44,6 \\
\hline C & 37,5 & 29,4 & 34,6 \\
\hline $\mathrm{D} / \mathrm{E}$ & 47,7 & 18,4 & 20,7 \\
\hline \multicolumn{4}{|l|}{ Sexo } \\
\hline Hombres & 50,1 & 47,9 & 60,5 \\
\hline Mujeres & 49,9 & 52,1 & 39,5 \\
\hline \multicolumn{4}{|l|}{ Grupos de edad } \\
\hline $15-25$ & 33,7 & 23,6 & 19,6 \\
\hline $26-37$ & 27,7 & 27,2 & 27,0 \\
\hline $38-50$ & 20,4 & 22,0 & 22,7 \\
\hline $51+$ & 18,2 & 27,2 & 30,7 \\
\hline \multicolumn{4}{|l|}{ Grado de Estudios } \\
\hline Ningún nivel & 0,4 & 0,2 & 0,4 \\
\hline Primaria & 7,8 & 3,4 & 3,5 \\
\hline Secundaria & 53,9 & 28,6 & 26,6 \\
\hline Técnico & 23,3 & 23,2 & 25,8 \\
\hline Superior & 13,7 & 39,4 & 38,3 \\
\hline Post-grado & 0,9 & 5,3 & 5,5 \\
\hline \multicolumn{4}{|l|}{ Categoría familiar } \\
\hline Ama de casa & 25,2 & 22,5 & 17,1 \\
\hline Jefe de familia & 28,1 & 28,5 & 39,7 \\
\hline Hijos/as & 0,0 & 0,0 & 0,0 \\
\hline Otras & 36,9 & 38,5 & 34,9 \\
\hline Ama/jefe & 9,9 & 10,5 & 8,2 \\
\hline \multicolumn{4}{|l|}{ Ocupación } \\
\hline $\begin{array}{l}\text { Ejecutivo/ } \\
\text { empresario/director }\end{array}$ & 0,2 & 1,3 & 0,8 \\
\hline $\begin{array}{l}\text { Profesional } \\
\text { independiente }\end{array}$ & 1,5 & 8,2 & 10,5 \\
\hline Empleado & 14,9 & 26,0 & 16,7 \\
\hline Obrero & 6,8 & 3,0 & 1,4 \\
\hline $\begin{array}{l}\text { Trabajador } \\
\text { independiente }\end{array}$ & 26,0 & 14,3 & 25,7 \\
\hline Estudiante & 19,4 & 16,9 & 19,4 \\
\hline Ama de casa & 23,4 & 20,7 & 13,6 \\
\hline Jubilado & 4,1 & 7,5 & 9,4 \\
\hline Desempleado & 3,1 & 2,1 & 2,3 \\
\hline Otras ocupaciones & 0,6 & 0,2 & 0,5 \\
\hline
\end{tabular}

a En Lima en 2011, el promedio del ingreso mensual de los diferentes niveles socioeconómicos (NSE) fueron de: NSE-A = S/. 10,418; NSE-B = S/. 3,017; NSE-C = S/. 1,542; NSE-D = S/. 1,092; NSE-E $=$ S/. 890 (Peru 21, 2012).

Fuente: CPI, 2010 
En San Martín, los tres principales diarios son: Voces con 3500 ejemplares por día; el diario Ahora con 4000 ediciones impresas; y el diario Hoy con 3000 ejemplares diarios. Cabe mencionar que este último diario se difunde de lunes a domingo, los dos anteriores de lunes a sábado.

\subsubsection{Televisión}

En el Perú la televisión se divide en señal abierta, la cual es gratuita a nivel nacional, y depende de la frecuencia y el alcance que tenga; y señal por cable, la cual tiene un costo, e incluye los canales internacionales. Con un total de 1.5 millones de clientes que actualmente cuentan con televisión de paga en Perú, Lima es la principal demandante de este servicio, con el 65\% de las suscripciones del país (Comunicar, 2011).

Actualmente existen 105 transmisoras de televisión en el Perú a nivel nacional, de las cuales 22 se encuentran en Lima (OEI, 2011). En lo que se refiere a receptores de televisión, en 1997 había 3060 en todo el país, y por cada mil habitantes, 126. De los diez canales más vistos del país, ocupa el séptimo lugar el canal del Estado (TNP canal 7), cuya señal se transmite a nivel nacional. Muchas ciudades del interior del país cuentan con canales propios, con programación y difusión independiente de los grandes canales de Lima y otras utilizan parte de la programación de los canales de la capital y la combinan con sus propios programas.

\subsubsection{Radio}

A nivel nacional las dos radios más escuchadas son RPP (Radio Programas del Perú) y CPN Radio (Cadena Peruana de Noticias). La primera es la estación limeña más escuchada en las provincias, ya que ofrece programas exclusivos para audiencias locales. Sin embargo, existen un número de radios de provincias que ocupan el primer lugar en los ranking regionales. De acuerdo con Menéndez (2007), en las diez ciudades más grandes del Perú (sin contar Lima), de las cinco estaciones más sintonizadas, tres o cuatro son locales, y sólo una o dos son de Lima. En zonas rurales, donde no necesariamente llega la prensa escrita o no tienen acceso a electricidad, la radio (la misma que funciona a través de pilas y/o baterías) juega un rol fundamental, ya que en muchos casos es la única fuente de información "externa". De acuerdo con Segundo Noé Cahuas Peas, Técnico Awajún de ORDEPISAN, "solo se podría trabajar con la radio en las comunidades pues la televisión llega muy poco".

Según Elías Peas Cahuas, Vicepresidente de FERIAM, "la radio es el medio de comunicación que más se utiliza en las comunidades nativas, pues es la más accesible, pero incluso hay comunidades como Cachiyacu, donde ni siquiera llega la señal de radio". Y añade, Otro problema es que cuando hay radio, éstas hablan español, pero hay comunidades por ejemplo que no hablan el castellano, sino sus lenguas aborígenes.

La radio permite a los campesinos tener acceso a información, ya sea local o nacional, y les brinda una herramienta educativa y de desarrollo. Un claro ejemplo del potencial de la radio como herramienta, es el caso de las "radioescuelas" o "radios del pueblo", que tienen como objetivo fomentar el desarrollo rural, a través del mejoramiento de la producción agropecuaria, la salud y la educación, entre otros temas. Dichas iniciativas consisten en la emisión de programas especialmente producidos para grupos locales (Gutiérrez, 2003).

\subsubsection{Otros medios de difusión de Noticias Ambientales}

Aunque en los medios de comunicación tradicionales que llegan al público mayor se incluyen temas ambientales, hay otros canales especializados que se enfocan en el medio ambiente. Por ejemplo, una plataforma virtual que llega a varias regiones y que se focaliza en temas ambientales es InfoRegion, una agencia de prensa ambiental que cuenta con una plataforma web, boletines, y emisiones radiales donde se transmite información en la selva alta del país. El MINAM apoya EcoZonaJovenes, una plataforma de noticias ambientales a través de su página web, con un enfoque más juvenil, enfocado a grupos de estudiantes. Adicionalmente varias ONG tienen blogs, como el caso de Actualidad Ambiental, un noticiario online hecho por la Sociedad Peruana de Derecho Ambiental (SPDA), donde se presentan noticias ambientales sobre el contexto peruano. 


\section{Metodología del estudio}

Este estudio es parte del GCS-REDD, que viene evaluando los procesos y proyectos tempranos de REDD al nivel mundial. El componente uno del GCS se enfoca en analizar los procesos y políticas de REDD al nivel nacional y subnacional en 12 países. Como ha sido previamente mencionado, los medios de comunicación forman una parte importante de estos procesos, particularmente en términos de la diseminación de información y formulación de discursos nacionales y locales. Por este motivo, el GCS ha desarrollado una metodología para analizar los discursos en los distintos medios escritos (prensa) nacionales y subnacionales (De Gregorio et al., 2012). Para el estudio de los medios en el Perú, seguimos esta metodología en dos etapas distintas de evaluación: 1) diarios nacionales; y, 2) diarios subnacionales en dos departamentos amazónicos, San Martín y Madre de Dios. Cuando se encontró una cantidad reducida de artículos sobre REDD en los diarios nacionales, se eligió trabajar en dos departamentos para contar así con estudios de caso subnacionales. Se eligió trabajar en San Martín y Madre de Dios debido a la presencia actual de: a) el mayor número de proyectos pilotos de REDD ( $\mathrm{SM}=7, \mathrm{MdD}=16)$ (MINAM, 2012); b) mayores avances en términos de consolidación de la Mesa REDD Regional (grupo de trabajo compuesto por el gobierno regional y organizaciones de la sociedad civil); y, c) avances en investigaciones y establecimiento de escenarios de referencia para la región. Aunque no son las regiones con mayor población, son las zonas con más actividades de REDD y por lo tanto, se asume que con una mayor posibilidad de mención de temas REDD en los diarios regionales.

El estudio se realizó en dos etapas: la primera, donde se realiza un análisis desde Lima de los diarios más importantes a nivel nacional; y la segunda, donde se realizan viajes a Madre de Dios y San Martín para realizar la evaluación de los diarios in situ. Además del análisis de los diarios, en ambas etapas se realizaron una serie de entrevistas a personas vinculadas con la temática ambiental y con los medios, con la finalidad de enriquecer el análisis.
A continuación se detallan los pasos metodológicos que se siguieron para la realización del presente estudio.

\subsection{Selección de diarios y artículos}

Si bien es cierto que sería interesante realizar una evaluación de la incidencia de REDD en los distintos medios de comunicación -incluyendo radio, televisión, y otros- el presente estudio se enfoca únicamente en prensa escrita (diarios).

\subsubsection{ETAPA 1: búsqueda en diarios a nivel nacional}

Para el caso del estudio en Perú se seleccionaron ocho diarios de distribución nacional: (1) El Comercio,

(2) Perú 21, (3) Gestión, (4) Expreso, (5) La República, (6) La Razón, (7) El Peruano y (8) Trome. La selección de los mismos obedeció a diversos criterios, como que son algunos de los diarios más leídos a nivel nacional, que cuentan con banner de búsqueda $^{3}$ en su página web (lo cual permite realizar las búsquedas on line), que son reconocidos por el público y que tienen distribución nacional. La premisa inicial para el estudio fue evaluar las noticias únicamente de tres diarios a nivel nacional, pero dado el bajo número de noticias encontradas para REDD, se decidió ampliar la búsqueda e incluir un mayor número de diarios. La identificación de los artículos se realizó a través de la búsqueda de palabras clave, tanto en los buscadores de las páginas web de los diarios, como en la intranet, en los casos donde se pudo acceder a la misma (diarios El Comercio y Gestión; para todas las palabras clave mencionadas a continuación, excepto "cambio climático + bosques", "reducción de emisiones + deforestación" y "protocolo de Kioto"). Es importante indicar que comúnmente las búsquedas en la intranet de los diarios no se encuentran abiertas al público en general y solo pueden acceder periodistas de los diarios de forma

3 Un banner de búsqueda es el buscador que se encuentra en las páginas Web, que permite ingresar palabras o frases para que sean ubicadas dentro del archivo de la misma. 
interna, lo que dificultó llegar a todos con este nivel de búsqueda. En una primera evaluación se realizó una búsqueda de las siguientes palabras clave en los banners de búsqueda (frases exactas):

- "REDD"

- "deforestación evitada"

Dado que la incidencia de artículos encontrados en esta búsqueda inicial, realizada con las palabras clave arriba mencionadas, arrojó un número muy pequeño de artículos, se realizó una segunda búsqueda para evaluar la incidencia de las siguientes palabras clave (frases exactas):

- "cambio climático + bosques"4

- "reducción de emisiones + deforestación"

- "cambio climático"

- "calentamiento global"

- "protocolo de Kioto"

- "deforestación"

De esta segunda búsqueda se determinó que se incluirían dentro del estudio los artículos que mencionaran las palabras clave "cambio climático + bosques" y "reducción de emisiones + deforestación" en una noticia. El resto de artículos encontrados con las demás palabras clave no son parte del presente estudio, pero se mencionan dado que son relevantes, ya que sirven para enmarcar el contexto de la temática de cambio climático en los medios de comunicación nacionales. Cabe mencionar que no se tiene la incidencia de estos artículos por ańos, sino de manera global.

La búsqueda de palabras clave se realizó sin tener en cuenta una fecha de inicio puntual y hasta fines de noviembre del 2011. El criterio temporal de la búsqueda está determinado por el funcionamiento del sistema on line de cada uno de los diarios para la identificación de noticias con las palabras clave. Esto quiere decir que es posible que en un diario la búsqueda tenga un periodo temporal mayor que en otro, si es que el buscador permite identificar noticias en un mayor rango de tiempo, ya sea por el funcionamiento del sistema, o por la base de datos con la que cuenta, entre otros factores. Por otro lado es importante mencionar que dado que el término REDD no se creó hasta diciembre del 2005, es lógico

4 Ambos términos en una misma noticia.

5 Ambos términos en una misma noticia. pensar que no existen noticias vinculadas a REDD antes de ese periodo.

Tres aspectos que se deben considerar relacionados con la precisión del número de noticias halladas y los buscadores de las páginas web de los diarios evaluados son: (a) las noticias disponibles en las páginas web $y$ en el intranet de los diarios no es necesariamente el número de noticias existentes, ya que las bases de datos electrónicas no necesariamente están actualizadas y hay noticias que han sido publicadas pero que no están actualmente disponibles; (b) los banners de búsqueda de los diarios no son 100\% confiables ya que en más de una oportunidad al realizar la búsqueda de una palabra clave, aparecía un número determinado de resultados, pero al momento de tratar de acceder a las noticias, en algunos casos no había acceso a las mismas, por lo que estas no han sido evaluadas en el presente estudio; y (c) es probable que algunas noticias sí estén en las bases de datos de los diarios pero no aparezcan al momento de realizar la búsqueda (e.g. en la búsqueda que se realizó para las palabras clave "reducción de emisiones + deforestación”, el único artículo encontrado tenía dentro del texto la palabra clave "REDD", pero al momento de realizar la búsqueda con la palabra clave "REDD”, este artículo no aparecía).

\subsubsection{ETAPA 2: Búsqueda en regiones}

Para el caso del estudio regional, en ambas regiones se seleccionaron los únicos diarios de relativa importancia. Para Madre de Dios los diarios evaluados fueron: (1) Don Jaque y (2) El Observador; mientras que los diarios seleccionados en San Martin fueron: (1) Voces, (2) Ahora, y (3) Hoy.

\section{Madre de Dios}

Para llevar a cabo el estudio en Madre de Dios se realizó un viaje entre los días 20 y 26 de noviembre de 2011, donde se visitó únicamente la capital, Puerto Maldonado, donde se concentran la mayor cantidad de organizaciones vinculadas con la temática ambiental, y donde se encuentran las imprentas de los principales diarios. Previo al viaje se realizó una búsqueda por Internet, y se identificó que únicamente Don Jaque contaba con página web, sin embargo, la información mostrada había caducado y en líneas generales existían problemas con la web. Las palabras clave buscadas fueron las mismas que para el caso de la Etapa 1. 
Con la finalidad de recabar las noticias ambientales y poder analizarlas se visitó la Biblioteca Municipal de Puerto Maldonado. En este recinto únicamente se contaba con archivos del diario Don Jaque, pues según criterios de la dirigencia es el único diario que circula continuamente. Los diarios se encontraban clasificados a partir del año 2004. Sin embargo, al revisar las diversas publicaciones, del 2005 en adelante (determinado para la metodología), se percibió que los diarios se encontraban en mal estado, existiendo también algunas noticias que no se lograron leer debido a que algunas páginas habían sido cortadas, a la pérdida de color del papel y a la mala calidad de los diarios.

Es preciso mencionar que como la Biblioteca Municipal no contaba con servicio de fotocopias y más aún, estando los diarios en mal estado, se optó por tomar fotografías a las noticias identificadas como relevantes para el estudio, para luego ser clasificadas de acuerdo a las palabras clave ya definidas.

Se buscó información, asimismo, en la Biblioteca de la Universidad Nacional Amazónica de Madre de Dios (UNAMAD), pero como en el caso anterior, únicamente se archivaba el diario Don Jaque. Sin embargo, se almacenaba sin orden específico, y no por años o fechas definidas. Como una tercera fuente de información se visitaron las oficinas de AIDER de Puerto Maldonado, que contaba con algunos archivos de diarios a través de su pequeña biblioteca, lo cual complementó el trabajo de búsqueda que se venía realizando en las dos anteriores bibliotecas.

\section{San Martín}

El viaje a San Martín se llevó a cabo del 4 al 10 de diciembre, y se visitó Moyobamba (la capital) y Tarapoto (lugar donde se encuentran la mayoría de organizaciones vinculadas con la temática ambiental). La dinámica de búsqueda de noticias fue similar a la realizada en Madre de Dios, a través de las páginas web de los diarios y ediciones impresas. En esta región se evaluaron los diarios Hoy, Voces y Ahora. Las dos últimas cuentan con su propia hemeroteca lo que permitió expandir la búsqueda en las ediciones físicas. Se debe mencionar que en ocasiones se encontraron desfases entre año y año, la calidad del papel no era la más adecuada y algunas noticias se habían borrado e incluso páginas completas habían sido rotas. Igualmente, como en el caso de Madre de Dios, se tomó fotografías a las noticias y estas fueron almacenadas por palabras clave previamente definidas.

Se visitó, asimismo, la Biblioteca Municipal de Moyobamba donde ocurrían los mismos problemas de desfase de información. Los diarios no estaban archivados adecuadamente y en algunas ocasiones meses enteros se habían extraviado, humedecido o habían sido comidos por las polillas.

\subsection{Enfoque del marco de medios}

El análisis de medios es un factor importante a considerar ya que los medios de comunicación son "un grupo influyente y heterogéneo de actores no estatales" (Boykoff, 2008) que tienen la particularidad de funcionar como fuentes de información y conductores de discursos ya que, por un lado, reflejan, y por el otro, afectan las percepciones sociales de un hecho. Es por esto que al analizar el tratamiento que se le da a los temas relacionados con REDD+ en los medios de comunicación se espera identificar los principales discursos y posiciones alrededor del tema. El análisis de medios permite tener un panorama de cómo los debates vinculados a políticas de REDD+ están siendo enmarcados en los distintos países, brindando un contexto para un análisis más profundo y permitiendo evaluar cómo los marcos han ido variando con el tiempo. Evidentemente, una de las grandes fortalezas de este estudio es que se realiza paralelamente en varios países, bajos los mismos criterios, lo que permite comprar los resultados y sacar interesantes conclusiones.

De acuerdo con Bennet (citado por Boykoff, 2008), un "marco de medios" (media frame) es un "amplio tema organizativo para seleccionar, enfatizar, y unir los elementos de una historia, tal como las escenas, los personajes, sus acciones, y la documentación de apoyo". En la práctica un marco es un lente conceptual que ayuda a presentar una situación real de una manera más enfocada, enfatizando una manera particular de comprender un tema, $y$ relegando otros en el fondo.

Los artículos de periódicos pueden ser divididos en varias secciones, pudiendo contener más de un marco. El "marco primario" (primary frame) es muy probable que se identifique en las partes más importantes del texto, como en el título, subtítulo y/o en los primeros párrafos. Además, los artículos 
posiblemente citen fuentes que apoyen el marco, las cuales serán más prestigiosas que las mencionadas en otros marcos. Para darle balance al artículo el marco normalmente incluye una refutación, o una visión alternativa a la que se plantea inicialmente. Sin embargo, a los adversarios normalmente se les da menos importancia, espacio y fuerza que a los "definidores primarios" (primary definers) o los defensores del marco primario.

Para artículos más largos y con un mayor nivel de profundidad en la discusión, los párrafos subsiguientes pueden examinar la historia desde un ángulo diferente, lo que permite identificar un "marco secundario" (secondary frame). La manera de identificar marcos secundarios es eliminando los elementos del texto que apoyan el marco primario, agrupando el texto restante de acuerdo a temas y evaluando su posición en el texto, así como la naturaleza y grado de las fuentes citadas.

\subsection{El proceso de codificación}

El ejercicio de codificación comprende la colección de información en tres niveles distintos. La codificación de Nivel 1 solo sirve para identificar variables descriptivas, que simplemente identifican el artículo. Se incluyen fecha y autor, número de páginas, la sección del periódico en la que aparecen y el tipo de artículo, entre otros. Si bien son empleadas para la identificación del artículo, también pueden ofrecer una perspectiva interesante sobre los cambios en la cobertura de temas de REDD en el tiempo y entre países. La codificación de Nivel 1 también permite identificar si el artículo hace una leve o profunda referencia a REDD. Solo en el segundo caso pasará al siguiente nivel. La codificación de Nivel 1 se aplica a todos los artículos en la base de datos.

La codificación de Nivel 2 permite compilar variables sobre el marco primario, y de ser el caso, los marcos secundarios. Esto incluye: (1) la manera en que el artículo enmarca el debate REDD (de tipo diagnóstico, pronóstico, sintomático o motivacional), tal como se detalla en el cuadro 4; (2) la escala política del debate (internacional, nacional, subnacional y local); y (3) los temas específicos alrededor del artículo (político, económico, ecológico, cultural y social). El análisis del Nivel 2 brinda suficiente información si lo que se busca
Cuadro 4. Categorías que describen el Tipo de Marco

\begin{tabular}{|c|c|}
\hline Término & Descripción \\
\hline Diagnóstico & $\begin{array}{l}\text { Identifica qué o a quién se debe culpar } \\
\text { por un problema (relacionado con } \\
\text { REDD), incluyendo el descarte de la } \\
\text { totalidad de la realidad del problema. }\end{array}$ \\
\hline Pronóstico & $\begin{array}{l}\text { Involucra la articulación de una posible } \\
\text { solución al problema, o por lo menos } \\
\text { un plan de ataque, y las estrategias } \\
\text { para llevar a cabo el plan. }\end{array}$ \\
\hline Sintomático & $\begin{array}{l}\text { Identifica por qué un tema puede } \\
\text { ser un problema, normalmente } \\
\text { discutiendo las consecuencias del } \\
\text { mismo. Por ejemplo, los efectos de } \\
\text { una mala política sobre REDD para } \\
\text { reducción de emisiones, sistemas } \\
\text { ecológicos, etc. }\end{array}$ \\
\hline Motivacional & $\begin{array}{l}\text { Va más allá de la existencia del tema y } \\
\text { sus causas y consecuencias, y plantea } \\
\text { razones morales y motivacionales de } \\
\text { por qué el orador y/u otras personas } \\
\text { deben interesarse por el tema o } \\
\text { ignorarlo. }\end{array}$ \\
\hline
\end{tabular}

es una breve identificación de temas generales reportados en artículos de periódicos.

El Nivel 3 identifica los marcos primario y secundario en mucho mayor detalle, incluyendo la identificación de los principales defensores y adversarios, sus posturas, la posición ideológica y los tipos de acciones. Este Nivel de codificación es mucho más intensivo y permite una identificación más detallada de los discursos principales que se utilizan para representar las posiciones ideológicas y creencias. Si se identifican defensores y adversarios dentro de los marcos, se puede calificar mejor sus posiciones. La evaluación en este Nivel permite identificar los distintos intereses y más tarde realizar el análisis de las coaliciones defendiendo los varios enfoques a las cuestiones de REDD.

La codificación de Nivel 3 también incluye un inventario de eventos de protesta, eventos de política y actores principales. Los eventos de protesta se definen como "una acción pública y colectiva relacionada con temas en los cuales asuntos explícitos relacionados con el ambiente (en nuestro caso REDD) son expresados como una dimensión central, organizada por instigadores no estatales con 
el propósito específico de criticar o disentir junto con demandas sociales y/o políticas" (Fillieule y Jiménez, 2006). Los eventos de protesta se evalúan en base a lo que se ha escrito en el artículo y no en los marcos. Los eventos políticos incluyen el tipo de evento, así como las respuestas generadas a raíz de él. Se definen como "un punto decisivo crítico, ubicado temporalmente en una secuencia de tomas de decisiones colectiva que debe ocurrir para que una opción política sea finalmente seleccionada" (Laumann y Knoke, 1987). Al igual que para el caso de los eventos de protesta, se evalúan en base a lo que se ha escrito en el artículo y no en los marcos. Cada artículo se deberá analizar en busca de hechos relevantes.

Se precisa como un actor principal a una organización o persona que se define a sí mismo y que es percibido por los demás como una parte del ámbito de la política nacional. Esta lista de actores principales contribuye a la identificación de todos los actores relevantes (principalmente organizacionales) que operan en el ámbito de la política de REDD.

Para el caso de ambas etapas del estudio en el Perú, los artículos fueron codificados en español ya que los artículos fueron escritos en ese idioma. Previo al inicio del proceso de codificación se realizó un taller de entrenamiento con expertos de CIFOR donde se explicó la metodología en detalle. Luego del taller se realizaron varias codificaciones de prueba entre tres personas del equipo de trabajo que asistieron al entrenamiento. Estas pruebas fueron comparadas en grupo, evaluando resultados disímiles con el propósito de unificar criterios sobre las variables y así asegurar una codificación acertada. Una vez unificados los criterios a nivel del equipo de trabajo, las propuestas de codificación fueron enviadas a los expertos de CIFOR para sus comentarios y posterior visto bueno. Esto permitió fortalecer las pautas de evaluación y asegurar que las noticias estuvieran codificadas con criterios compatibles a las investigaciones en otros países.

\subsection{Entrevistas}

Para complementar la información recabada en la búsqueda y codificación de artículos sobre REDD en los distintos diarios, se realizaron una serie de entrevistas cortas a periodistas y a expertos nacionales en REDD y en temas vinculados con el medio ambiente. Todas las entrevistas a periodistas fueron realizadas de manera presencial. Todas las entrevistas realizadas de manera presencial fueron grabadas y luego transcritas. El esquema de las entrevistas fue diseñado para darle mayor profundidad al análisis y las preguntas se encuentran desarrolladas en el capítulo 6.

\subsubsection{ETAPA 1: Entrevistas del estudio a nivel nacional}

En el estudio a nivel nacional se realizaron en total siete entrevistas a periodistas de diarios y medios de envergadura nacional, y once entrevistas a expertos en REDD y personas vinculadas con la temática ambiental, residentes en su mayoría en Lima.

Para el caso de los expertos en REDD de esta primera etapa del estudio se realizaron algunas entrevistas por medio de correo electrónico, debido a que algunos se encontraban fuera de Lima.

\section{Entrevistas a periodistas}

Para el estudio nacional, previo a la realización de las entrevistas, se hizo un sondeo preliminar de los artículos identificados y no se logró identificar a un grupo de periodistas que escriba frecuentemente sobre los temas evaluados, por lo que se seleccionaron a personas vinculadas con los medios de comunicación (periodistas, editores, entre otros).

En total se realizaron siete entrevistas a personas vinculadas con los medios de comunicación: dos entrevistas a personal de Perú 21 (un periodista y una editora); una entrevista al Jefe de Informaciones del diario Expreso; una entrevista al editor del diario La República; dos entrevistas a periodistas de El Comercio y finalmente, una entrevista al encargado de sistemas del mismo diario, con la finalidad de entender el funcionamiento del Internet y el intranet, así como conocer el sistema de archivo de noticias. Las preguntas fueron elaboradas con la finalidad de conocer la opinión de los entrevistados sobre el impacto que tienen los medios de comunicación en la sociedad. La duración promedio fue de 30 minutos cada una, y la mayoría de las preguntas fueron abiertas, lo que le permitió a los entrevistados expresar sus opiniones sobre distintos puntos. Las preguntas cubrieron desde la importancia de los medios de comunicación en brindar información 
sobre la temática ambiental, hasta la calidad de la información misma. Adicionalmente, se les hizo una pregunta cerrada que permitía rankear a los diarios en función a la importancia que le daban al trato de la temática ambiental. Todas las entrevistas a periodistas fueron realizadas de manera presencial. Los periodistas entrevistados, sus cargos y lugares de trabajo se muestran en el cuadro 5.

\section{Entrevistas a expertos en REDD y gente vinculada con la temática ambiental}

Las entrevistas a expertos en REDD se realizaron para complementar el análisis debido al bajo número de artículos encontrados conteniendo las palabras clave requeridas inicialmente para el estudio. La selección de entrevistados se hizo teniendo en cuenta a personas vinculadas a REDD tanto del sector público, sector privado y ONG. Todas las personas entrevistadas se seleccionaron de la lista de miembros de Grupo REDD Nacional, teniendo en cuenta de incluir a personas de los tres sectores.

La idea inicial fue realizar todas las entrevistas de manera presencial, pero algunas de las personas a entrevistar se encontraban fuera de Lima o estaban ocupadas y prefirieron responder de manera electrónica. En total se realizaron cinco entrevistas presenciales y seis entrevistas virtuales. La convocatoria se hizo a través de un correo electrónico donde se explicaba la finalidad del estudio GCS-REDD, así como el análisis de medios. Se enviaron un total de diecisiete convocatorias, de

\section{Cuadro 5. Periodistas del estudio a nivel nacional} entrevistados

\begin{tabular}{|c|c|c|c|}
\hline No & Nombre & Cargo & $\begin{array}{l}\text { Lugar de } \\
\text { trabajo }\end{array}$ \\
\hline 1 & Gonzalo Pajares & Periodista & Perú 21 \\
\hline 2 & Claudia Izaguirre & Editora & Perú 21 \\
\hline 3 & Francisco Ínsua & $\begin{array}{l}\text { Jefe de } \\
\text { Informaciones }\end{array}$ & Expreso \\
\hline 4 & Nelly Luna & $\begin{array}{l}\text { Periodista, } \\
\text { sección Fin de } \\
\text { Semana }\end{array}$ & El Comercio \\
\hline 5 & Roberto Ochoa & Editor & La República \\
\hline 6 & Mariella Balbi & Periodista & $\begin{array}{l}\text { El Comercio y } \\
\text { CPN Radio }\end{array}$ \\
\hline 7 & Carlos Batalla & $\begin{array}{l}\text { Encargado del } \\
\text { Excalibur }^{\mathrm{a}}\end{array}$ & El Comercio \\
\hline
\end{tabular}

a Programa de almacenamiento de noticias, que facilita su búsqueda, usado por el diario El Comercio. las cuales sólo respondieron once. Las entrevistas realizadas a los expertos en REDD, además de contener varias de las preguntas abiertas realizadas a los periodistas, contenían una serie de preguntas cerradas. Estas preguntas fueron realizadas con la finalidad de recabar información más precisa sobre las percepciones de los entrevistados con relación al impacto de los medios de comunicación en los tomadores de decisiones, así como la disponibilidad de información relacionada con REDD. Los expertos en REDD entrevistados, sus cargos, lugares de trabajo y sector al que pertenecen se muestran en el cuadro 6 .

\subsubsection{ETAPA 2: Entrevistas en regiones}

Para el caso de las entrevistas, antes de los viajes se hicieron las coordinaciones necesarias con los principales miembros de los diarios de cada región y con profesionales pertenecientes a organizaciones vinculadas con REDD y otros temas ambientales. La convocatoria se realizó inicialmente a través de correo electrónico, principalmente a través de contactos de la zona y tomando como referencia la base de datos de los miembros de las mesas REDD de ambas regiones.

Para realizar las entrevistas se preparó un cuestionario similar al empleado en las entrevistas realizadas en la primera etapa, en Lima. Cada entrevista tuvo una duración de entre 25 a 40 minutos y fueron registradas en una grabadora. Al final de cada entrevista se les entregó un pequeño cuestionario para marcar y llenar, con la intención de complementar datos importantes sobre las organizaciones y algunas perspectivas informativas y comunicacionales de cada una de ellas. Luego de realizadas las entrevistas, éstas fueron transcritas en su totalidad.

\section{Madre de Dios}

Las entrevistas en Madre de Dios se realizaron en noviembre de 2011. Cada día se entrevistaron alrededor de cuatro personas, entre periodistas y miembros de organizaciones. La lista de personas entrevistadas se detalla en los cuadros 7 y 8 .

\section{San Martín}

En San Martín las entrevistas se iniciaron en diciembre de 2011, realizándose entrevistas tanto en Moyobamba, la capital, como en Tarapoto. La lista de personas entrevistadas se encuentra en los cuadros 9 y 10 . 
$\mathrm{Al}$ igual que para el caso de Madre de Dios, las entrevistas fueron luego transcritas y sistematizadas para facilitar el análisis.

\subsection{Análisis de las 3Es: Efectividad, Eficiencia, Equidad}

Un aspecto del GCS-REDD involucra un análisis de las iniciativas tempranas de REDD en términos de su éxito en ser efectivos, eficientes y equitativos (3Es) y que se generen cobeneficios como reducción de la pobreza y conservación de la biodiversidad (3Es+). El cuadro 11 muestra más detalles sobre las 3 Es de REDD.

El análisis de los marcos en términos de sus enfoques en 3Es pretende evaluar la frecuencia de artículos que se enfocan en los diferentes temas. Así se puede entender el conjunto de artículos de los medios como representación de la importancia de diferentes aspectos de REDD en los discursos.

\section{Cuadro 6. Expertos en REDD y personas vinculadas a la temática ambiental entrevistados en el estudio de nivel nacional}

\begin{tabular}{|c|c|c|c|c|}
\hline No & Nombre & Cargo & Lugar de trabajo & Sector \\
\hline 1 & Bertha Alvarado ${ }^{a}$ & Especialista & DGFFS - MINAG & Público \\
\hline 2 & Elvira Gómez & Experto en REDD & DGCCDRH - MINAM & Público \\
\hline 3 & Julia Justo & Directora Ejecutiva & FONAM & Público \\
\hline 4 & Alberto Paniagua & Director Ejecutivo & PROFONANPE & Público \\
\hline 5 & Roberto Persivale ${ }^{a}$ & Director & Asesorandes & Privado \\
\hline 6 & José Luis Alzamora & Gerente de Proyectos & BioForest & Privado \\
\hline 7 & Juan José Rodríguez & Coordinador de Proyectos & TNC & ONG \\
\hline 8 & Eddy Mendoza & Coordinador de Ordenamiento Territorial & $\mathrm{Cl}$ & ONG \\
\hline 9 & Lucía Ruiz & Directora Ejecutiva & CIMA & ONG \\
\hline 10 & Alonso Castro & Experto en REDD & AIDER & ONG \\
\hline 11 & Tania García ${ }^{a}$ & Experta en REDD & DAR & ONG \\
\hline
\end{tabular}

a Entrevistas realizadas vía correo electrónico

\section{Cuadro 7. Madre de Dios: miembros de los medios de comunicación entrevistados}

\begin{tabular}{llll}
\hline No & Nombre & Cargo & Lugar de trabajo \\
\hline 1 & José Antonio Cevallos & Gerente & Diario Don Jaque \\
2 & Leónidas Tito Laura & Gerente & Diario El Observador \\
3 & Grimaldo Taboada & Propietario Director & Diario Internacional Mi Frontera \\
4 & David Mejía & Periodista y conductor & Página Inforegión y Programa Radial Diálogo Ciudadano \\
5 & José Antonio Huamaní & Conductor & Programa Telepuerto al Día \\
6 & Alonso Paz & Conductor & Espacio radial Noticiero de la 1 y Programa Televisivo \\
7 & Julio Blanco & Periodista & Intercambio \\
\hline
\end{tabular}


Cuadro 8. Madre de Dios: expertos en REDD y personas vinculadas a la temática ambiental entrevistados

\begin{tabular}{|c|c|c|c|c|}
\hline No & Nombre & Cargo & Lugar de trabajo & Sector \\
\hline 1 & Bruno Sanguinetti & Gerente & Consorcio Madre de Dios & Público \\
\hline 2 & Nelson Kroll & Coordinador del proyecto & MADERACRE & Privado \\
\hline 3 & Andrea Chávez & $\begin{array}{l}\text { Representante de la Universidad } \\
\text { de la Florida en el Consorcio } \\
\text { Madre de Dios }\end{array}$ & Consorcio Madre de Dios & Publico \\
\hline 4 & Mishari García Roca & Director & $\begin{array}{l}\text { Oficina de Cooperación Técnica } \\
\text { Internacional de UNAMAD }\end{array}$ & Público \\
\hline 5 & Oscar Macedo & Jefe de Relaciones Públicas & $\begin{array}{l}\text { Gobierno Regional de Madre de } \\
\text { Dios }\end{array}$ & Público \\
\hline 6 & Carlos Sánchez & Coordinador Regional & AIDER & ONG \\
\hline 7 & Jaime Semizo & Coordinador & Proyecto Tambopata ISUR & Privado \\
\hline 8 & Juan Carlos Flores & Gerente Regional & $\begin{array}{l}\text { Bosques Amazónicos de Madre } \\
\text { de Dios }\end{array}$ & Privado \\
\hline 9 & Melina Panduro & $\begin{array}{l}\text { Subgerente de Proyectos y } \\
\text { Relaciones Comunitarias }\end{array}$ & Candela Perú & Privado \\
\hline 10 & Pastor Vidal La Madrid & Presidente & $\begin{array}{l}\text { Asociación de Despachadores } \\
\text { de Producto Forestal de Madre } \\
\text { de Dios }\end{array}$ & Privado \\
\hline 11 & Víctor Zambrano & Presidente & $\begin{array}{l}\text { Comité de Gestión de la Reserva } \\
\text { Nacional Tambopata }\end{array}$ & Privado \\
\hline 12 & Augusto Mulanovich & Director Nacional & ACCA & ONG \\
\hline 13 & Iván Cárdenas & Coordinador & $\begin{array}{l}\text { Federación Castañera } \\
\text { FEPROCAN - Agricultura } \\
\text { Ecológica }\end{array}$ & Privado \\
\hline 14 & Pedro Casanova & $\begin{array}{l}\text { Secretario Técnico de Asuntos } \\
\text { Agrarios }\end{array}$ & $\begin{array}{l}\text { Federación Agraria de Madre de } \\
\text { Dios }\end{array}$ & Privado \\
\hline 15 & William Moreno & Coordinador Regional & CAMDE PERÚ & ONG \\
\hline 16 & Claudio Delgado Vega & $\begin{array}{l}\text { Subgerente de Recursos } \\
\text { Naturales }\end{array}$ & Gobierno Regional & Público \\
\hline 17 & $\begin{array}{l}\text { José Luis Mamani } \\
\text { Condori }\end{array}$ & $\begin{array}{l}\text { Egresado de la Facultad de } \\
\text { Ingeniería Forestal de la } \\
\text { UNAMAD }\end{array}$ & & Público \\
\hline
\end{tabular}

Cuadro 9. San Martín: miembros de los medios de comunicación entrevistados

\begin{tabular}{llll}
\hline No & Nombre & Cargo & Lugar de trabajo \\
\hline 1 & Lenin Quevedo Bardales & Director Periodístico & Diario Voces \\
2 & Marco Carrillo & Editor y redactor & Diario Ahora \\
3 & Julio García Montenegro & Director & Diario Hoy \\
\hline
\end{tabular}


Cuadro 10. San Martín: expertos en REDD y personas vinculadas a la temática ambiental entrevistados

\begin{tabular}{|c|c|c|c|c|}
\hline No & Nombre & Cargo & Lugar de trabajo & Sector \\
\hline 1 & Alex Juárez & Coordinador & $\begin{array}{l}\text { Asociación Peruana para la Conservación de la } \\
\text { Naturaleza (APECO) }\end{array}$ & ONG \\
\hline 2 & Elías Peas Cahuas & Vicepresidente & $\begin{array}{l}\text { Federación Regional e Indígena Awajún del } \\
\text { Alto Mayo (FERIAM) }\end{array}$ & Privado \\
\hline 3 & $\begin{array}{l}\text { Segundo Noé } \\
\text { Cahuas Peas }\end{array}$ & Técnico Awajún & $\begin{array}{l}\text { Oficina Regional de Desarrollo de los Pueblos } \\
\text { Indígenas de San Martín (ORDEPISAN) }\end{array}$ & Público \\
\hline 4 & Karina Pinasco & $\begin{array}{l}\text { Directora de Políticas y } \\
\text { Proyectos }\end{array}$ & Amazónicos por la Amazonía (AMPA) & ONG \\
\hline 5 & Karla Mendoza & Secretaria Técnica & Mesa REDD en San Martín & Público \\
\hline 6 & Sebastián Inoñam & Director de Gestión Territorial & Autoridad Regional Ambiental (ARA) & Público \\
\hline 7 & Silvia Reátegui & Gerente & Autoridad Regional Ambiental (ARA) & Público \\
\hline 8 & $\begin{array}{l}\text { Cinthia } \\
\text { Mongylardi }\end{array}$ & Directora & Programa CIMA Cordillera Azul & ONG \\
\hline 9 & Walter Aguirre & Comunicador & Programa CIMA Cordillera Azul & ONG \\
\hline 10 & Mario Ríos & $\begin{array}{l}\text { Director de Medio Ambiente } \\
\text { y Jefe de Conservación y } \\
\text { Reforestación }\end{array}$ & Gobierno Regional & Público \\
\hline 11 & $\begin{array}{l}\text { Martha del } \\
\text { Castillo }\end{array}$ & Coordinadora ejecutiva & $\begin{array}{l}\text { Centro de Desarrollo e Investigación de la Selva } \\
\text { Alta (CEDISA) }\end{array}$ & ONG \\
\hline 12 & Miguel Alva & $\begin{array}{l}\text { Director Ejecutivo } \\
\text { de Administración y } \\
\text { Conservación de Recursos } \\
\text { Naturales }\end{array}$ & Gobierno Regional & Público \\
\hline 13 & Jessica Quipas & $\begin{array}{l}\text { Subgerencia de la Gestión } \\
\text { Ambiental y Ordenamiento } \\
\text { Territorial }\end{array}$ & Municipalidad Provincial de San Martín & Público \\
\hline 14 & Jessica Untama & $\begin{array}{l}\text { Consultora del tema de } \\
\text { Conservación }\end{array}$ & Gobierno Regional y Cámara de Comercio & Público \\
\hline
\end{tabular}

Cuadro 11. Las 3Es (Efectividad, Eficiencia, Equidad)

\begin{tabular}{lll}
\hline Término & Descripción & Pregunta que busca resolver \\
\hline Efectividad & $\begin{array}{l}\text { Se refiere a la cantidad de emisiones reducidas } \\
\text { o remociones incrementadas debido a acciones } \\
\text { de REDD+. }\end{array}$ & $\begin{array}{l}\text { ¿El mecanismo está alcanzando las metas de } \\
\text { reducción de emisiones de GEI? }\end{array}$ \\
Eficiencia & $\begin{array}{l}\text { Se refiere al costo de estas reducciones de } \\
\text { emisiones o aumento de las remociones. }\end{array}$ & ¿Se ha cumplido esta meta a un costo mínimo? \\
Equidad & $\begin{array}{l}\text { Se refiere a la distribución de los costos y } \\
\text { beneficios de REDD+. }\end{array}$ & $\begin{array}{l}\text { ¿Cuáles son las consecuencias en términos de } \\
\text { distribución y beneficios colaterales? }\end{array}$ \\
\hline
\end{tabular}

Fuente: Angelsen y Wertz-Kanounnikoff, 2008 


\section{Resultados y análisis de la codificación de noticias}

A continuación, se detallan los resultados de las evaluaciones realizadas en ambas etapas del estudio.

\subsection{Incidencia de artículos en los diarios seleccionados: Evaluación del Nivel 1}

\subsubsection{ETAPA 1: Número de artículos a nivel nacional}

Para el análisis nacional, en total se evaluaron 33 artículos para el G1 (palabras clave "REDD", "deforestación evitada" y "reducción de emisiones + deforestación"); y 203 artículos para el G2 (palabras clave "cambio climático + bosques"). Se deberá tener en cuenta que existe una superposición del número de artículos, lo que quiere decir que el universo total de artículos evaluados no equivale a la suma de los artículos identificados para cada uno de los grupos, como se observa en la figura 2 .

De esto se deduce que hay un pequeño grupo de artículos encontrados que hablan tanto de REDD como de cambio climático y bosques (nueve en total), lo cual llama la atención no por el hecho de que se repitan noticias en ambas búsquedas, sino por el bajo número de noticias que mencionan ambos temas, ya que REDD, bosques, y cambio climático son aspectos que están estrechamente relacionados.

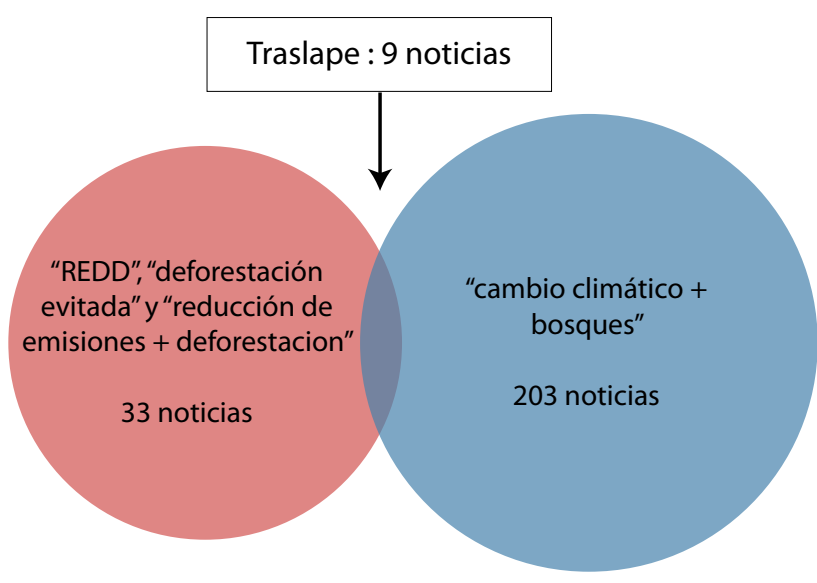

Figura 2. Traslape de noticias con las palabras clave analizadas a nivel nacional
La distribución de estos artículos por palabras clave y años se encuentra en la figura 3. Como se puede notar, el mayor número de artículos con las palabras clave del G2 ("cambio climático + bosques") aparecen en el 2010, con 77 apariciones, seguido del año 2009, con 42 artículos. Para el caso del G1 ("REDD”, "deforestación evitada" y "reducción de emisiones + deforestación"), el número de incidencias del 2010 es de 14, sólo dos noticias más que para el año 2009. Para el año 2011 se encontraron cuatro noticias del G1. Se deberá tener en cuenta que la búsqueda se realizó hasta fines de noviembre del 2011, por lo que los datos del 2011 no son comparables con los otros años.

La figura 4 muestra la incidencia de artículos encontrados con la búsqueda más amplia de palabras clave. Como se puede apreciar en la figura, los términos más amplios como "cambio climático" (con 4494 apariciones), "calentamiento global" (con 2612 apariciones), y "deforestación” (con 1220 apariciones) tienen una incidencia mucho mayor que los términos más específicos como "REDD" (con 30 apariciones), "deforestación evitada" (con dos apariciones), o "reducción de emisiones + deforestación" (con solo una aparición). Si se considera el número total de noticias halladas por diario se tiene lo siguiente, de mayor a menor: (i) El Comercio con 5181 noticias; (ii) La República con 2368noticias; (iii) El Peruano con 489 noticias; (iv) Gestión con 221 noticias; (v) Perú 21 con 210 noticias; (vi) Trome con 184 noticias; (vii) La Razón con 61 noticias; y (viii) Expreso en último lugar con 13 noticias.

Cabe mencionar que para el presente estudio solo se realizó la codificación de los artículos conteniendo las palabras clave "REDD", "deforestación evitada", y "reducción de emisiones + deforestación" (G1), y "cambio climático + bosques" (G2). Lamentablemente no se cuenta con información de la fecha exacta de aparición de los artículos que contienen las palabras clave "cambio climático", "calentamiento global", "deforestación" y "Protocolo de Kioto" dado que el banner de búsqueda de los diarios evaluados no permite filtrar las noticias 


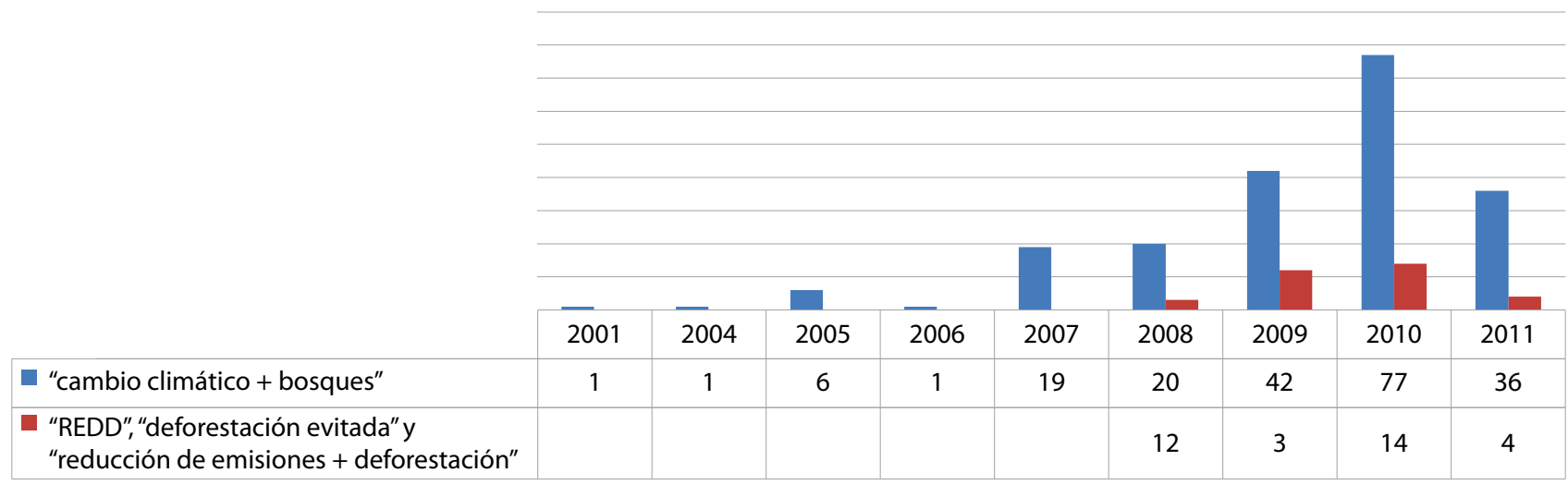

Figura 3. Frecuencia de aparición de artículos de diarios de alcance nacional mencionando: "cambio climático + bosques"; y "REDD", "deforestación evitada" y "reducción de emisiones + deforestación" Nota: Para todos los gráficos, las celdas que se encuentran en blanco quieren decir que no aparecieron resultados para esa búsqueda.

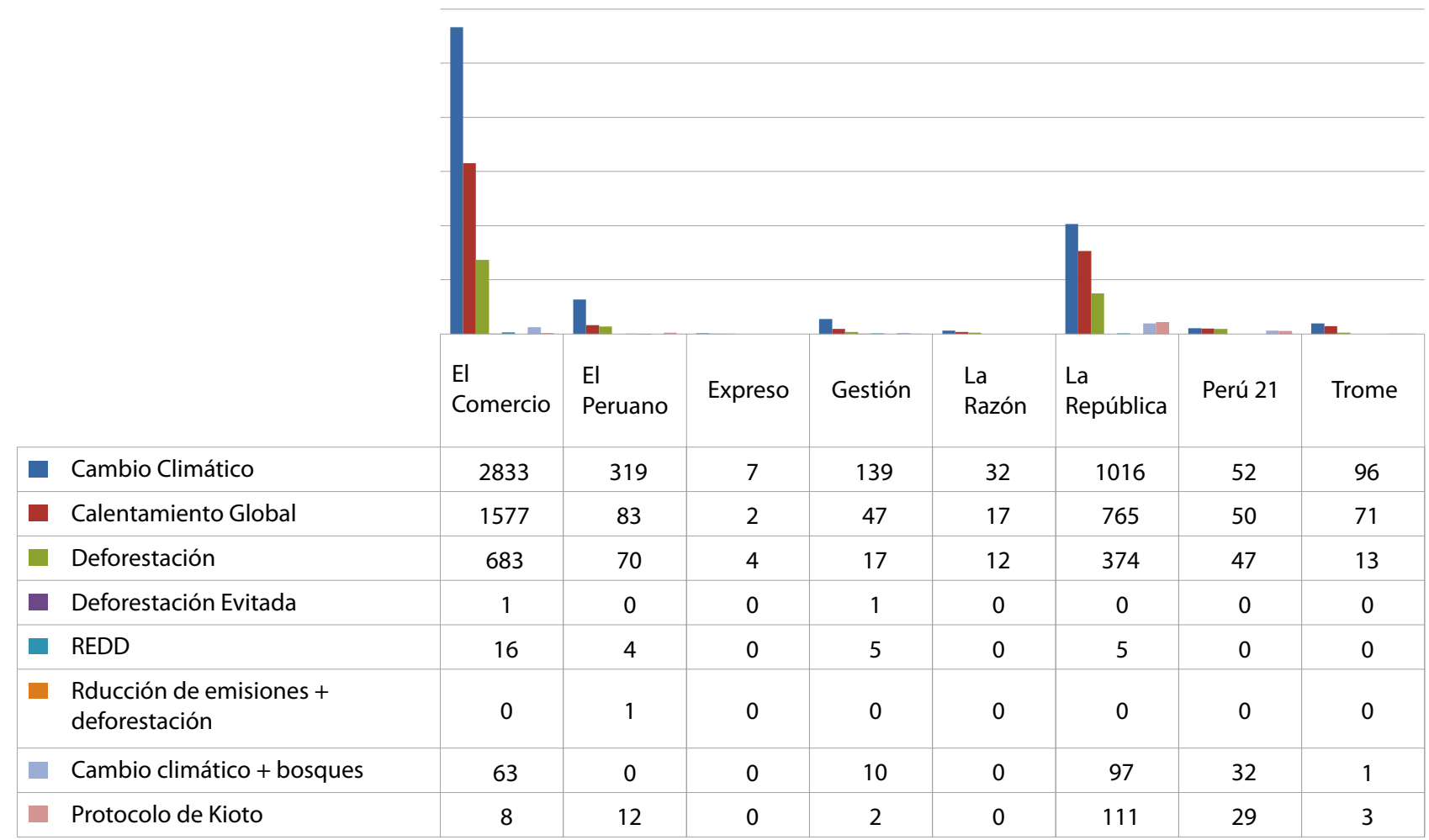

Figura 4. Frecuencia de noticias por diario de alcance nacional, de acuerdo a grupo mayor de palabras clave

por ańos y el análisis de los temas más amplios se encuentra fuera del alcance del presente estudio. Si se evalúa la incidencia de noticias por diario para las palabras clave del G1 y G2 (ver Figura 5), se observa claramente que El Comercio lleva la delantera únicamente para el G1, pero es La República quien lidera el número de noticias para el G2. Perú 21 se encuentra en tercer lugar para el
G2, no conteniendo ninguna noticia de los temas específicamente vinculados con REDD (G1).

Durante las entrevistas realizadas, tanto a expertos como a periodistas, se les solicitó a los entrevistados que numerasen en orden de prioridad (del 1 al 9) una lista de diarios en base a su percepción de qué tanto tratan los temas ambientales. En el cuadro 12 


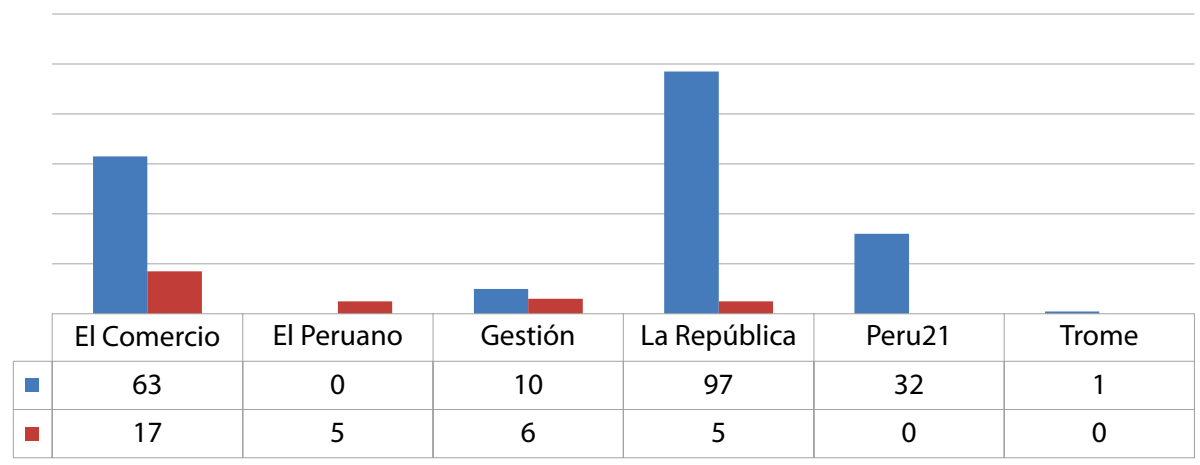

Figura 5. Número de artículos hallados por diario de alcance nacional para "REDD", "deforestación evitada", "reducción de emisiones + deforestación"; y "cambio climático + bosques"

Cuadro 12. Ranking de los diarios según la percepción de los entrevistados, versus la incidencia real de artículos

\begin{tabular}{|c|c|c|c|c|c|c|}
\hline \multirow[t]{2}{*}{ Diario } & \multicolumn{3}{|c|}{ Ranking según percepción de entrevistados } & \multicolumn{3}{|c|}{ Ranking según incidencia real de noticias } \\
\hline & Periodistas & Expertos & Global $^{\mathrm{a}}$ & $\mathrm{G} 1^{\mathrm{b}}$ & $G 2^{c}$ & Grupo mayor $^{d}$ \\
\hline El Comercio & 1 & 1 & 1 & 1 & 2 & 1 \\
\hline Perú 21 & 3 & 2 & 2 & $s / n$ & 3 & 5 \\
\hline La República & 2 & 3 & 3 & 3 & 1 & 2 \\
\hline El Peruano & 5 & 4 & 4 & 3 & $s / n$ & 3 \\
\hline Gestión & 4 & 5 & 5 & 2 & 4 & 4 \\
\hline Expreso & 7 & 6 & 6 & $s / n$ & $s / n$ & 8 \\
\hline Correo & 6 & 7 & 7 & $n / d$ & $n / d$ & $n / d$ \\
\hline La Razón & 8 & 8 & 8 & $s / n$ & $s / n$ & 7 \\
\hline Trome & 9 & 9 & 9 & $s / n$ & 5 & 6 \\
\hline
\end{tabular}

a El valor Global está basado en la sumatoria de las respuestas de ambos grupos.

b G1: "REDD”, “deforestación evitada” y"reducción de emisiones + deforestación”.

c G2: "cambio climático + bosques".

d Grupo mayor: G1, G2, Cambio Climático, Calentamiento Global, Protocolo de Kioto.

s/n: no se hallaron noticias para esa búsqueda; n/d: no disponible; el diario Correo no fue parte del estudio.

se encuentra el ranking para el grupo de periodistas, para el grupo de expertos en REDD, y para la suma de todos los entrevistados, así como el ranking real de acuerdo al número de noticias para los distintos grupos de búsqueda.

Resalta la diferencia de artículos encontrados para los distintos diarios, siendo El Comercio el que tiene una incidencia mucho mayor de noticias para la mayoría de palabras clave buscadas. Esto se complementa con lo mencionado por Nelly Luna (periodista entrevistada de El Comercio) cuando menciona que "en El Comercio, entre sus principios rectores, incluye el tema ambiental como uno de los pilares en investigación porque considera que un ambiente sano es base para la calidad de vida de las personas" y adicionalmente se apoya en el comentario de Alberto Paniagua, de PROFONANPE, que menciona que "El Comercio difunde este tipo de información todos los fines de semana a través de Somos y suplementos" que "siempre hay algo sobre el tema medioambiental" y que "El Comercio "es el diario que más información, noticias y reportajes hace sobre el tema”.

Como se puede apreciar en el cuadro 12, el diario mejor posicionado por todos los entrevistados, tanto para el grupo de periodistas como para el grupo de 
expertos fue El Comercio, dato que coincide con la incidencia de noticias halladas para todas las palabras clave (incluyendo las palabras clave que no son parte del estudio) y para el grupo de G1, mas no para el G2, donde el diario con mayor número de noticias es La República. Según el ranking, La República se encuentra en 2 do puesto para los periodistas, lo que se ajusta a la realidad, pero en 3er puesto para los expertos en REDD, quienes posicionan a Perú 21 como segundo. Ambos grupos coinciden en que La Razón se ubica en 8 vo puesto y Trome en 9no.

\section{REDD en los medios de alcance nacional: Evaluación del Nivel 1}

Comparando estos resultados con los hallazgos en Brasil (país con el que se comparte la Amazonía y algunos de los problemas y causas de la deforestación y degradación), donde se encontraron (en el marco del GCS-REDD) un total de 409 artículos en cuatro diarios (May et al., 2011), el número de noticias halladas en el Perú es realmente pequeño, no llegando ni al 8\% del número de noticias halladas en Brasil. En otros países se han encontrado números similares a los del Perú como es el caso de Camerún, con 14 artículos (Kenguom, 2011) y en Vietnam con 18 artículos (Pham, 2011), mientras que en Indonesia se encontraron 190 artículos hasta 2010 (Cronin y Santoso, 2010). Si bien el número de noticias es bastante bajo para el Perú, hay una tendencia creciente, como se puede ver en la figura 6, y como lo ratifica Eddy Mendoza de CI, al mencionar que "en los últimos 10 años ha habido un cambio positivo. En diarios importantes como El Comercio, La República y RPP tocan los temas ambientales".
Sobre los artículos del año 2008 se puede mencionar que el primero, del 5 de marzo, denominado "Financiarán primer proyecto para evitar deforestación de bosques" (2008) trata sobre las primeras iniciativas que se dan en el país y el financiamiento de las mismas. El segundo, "Bonos de carbono financiarían proyectos forestales en Perú" (2008) del $1^{\circ}$ de octubre, trata sobre el potencial del Perú para la emisión de bonos de carbono y hace una descripción del mecanismo REDD. El tercer artículo del 5 de octubre, titulado "Ecuador: ¿Medio ambiente o petróleo?” (2008) solo hace una mención superficial sobre deforestación evitada y menciona la posible venta de bonos de no contaminación ambiental por parte del gobierno ecuatoriano.

Para el año 2009 se encontraron en la evaluación a nivel nacional 12 noticias que mencionaron REDD; mientras que para el año 2010 se encontraron 14 noticias en los diarios de distribución nacional, y para el 2011 se hallaron cuatro noticias en los diarios de distribución nacional.

En la figura 6 se puede apreciar el número de artículos encontrados para cada uno de los diarios de distribución nacional analizados que contenían artículos sobre REDD. De los ocho diarios, El Comercio es el que presentó más noticias, con un total de 17 artículos, seguido por Gestión, con seis, y La República, y El Peruano, ambos con cinco. En los diarios Perú 21, Expreso, La Razón y Trome no se encontraron artículos con las palabras clave del G1 en las páginas web.

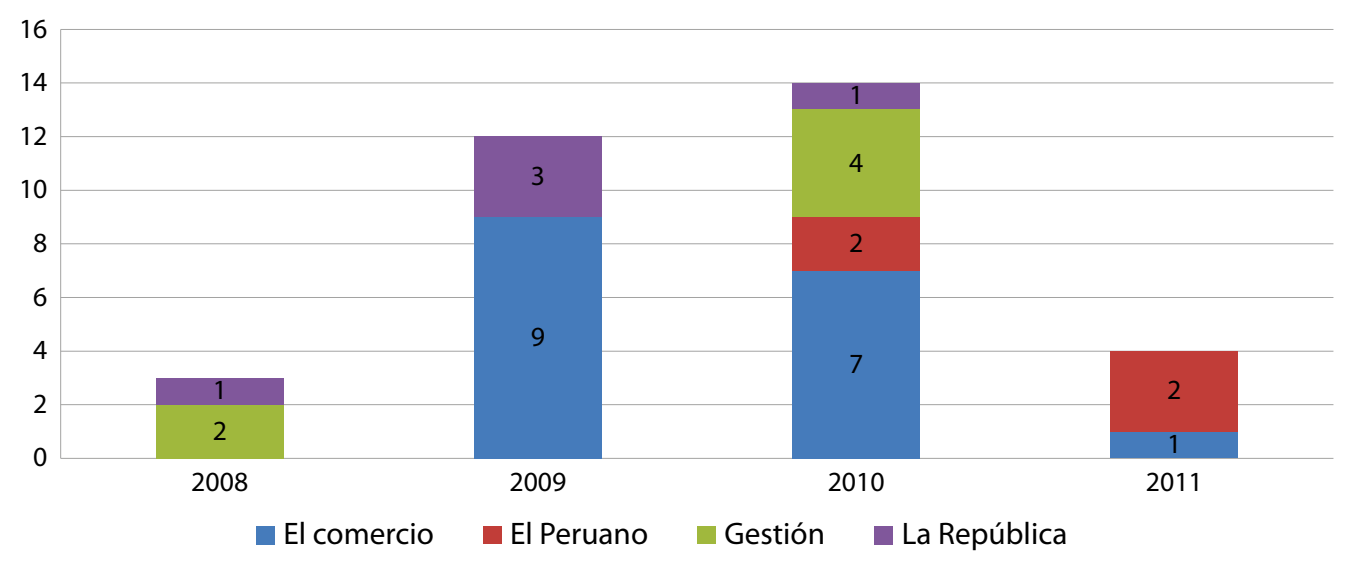

Figura 6. Frecuencia de cobertura por año y por diario de alcance nacional, para "REDD", "deforestación evitada" y "reducción de emisiones + deforestación" 


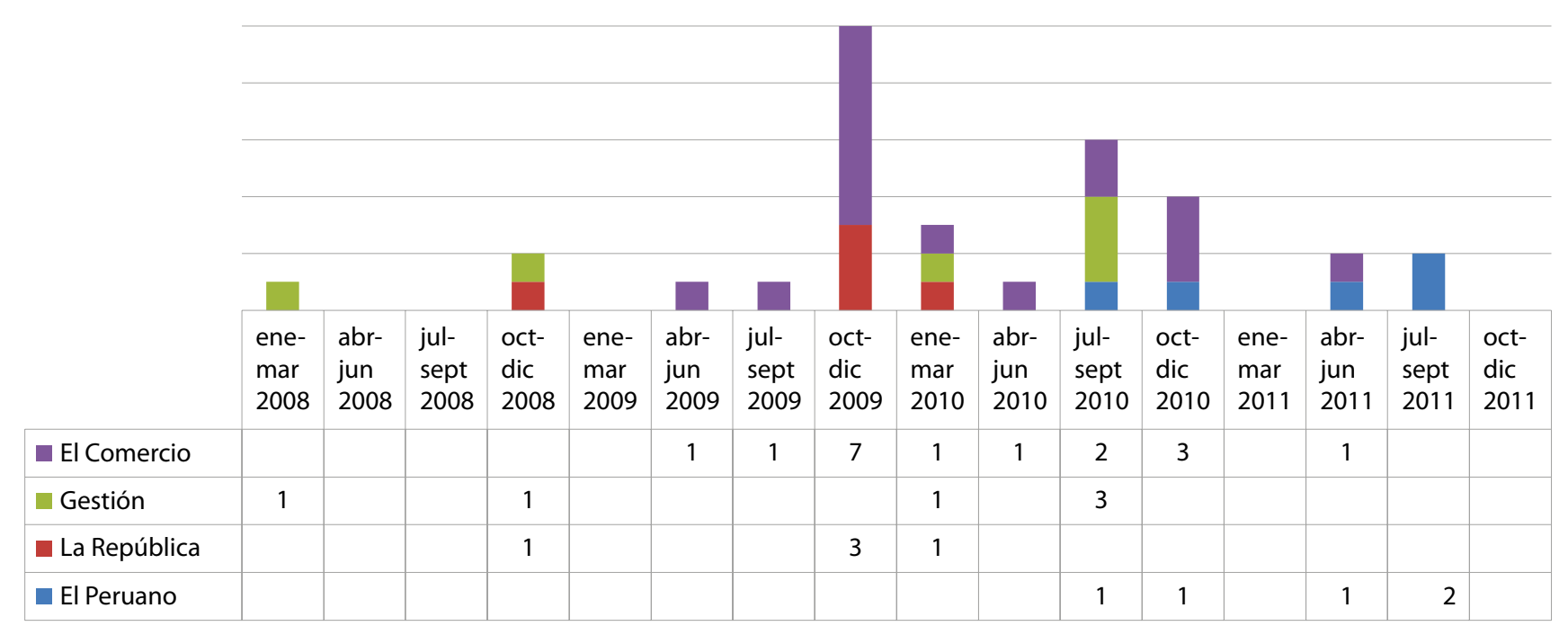

Figura 7. Frecuencia de cobertura por diario de alcance nacional y por trimestre, para "REDD", "deforestación evitada" y "reducción de emisiones + deforestación"

Si se analiza la incidencia de noticias por trimestre, como se puede ver en la figura 7 , el pico más alto de noticias del G1 se da entre octubre y diciembre del 2009, con un total de diez artículos, lo que coincide con la COP 15 en Copenhague (del 7 al 19 de diciembre). De estas noticias, todas están relacionadas con la COP y siete se dan en el mes de diciembre. Las dos noticias de octubre son escritas desde Bangkok, a raíz de la cumbre preparatoria para la COP 15 y ambas hablan sobre la falta de compromisos logrados y la falta de claridad en varios temas a tratar en Copenhague, siendo REDD uno de ellos. En la noticia de noviembre hay un párrafo que alude al rumbo de REDD en Copenhague. Uno de los artículos de diciembre hace un recuento de los sucesos rumbo a Copenhague a la vez que explica los avances y los posibles desenlaces; dos noticias presentan anécdotas y posturas de diferentes países (Colombia y la Coalición Africana); una presenta la postura de las organizaciones indígenas del Amazonas; otra se refiere a Jane Goodall (líder de opinión en la temática ambiental y de conservación) y una charla que realizó en Copenhague; y las dos restantes tratan temas del mecanismo REDD y bosques peruanos.

Temas sobre la COP 15 se continuaron tocando durante 2010, con dos noticias de enero del 2010. Una de ellas (titulada "Decepción y esperanza") resume el sentimiento post Copenhague al mencionar que "las expectativas por un acuerdo climático ambicioso y vinculante se estrellaron con la indolencia de los negociadores designados por cada país".

Si bien hay un segundo pico en el trimestre de julio a septiembre del 2010, las noticias no están relacionadas con ningún evento particular y tratan sobre distintos temas vinculados con REDD, entre los que se encuentran hechos nacionales e internacionales. El tercer pico que se puede apreciar en la figura 7 corresponde a los meses de octubre a diciembre del 2010 y coincide con la COP 16 en Cancún, México. De las cuatro noticias, tres están vinculadas directamente con la COP.

En el año 2011 se tienen cuatro noticias en total, dos de las cuales se dan en junio, una en julio y la última en setiembre. No se ha determinado que haya un patrón de frecuencia de noticias debidas a algún factor externo, debido principalmente al bajo número de noticias encontradas.

Esta coincidencia de picos de noticias con hechos internacionales como las COP pone en evidencia que los diarios tratan la temática REDD, en su mayoría, cuando hay un evento de gran envergadura a nivel mundial que toca este punto entre otros temas. A la vez, se hace evidente que hay una falta de cobertura de temas a nivel nacional y local, ya sea porque no 
existen noticias a ser reportadas o porque la prensa no las considera relevantes. Esto se refleja también en las entrevistas realizadas, ya que, según algunos entrevistados, la información que se brinda es más descriptiva, y usualmente está asociada a informar sobre algún evento internacional.

\section{Cambio climático y bosques en los medios de alcance nacional: Evaluación del Nivel 1}

La primera noticia con las palabras clave "cambio climático + bosques" aparece en el año 2001, en la editorial del diario La República, titulada "Efecto Invernadero" (2001). Como se ve en la figura 8, durante los años 2002 y 2003 no aparece ninguna noticia con estas palabras clave y solo hasta 2004 aparece nuevamente una noticia en el mismo diario titulada "El hombre: la especie más peligrosa" (2004). En 2005 hay un leve pico, con seis noticias, bajando en 2006 a una. Desde el año 2007 se puede notar un crecimiento constante, alcanzando 77 noticias en 2010. Evaluando el año 2011 (hasta fines de noviembre) se contó con 36 noticias, 30 noticias menos que para el mismo periodo del 2010.

Si se dividen las noticias en trimestres, como se observa en la figura 9, se observa una serie de picos, la mayoría de los cuales no están vinculados necesariamente con ningún tema en particular. Para el caso del pico de abril a junio del 2007, coincide con que ocurrió la Octava Sesión del IPCC Grupo de Trabajo II en Bruselas, Bélgica (del 2 al 5 de abril) y la reunión del G8 en Heiligendamm, Alemania (del 6 al 8 de junio), hechos que se mencionan en varios de los artículos del mencionado trimestre.

El pico de noticias que se generó de octubre a diciembre del 2009, coincide con la COP 15 en Copenhague. En este periodo se encontraron 18 noticias, muchas de las cuales están vinculadas con eventos de la COP y previos a ella. Una situación similar se presenta en el periodo de octubre a diciembre del 2010, que coincide con la COP 16 en Cancún, donde se da un pico de 25 noticias, en gran parte debido a sucesos y temas vinculados con la COP.

$\mathrm{Al}$ igual que para el caso de las noticias del G1, es importante notar que los picos se dan debido a eventos internacionales y no a sucesos a nivel nacional o local. Esto nuevamente evidencia la falta de interés de los medios de comunicación de cubrir hechos nacionales vinculados con la temática ambiental, lo cual puede deberse a una serie de razones, como considerar que no son relevantes o que no van a incrementar las ventas de los diarios. Hay algunos hechos importantes que se han dado en el país que no se han visto reflejados en las noticias halladas, como por ejemplo:

- El lanzamiento de la "Alianza pionera en el manejo sostenible de bosques para la mitigación del cambio climático", la cual fue suscrita entre Scotiabank Perú y la empresa forestal Maderacre, con la finalidad que el banco neutralice sus emisiones de gases de efecto invernadero $\left(\mathrm{CO}_{2}\right)$, la cual tuvo el aval del MINAM.

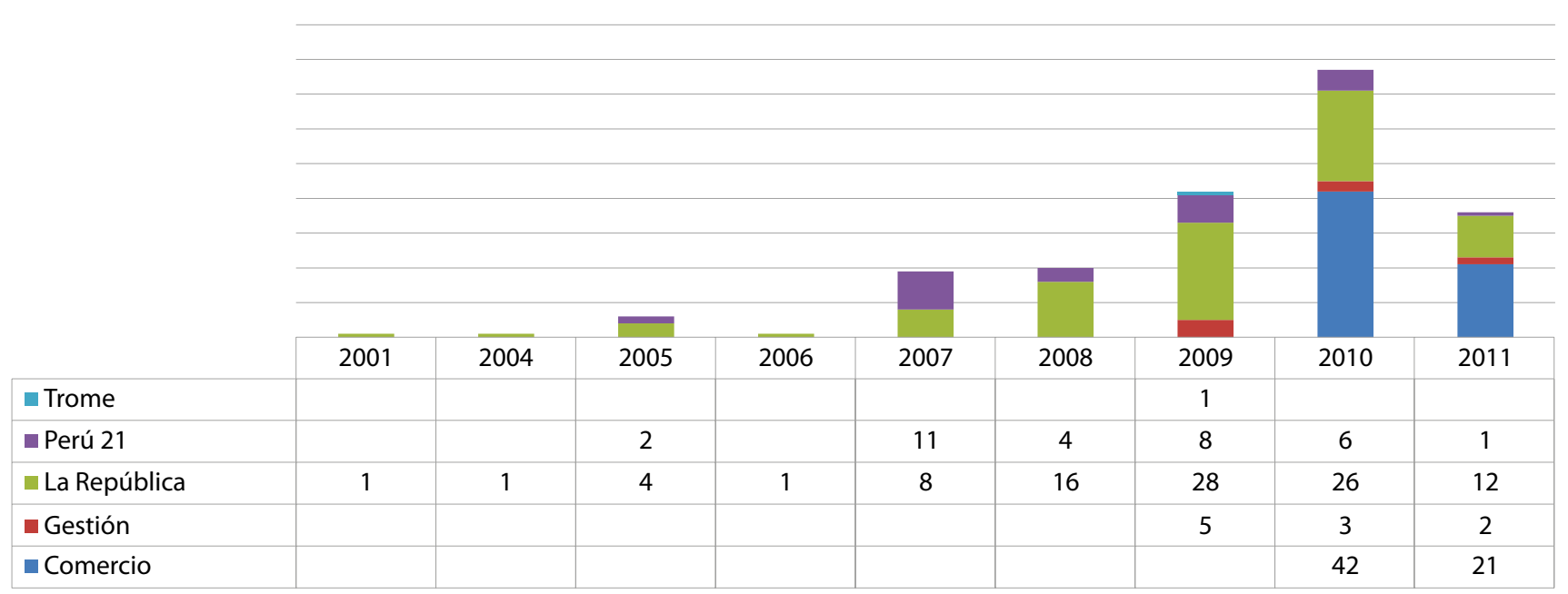

Figura 8. Frecuencia de cobertura por año y por diario de alcance nacional, para "cambio climático + bosques" 


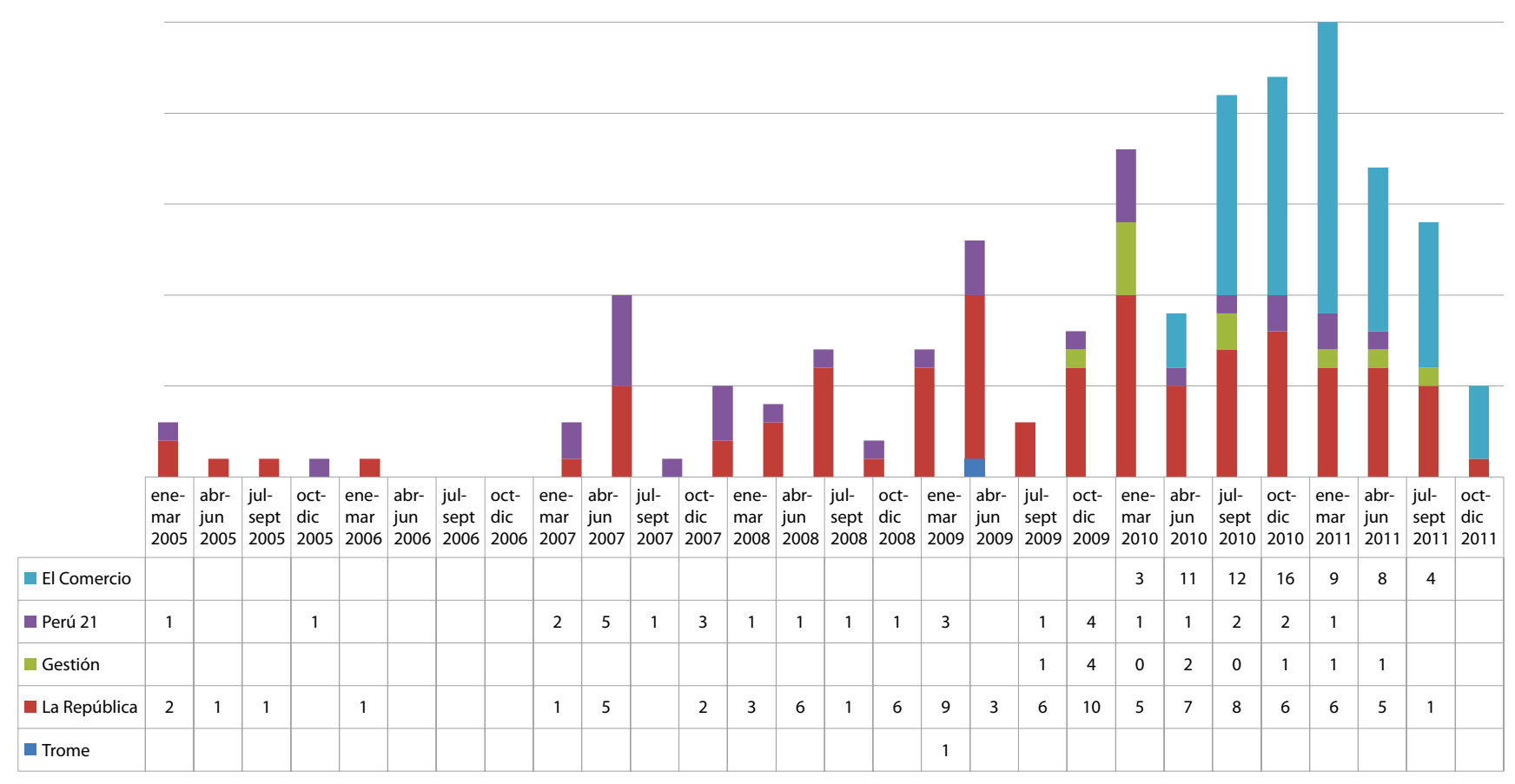

Figura 9. Frecuencia de cobertura por trimestre y por diario de alcance nacional, para "cambio climático + bosques"

- La presentación de la Segunda Comunicación Nacional del Perú a la CMNUCC.

- Fondos destinados a financiar proyectos relacionados con la conservación y el manejo de los bosques, como los fondos provenientes de la Fundación Moore, KfW, o el FCPF.

\subsubsection{ETAPA 2: Número de artículos a nivel regional}

En total se evaluaron 10 artículos para el G1 ("REDD", "deforestación evitada" y "reducción de emisiones + deforestación"); y 10 artículos para el G2 ("cambio climático + bosques"). La distribución de estos artículos por diario, palabra clave y ańo se encuentra en la figura 10. Cabe mencionar que todos los artículos evaluados, tanto para el G1 como para el G2, fueron hallados a través de las páginas web de los diarios, no habiéndose hallado ningún artículo de estos dos grupos en la búsqueda física. Si se evalúa la figura 10 se puede identificar que los únicos diarios donde se hallaron los artículos evaluados son de la Región San Martín.

Como se puede ver, no se encontraron noticias de ninguno de los dos grupos de palabras clave antes

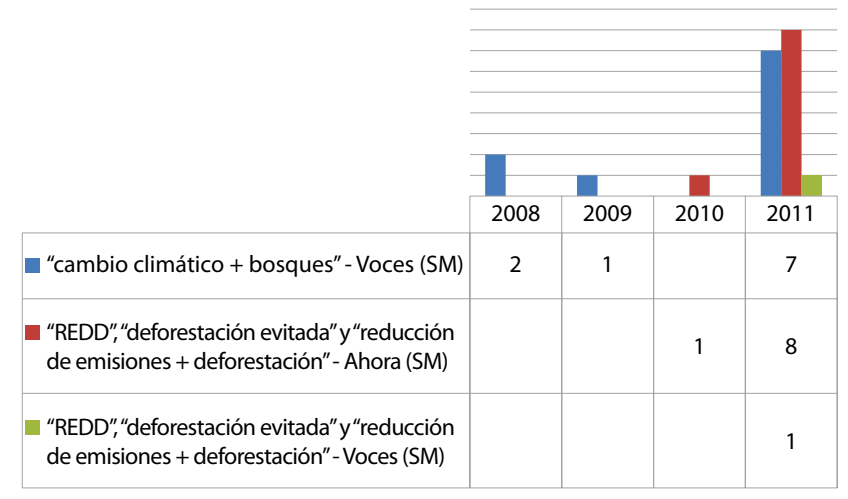

Figura 10. Frecuencia de aparición de artículos por diario regional, mencionando: "cambio climático + bosques"; y "REDD", "deforestación evitada" y "reducción de emisiones + deforestación"

del año 2008, habiéndose encontrado relativamente pocas noticias hasta el 2011, donde se encuentra el mayor número de incidencias detectadas, con 7 artículos para el G2, y 9 para el G1. Vale la pena mencionar que la búsqueda de noticias fue difícil ya que las páginas web de los diarios no se encuentran actualizadas, y en muchos casos no se consiguieron las versiones impresas de muchas ediciones. 


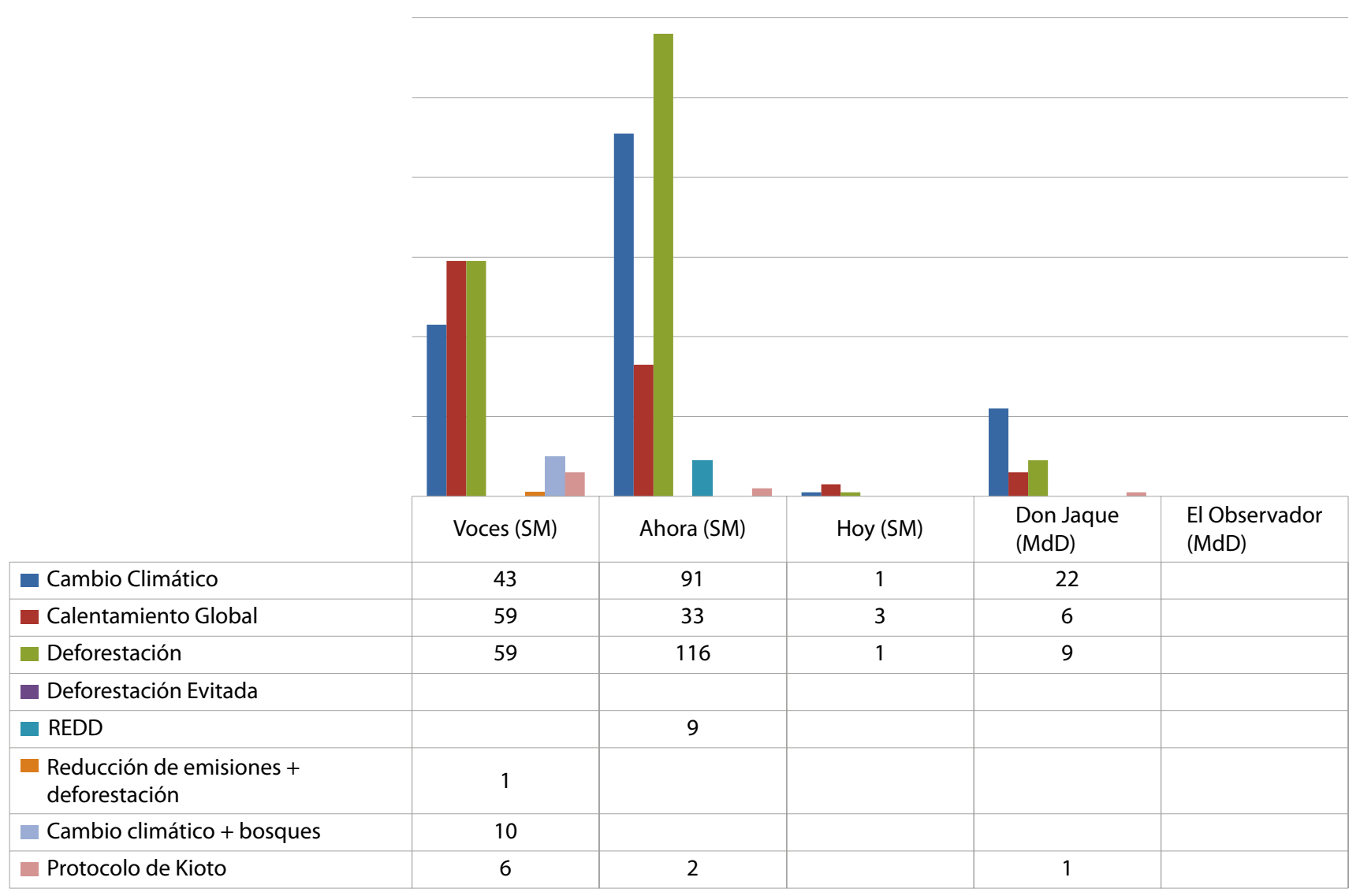

Figura 11. Frecuencia de noticias por diario regional, de acuerdo a grupo mayor de palabras clave

$\mathrm{Al}$ igual que para el caso de la primera etapa, la búsqueda de noticias se realizó hasta fines de noviembre del año 2011.

Si se considera la búsqueda ampliada de palabras clave (Figura 11), al igual que para el caso del estudio de diarios de cobertura nacional, es evidente que los términos más frecuentes son "cambio climático" (con 157 apariciones), calentamiento global (101 noticias), y deforestación (con 185 noticias). A diferencia de la evaluación a nivel nacional, en las regiones se puede apreciar que la palabra clave más frecuente es "deforestación", debido a que es un tema muy común en ambas regiones.

En relación a los diarios, es evidente que el diario Ahora es el que tiene una incidencia mucho mayor de noticias, con 251 artículos; segundo el diario Voces, con 178 apariciones. Ambos diarios son de la región San Martín. En el diario El Observador de Madre de Dios no se halló ningún artículo conteniendo las palabras clave evaluadas.
$\mathrm{Al}$ igual que para las entrevistas de la evaluación nacional, también se realizaron entrevistas a los periodistas y expertos regionales, donde se les pidió que numeraran en orden de prioridad (del 1 al 3) una lista de diarios en base a su percepción de qué tanto tratan los temas ambientales. En el cuadro 13 se encuentra el ranking para el grupo de periodistas, para el grupo de expertos en REDD, y para la suma de todos los entrevistados.

Para Madre de Dios, si se compara el ranking de percepción de los entrevistados, con el ranking real de noticias halladas, se puede ver que Don Jaque es el diario mejor clasificado, lo que concuerda con el número de noticias halladas para el grupo mayor de palabras clave. Vale la pena resaltar que para El Observador no se hallaron noticias de ninguna de las búsquedas.

Para San Martín, a nivel global el diario que fue elegido como el que más noticias ambientales presenta es Voces, el cual fue el que tuvo una mayor 
Cuadro 13. Ranking de los diarios regionales según la percepción de los entrevistados

\begin{tabular}{lllccccc}
\hline & Diarios & \multicolumn{3}{l}{$\begin{array}{l}\text { Ranking según percepción de } \\
\text { entrevistados }\end{array}$} & \multicolumn{3}{l}{$\begin{array}{l}\text { Ranking según incidencia real de } \\
\text { noticias }\end{array}$} \\
\cline { 2 - 8 } & & Periodistas & Expertos & Global & G1 & G2 & Grupo Mayor \\
\hline \multirow{2}{*}{ Madre de Dios } & Don Jaque & 1 & 1 & 1 & $\mathrm{~s} / \mathrm{d}$ & $\mathrm{s} / \mathrm{d}$ & 1 \\
& El Observador & 2 & 2 & 2 & $\mathrm{~s} / \mathrm{d}$ & $\mathrm{s} / \mathrm{d}$ & $\mathrm{s} / \mathrm{d}$ \\
\hline \multirow{2}{*}{ San Martín } & Voces & 2 & 1 & 1 & 2 & 1 & 2 \\
& Ahora & 1 & 2 & 2 & 1 & $\mathrm{~s} / \mathrm{d}$ & 1 \\
& Hoy & 3 & 3 & 3 & $\mathrm{~s} / \mathrm{d}$ & $\mathrm{s} / \mathrm{d}$ & 3 \\
\hline
\end{tabular}

"REDD", "deforestación evitada" $y$ " reducción de emisiones + deforestación"

"cambio climático + bosques"
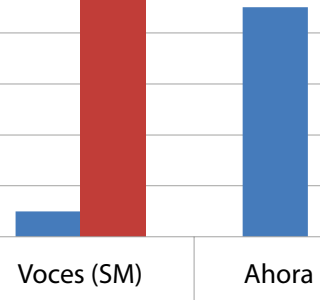

1

10

Figura 12. Número de artículos hallados por diario regional para "REDD", “deforestación evitada", "reducción de emisiones + deforestación"; y "cambio climático + bosques"

incidencia de noticias para la búsqueda del G2, pero no para el G1 ni para el grupo mayor de palabras clave. El diario Ahora, que fue posicionado en segundo lugar a nivel global, pero en primer lugar por el grupo de periodistas, fue en el que se hallaron una mayor cantidad de artículos, tanto para la búsqueda del G1 como para la búsqueda mayor de palabras clave.

Como se muestra en la figura 12, al analizar únicamente los dos grupos de palabras clave evaluados en el estudio, se puede ver claramente que es el diario Ahora el que contiene un número mayor de artículos que mencionan las palabras clave del G1, con nueve incidencias; mientras que el diario Voces lleva la delantera para las palabras clave del G2, con diez incidencias. En ninguno de los diarios de Madre de Dios evaluados se hallaron noticias con las palabras clave del G1 o el G2.

\section{REDD en los medios regionales. Evaluación del Nivel 1}

Como se puede ver en la figura 13, no se han hallado noticias que hablen sobre REDD hasta el año 2010, donde se encuentra una sola noticia en el diario Ahora de San Martín. En el año 2011 hubo un leve pico, y se encuentran nueve noticias en total, 8 pertenecientes al diario Ahora, y una al diario Voces, ambos en San Martín. Como ya se mencionó anteriormente, no se encontraron noticias del G1 para Madre de Dios. La primera noticia hallada, del 18 de octubre, se titula " 29 científicos internacionales evaluaron bosques de Ucayali" (2010) y trata sobre una delegación de científicos de REDD-Alert de distintas partes del mundo para evaluar las posibilidades de la cuenca del Aguaytía y ser considerada dentro de un programa de deforestación evitada.

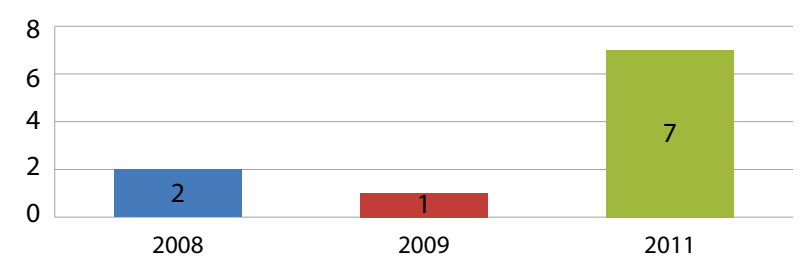

Figura 13. Frecuencia de cobertura por año y por diario regional, para "cambio climático + bosques" 
Ahora y Voces, fueron los únicos diarios donde se identificaron noticias sobre REDD. El diario Ahora de San Martín es el que presentó más noticias, con un total de 9 artículos (8 en 2011 y 1 en 2010), mientras que en el diario Voces se halló solo una en 2011. En los diarios Hoy, Don Jaque, y El Observador no se encontraron artículos con las palabras clave del G1, ni en las páginas Web, ni en las búsquedas realizadas en físico.

De acuerdo a la percepción de los entrevistados a nivel regional, es muy escaso lo que difunden los medios sobre REDD, y las noticias ligadas a este tema son básicamente sobre servicios ambientales o de bonos de carbono. El potencial noticioso sobre el tema ambiental está vinculado a denuncias y conflictos sociales en torno a la tala ilegal, minería, contaminación, etc. Bruno Sanguinetti, Gerente del Consorcio Madre de Dios, quien ha vivido muchos años en la región, manifiesta que "la comunicación con respecto a REDD se limita a que las instituciones provean de noticias a los medios. No hay noticias al respecto, ni siquiera de gestión ambiental. En general, creo que el tema ambiental no es tomado como relevante y si bien hoy en día, se difunden algunas cosas, gracias a que está ligado al tema minero, por la coyuntura que está sucediendo actualmente, REDD como parte del manejo de información en Madre de Dios no se da”.

Para Andrea Chávez, representante de la Universidad de Florida, los temas REDD "más que nada son e-searches [búsquedas electrónicas], pero aún no se tiene una estructura en donde se tenga recopilada toda la información. Las mismas instituciones, por ello, deben empezar a sistematizar su propia información. El gobierno regional que debería tener información tampoco tiene muy bien recopilada su data... existe mucha información que viene de fuera, a partir de investigaciones hechas acá en la zona, sobre todo en los meses de verano. Lo malo es que esa investigación en muchos de los casos ya no regresa y para nosotros sería muy relevante el análisis de esos trabajos e informaciones". "Aquí en Madre de Dios, en términos de REDD todavía hay muchas expectativas y hay mucha mala información, porque a nivel local, no es que no se entienda, simplemente se tiene una mala información y tergiversación de la información", concluye Chávez.

Mario Rios, Director de Medio Ambiente y Jefe de Conservación y Reforestación del Gobierno Regional, afirma que "no ha visto medios que traten el tema. Todavía se siente el tema muy técnico. El lenguaje, por otro lado, es muy complicado, incluso para los propios técnicos.".

\section{Cambio climático y bosques en los medios regionales: Evaluación del Nivel 1}

Para el caso de la búsqueda del G2, "cambio climático + bosques", también se hallaron 10 noticias, pero distribuidas entre los años 2008, 2009 y 2011. Todas las noticias evaluadas fueron halladas a través de la página web del diario Voces de San Martín.

Tal como se muestra en la figura 13, se hallaron dos noticias correspondientes al año 2008. La primera noticia se titula "Adaptación al cambio climático" (2008), del 15 de octubre, y trata sobre la vulnerabilidad de los más necesitados frente a cambios climáticos, y la necesidad de adaptarse. La segunda noticia de 2008, del 28 de octubre, se titula "Resultados de escenarios de cambio climático" (2008) y habla sobre la presentación de un estudio sobre escenarios de cambio climático para la cuenca del río Mayo, y menciona algunas de las conclusiones del mismo.

La noticia del 2009, "Premian a ganadores de concurso de dibujo sobre cambio climático" (2009), es del 16 de setiembre y trata sobre un concurso de pintura sobre cambio climático para estudiantes.

De las siete noticias del año 2011, vale la pena mencionar "En San Martín se trabaja en el cumplimiento de compromisos para mitigar daños del efecto invernadero" (2011), del 8 de agosto, que hace una reseńa sobre los sucesos vinculados con el cambio climático, mencionando el Protocolo de Kioto, los acuerdos pactados y algunos sucesos relacionados. Las seis noticias restantes hablan de temas diversos: en algunas se anuncian eventos ("II Encuentro de nacionalidades indígenas amazónicas" (2011)), mientras que en otras se informa de anuncios puntuales ("Presidentes regionales darán a conocer problemática de la selva peruana" (2011), "Gobierno peruano destinará 12 millones de dólares para la conservación de bosques" (2011)).

\subsubsection{Autoría de los artículos analizados}

Si se evalúa la autoría de los artículos publicados en los distintos diarios, tanto a nivel nacional como regional, se puede observar que muchos de los nombres se repiten, inclusive para las dos búsquedas realizadas (G1 y G2). Se debe mencionar, sin embargo, que no se ha encontrado un autor que 
escriba tanto para los diarios de alcance nacional como para los de alcance regional.

\section{ETAPA 1: Autoría en diarios de nivel nacional}

Como se puede apreciar en las figuras 14 y 15, para el caso del análisis nacional, los autores que más se repiten en los artículos evaluados son las agencias de noticias internacionales, como $\mathrm{EFE}^{6}$, Andina ${ }^{7}, \mathrm{AP}^{8}$, $\mathrm{AFP}^{9}, \mathrm{DPA}^{10}$ y Reuters $^{11}$, las cuales alcanzan el $27 \%$ para el G1 y el 37\% para el G2.

Para el estudio nacional, dentro de los dos grupos de palabras clave el autor que más se repite es EFE, con cinco artículos para el G1 y 37 artículos para el G2. Andina es el autor que se encuentra en segundo puesto, con 17 artículos para el G2 y ninguno para el G1. Otro autor que se repite en varias ocasiones, es Reuters, con tres artículos para el G1 y siete para el G2. El periodista que más artículos ha escrito es Erik Struyf, corresponsal de El Comercio en Bruselas, con tres artículos para el G1 y ninguno para el G2 (las noticias cubiertas por Struyf corresponden a los eventos de la COP 15 en Copenhague). Es sorprendente que no exista al menos un periodista que se repita en más de tres oportunidades. Esto, nuevamente, refleja la falta de interés de los medios para cubrir temas ambientales, y en especial REDD, y la falta de conocimiento de los distintos periodistas sobre la temática ambiental. Como lo indica Alberto Paniagua de PROFONANPE: "los mismos entrevistadores y periodistas de los distintos medios no manejan los temas. Ellos deberían tener en su formación temas y conocimientos sobre problemas ambientales. Creo que este tema debe estar incluido en el currículo de las universidades del país".

Asimismo, llama la atención la cantidad de artículos codificados como "sin fuente", lo que quiere decir que no cuentan con un autor identificado en la noticia. Para ambos grupos de búsqueda éste es el

6 EFE es una agencia internacional de noticias en español (http://www.efe.com).

7 Andina es la Agencia Peruana de Noticias (http://www. andina.com.pe/Espanol/).

8 AP es la agencia de noticias internacional Associated Press (http://www.ap.org/).

9 AFP es la Agence France-Presse (http://www.afp.com/ afpcom/es/content/news).

10 DPA es la Agencia Alemana de Noticias (http://www.dpa.de).

11 Reuters es la agencia internacional de noticias más grande a nivel mundial (http://www.reuters.com/). grupo con un mayor número de noticias: 11 para el G1 (33\%) y 73 para el G2 (36\%). Es posible que estos artículos sin fuente hayan sido escritos por alguno de los periodistas que sí han sido referenciados adecuadamente en los otros artículos, lo que podría estar generando distorsiones en el análisis de autoría.

\section{ETAPA 2: Autoría en diarios de alcance regional}

Para el estudio regional, como se puede apreciar en las figuras 16 y 17 , el autor que se repite con mayor frecuencia es W. la Torre para el G1, con cinco artículos; y Juan Tejada para el G2, con dos artículos.

Nuevamente llama la atención la cantidad de artículos sin fuente, siendo mucho más evidente para los artículos del G2, donde siete de los diez artículos hallados no cuentan con un autor.

\subsection{Análisis de los artículos en el Nivel 2 y $3^{12}$}

De los 33 artículos codificados en la primera etapa para las palabras clave del G1, siete fueron codificados hasta Nivel 1, debido a que solo hacían mención al término y no lo analizaban con profundidad; siete fueron codificados hasta el Nivel 2, debido a que no contaban con un defensor o con un adversario; y los 19 restantes llegaron a una codificación de Nivel 3.

De ahora en adelante el análisis corresponde solo a las 26 noticias de Nivel 2 y 3.

Ninguno de los diez artículos hallados en la búsqueda de diarios regionales para las palabra clave del G1 llegaron a ser codificados más allá del Nivel 1, ya que no analizaban la temática de REDD con mayor profundidad.

De entre los mencionados 26 artículos de Nivel 2 y 3 , para ninguno se pudo identificar un marco secundario, teniendo todos únicamente un marco principal. De esto se deduce que ningún artículo evalúa REDD desde más de un ángulo lo que una vez más confirma la falta de cobertura y profundidad que recibe REDD en la prensa nacional. Todos los artículos del G2, "cambio climático + bosques" fueron codificados hasta el Nivel 1 debido a que no

12 Los artículos con las palabras clave "cambio climático + bosques" se analizaron únicamente hasta el Nivel 1, ya que no contenían información sobre REDD. 


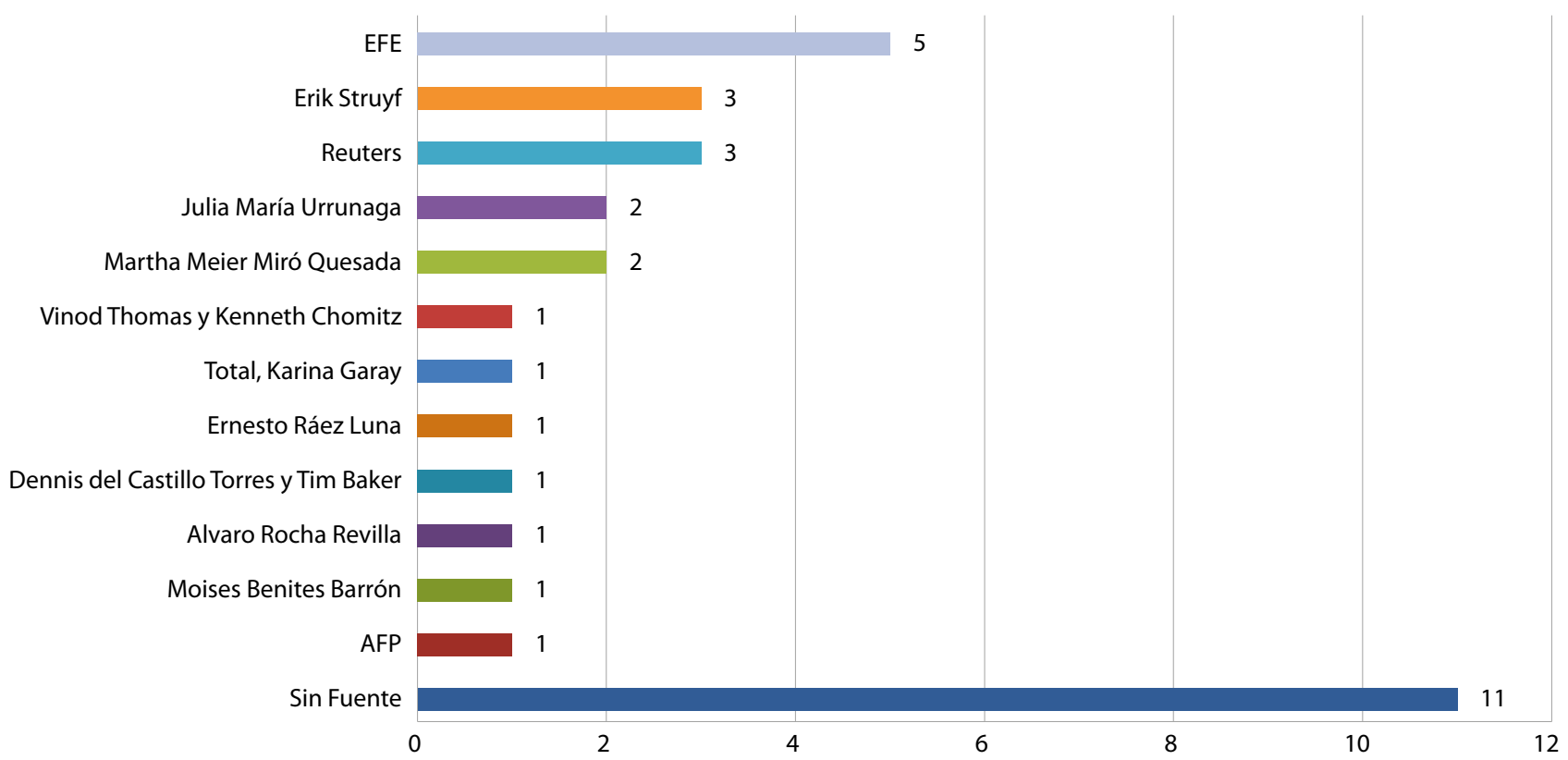

Figura 14. Frecuencia de artículos de diarios de alcance nacional, por autor, para "REDD", "deforestación evitada" y "reducción de emisiones + deforestación"

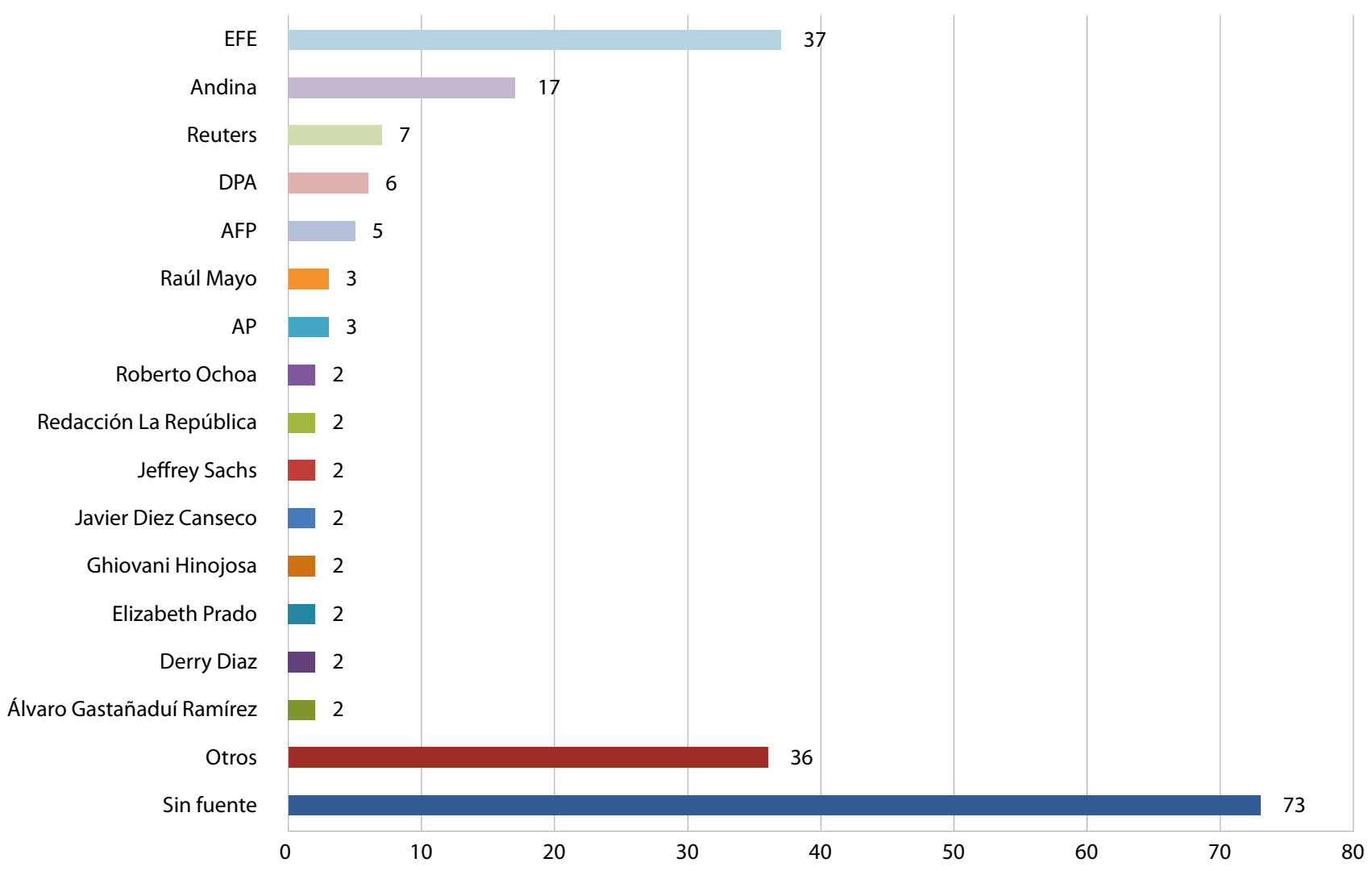

Figura 15. Frecuencia de artículos de diarios de alcance nacional por autor, para "cambio climático + bosques" Nota: El autor "Otros" se refiere a 36 autores diferentes que aparecen sólo una vez y han sido agrupados para facilitar el análisis. 


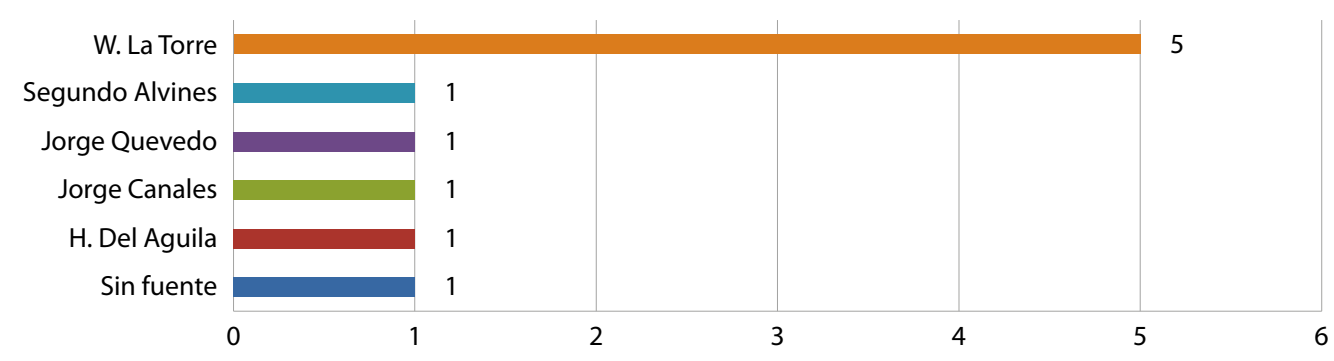

Figura 16. Frecuencia de artículos por autor en diarios regionales, para "REDD", "deforestación evitada" y "reducción de emisiones + deforestación"

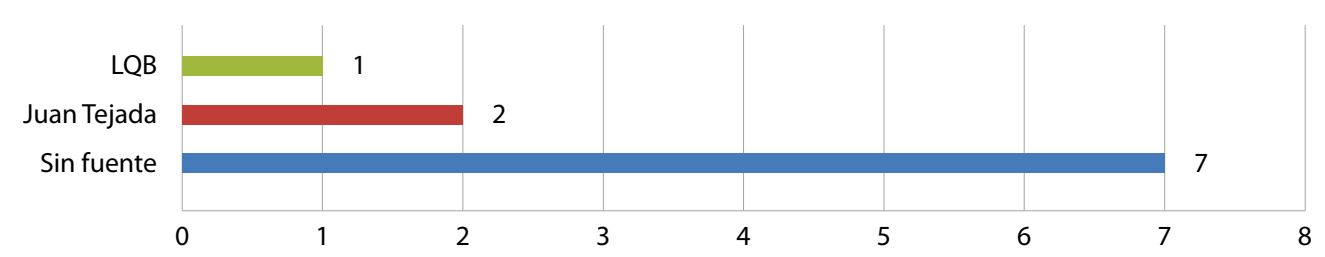

Figura 17. Frecuencia de artículos por autor en diarios regionales, para "cambio climático + bosques"

contenían información sobre REDD, razón por la cual quedan excluidos del análisis de esta sección.

\subsubsection{Análisis de los "marcos de medios"}

Como se puede apreciar en la figura 18, de las 26 noticias que pasaron el primer Nivel, siete contienen marcos primarios del tipo motivacional, dos sintomático, diez de pronóstico y siete de diagnóstico. Debido al bajo número de artículos y a que sólo aparecieron a partir del año 2008 es difícil determinar una tendencia clara. Lo que sí se puede apreciar es que ha habido un cambio del ańo 2009 al 2010, pasando de una predominancia de artículos de tipo diagnóstico -con cinco de los nueve artículos en

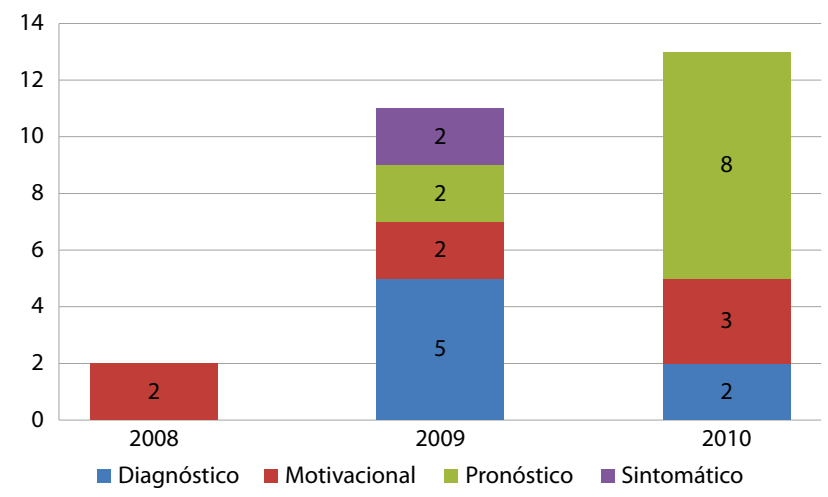

Figura 18. Evolución de la categoría de los marcos primarios por año, para "REDD", "deforestación evitada" y"reducción de emisiones + deforestación" el 2009- a artículos de tipo pronóstico, con ocho de los trece artículos.

Un ejemplo de un artículo que contiene un marco primario del tipo pronóstico es "De castańo a oscuro" (2009), el cual no solo expone los actuales problemas de los castañeros, como son la deforestación y las invasiones, sino que plantea que una posible solución al problema sería incluir a los castañales como un esquema REDD, con la finalidad de salvaguardar la permanencia de los bosques.

\subsubsection{Nivel de cobertura}

Como se puede apreciar en la figura 19, la mayoría de los artículos publicados se enfocaron en temas internacionales, con un total de 19 artículos, lo que equivale a $73 \%$ de los 26 artículos evaluados. Como menciona Elvira Gómez del Ministerio del Ambiente en relación a la información que aparece en las noticias: "considero también que se incluye noticias más de corte internacional que nacional". Adicionalmente, ella sugiere "son eventos más descriptivos, de una cumbre o algún acontecimiento internacional".

Si bien en el año 2008 los únicos dos artículos encontrados se enfocaron en temas nacionales, en el 2009 ocurrió que nueve de los 11 artículos se enfocaron en un nivel internacional, y para el año 2010, diez de los 13 se enfocaron en temas 


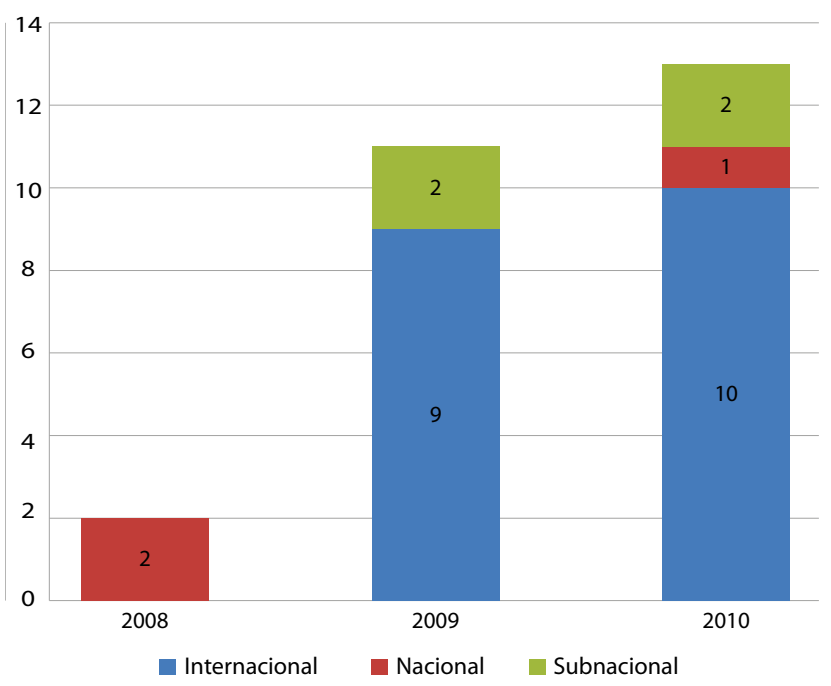

Figura 19. Número de artículos por año por nivel, para "REDD", "deforestación evitada" y "reducción de emisiones + deforestación"

internacionales. De los 26 artículos observamos que $15,5 \%$ son subnacionales mientras que $11,5 \%$ son de nivel nacional, no habiéndose encontrado ninguna noticia local.

En el 2009 diez de las 12 noticias se dieron en el periodo de octubre a diciembre, lo que coincide con la COP. De estas diez noticias, nueve fueron evaluadas más allá del Nivel 1 , siendo ocho de carácter internacional. Algunos de los títulos de las noticias de el periodo octubre-diciembre del 2009 fueron "Especial: Conferencia de Copenhague" (2009), "Coalición africana se pone fuerte en reunión mundial" (2009) y "Cambio climático: indígenas piden compensación económica" (2009), las cuales hablan de lo que sucedía durante la COP.

Para el año 2010, las cuatro noticias del periodo de octubre a diciembre son de carácter internacional y tres de ellas están vinculadas con la COP 16 en Cancún, ya que tratan de hechos ocurridos durante la COP ("Desde hoy se buscará una nueva dinámica ambiental" (2010), "Medidas contra la deforestación pueden reducir hasta en $80 \%$ la extinción de especies, según estudio" (2010), "El nuevo Google Earth Engine ayudará a evitar la deforestación” (2010)). Del primer trimestre del año 2010, las tres noticias hacen referencia a la COP 15 en Copenhague, siendo dos de carácter internacional ("Revela un estudio de las Naciones Unidas" (2010) y "Los bosques y el clima” (2010)), y una de carácter nacional
(“Decepción y esperanza” (2010)). El resto de noticias internacionales del 2010 están relacionadas a distintos sucesos, que no coinciden con ningún evento en particular y tratan sobre distintos temas vinculados con REDD.

Las cuatro noticias de carácter subnacional identificadas pertenecen a los ańos 2009 y 2010 , con dos noticias en cada año. La primera noticia del 2009, denominada "De castańo a oscuro" (2009) habla sobre los actuales problemas que afectan a los castañeros de la región Madre de Dios, y de la implementación de un esquema REDD para evitar mayores dańos en la zona. La segunda noticia del 2009, "Hermano fuego, hermano bosque" (2009), trata sobre los incendios forestales que se dan por causas antropogénicas, y menciona el Observatorio de Fuego para Madre de Dios como una iniciativa interesante. "Venderán bonos de carbono gracias a los bosques" (2010), se da en el año 2010 y se relaciona con la elaboración de un proyecto REDD en el área de conservación regional Angostura-Faical, en Tumbes. La última noticia de carácter subnacional se llama "La importancia del cuanto" (2010) y, dentro de otros temas, menciona dos proyectos REDD en Madre de Dios.

Si se analiza la autoría de estos artículos (lo cual ya se ha realizado en un mayor nivel de detalle en el punto 5.1.3), se puede ver que de las 26 noticias, seis no cuentan con un autor identificado, por lo que no se puede relacionar la autoría de la misma con el nivel de cobertura. Las nueve noticias que tienen por autor a una agencia internacional (EFE, AFP, Reuters) tienen un nivel de cobertura internacional.

Las 11 noticias restantes son escritas por distintos individuos, habiendo algunos autores que se repiten, como es el caso de Erik Struyf (corresponsal de El Comercio en Bruselas), con tres artículos internacionales; y Julia María Urrunaga (Presidenta de EIA Perú) con dos artículos internacionales.

Del resto de artículos escritos por individuos, hay tres de carácter subnacional, escritos por Alvaro Rocha Revilla (periodista de la Revista sabatina Somos, de El Comercio), Ernesto Raéz Luna (Director de Ciencia y Desarrollo del Centro para la Sostenibilidad Ambiental de la Universidad Peruana Cayetano Heredia), y Moisés Benites Barrón (Analista Senior en Comunicaciones en Bosques Amazónicos); y 
tres noticias de carácter internacional escritas por distintos autores.

El hecho de que la gran mayoría de artículos son de tipo internacional puede deberse a muchos factores, dentro de los cuales se encuentran los siguientes: (i) no hay una postura clara del gobierno sobre REDD u otros temas relacionados; (ii) no hay una organización o grupo de actores que haya adoptado la defensa (o el ataque) de REDD; (iii) la mayoría de avances o iniciativas que se dan en REDD ocurren en provincias, donde puede no haber cobertura mediática; (iv) los diarios nacionales no necesariamente tienen una política de cubrir aspectos relacionados con el ambiente, aunque con el tiempo esto ha ido cambiando; (v) los autores de los artículos no están capacitados en el tema, por lo que pueden no escribir sobre temas complejos que no necesariamente comprenden.

\subsubsection{Temas tratados}

Como se puede observar en las figuras 20 y 21 , de las 26 noticias evaluadas en profundidad, hay dos temas que han sido tocados de manera más frecuente en los artículos, (1) Políticas y Formulación de políticas, con 8 artículos (31\%), y (2) Ecología, con siete noticias $(27 \%)$.

En el grupo Políticas y Formulación de Políticas, referido a debates y procesos políticos para el diseño e implementación de REDD, el subtópico más frecuente es el de organizaciones internacionales y debates políticos, con seis de los ocho artículos del grupo, seguido por actividades de readiness para REDD, con dos noticias. Cabe mencionar que todas las noticias de este grupo son de carácter internacional y no hablan, en la mayoría de artículos, de políticas a nivel nacional o local, sino que, como en el caso de "Emisión imposible" (2009) tocan temas relacionados con la falta de decisión política para sacar adelante mecanismos para combatir el cambio climático.

Uno de los artículos del subgrupo que trata de organizaciones internacionales y debates políticos es "Desde hoy se buscará una nueva dinámica ambiental" (2010), un artículo que se da en el marco de la COP 16 en Cancún, y se menciona la iniciativa de Perú de haberse comprometido a conservar 54 millones de hectáreas de bosques a través del Programa Nacional de Conservación de Bosques.

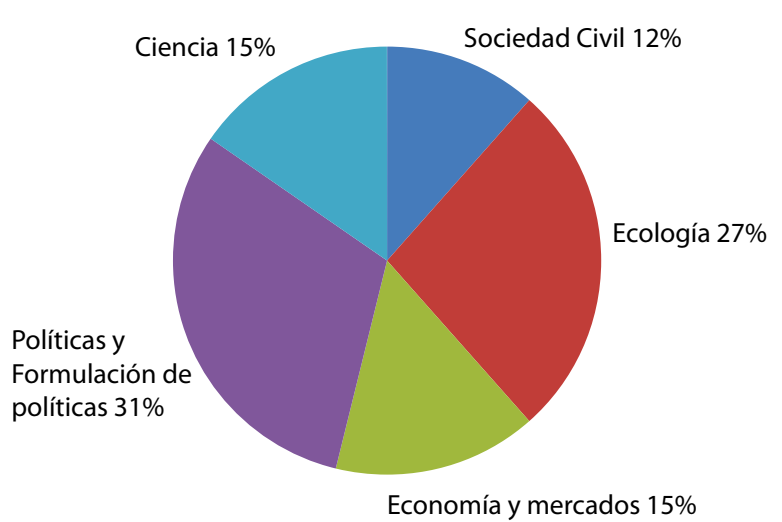

Figura 20. Metatópicos identificados para "REDD", "deforestación evitada" y "reducción de emisiones + deforestación"

Esta iniciativa fue presentada por primera vez en Poznan, en 2008, por el Ministro del Ambiente.

Del grupo Ecología, que se refiere mayormente a temas vinculados con bosques, plantas, biodiversidad y conservación, entre otros, más de la mitad de las noticias tratan específicamente sobre deforestación (cuatro en total). El resto de noticias del grupo se divide en conservación de bosques, con dos noticias, y conservación de la biodiversidad, con una noticia.

De las siete noticias que hablan de Ecología vale la pena resaltar la que trata sobre la conservación de la biodiversidad, "Medidas contra la deforestación pueden reducir hasta en $80 \%$ la extinción de especies, según estudio" (2010), la cual menciona un informe presentado por Conservación Internacional en Cancún que indica que si se contara con el financiamiento adecuado para REDD, se podrían reducir los índices de extinción de miles de especies en hasta $80 \%$ en cinco años.

En el grupo Economía y Mercados (15\%), dos de las cuatro noticias hablan de financiamiento, una del costo-beneficio de REDD, y la otra de comercio de carbono.

Los cuatro artículos del grupo de Ciencia hablan de nuevos métodos científicos y finalmente las tres noticias del grupo Sociedad Civil se relacionan con los intereses de la sociedad civil.

La mayoría de las noticias, si bien el tema central puede variar, hablan de los problemas asociados a 
57. Nuevos métodos científicos, fundamentos y nuevos estudios

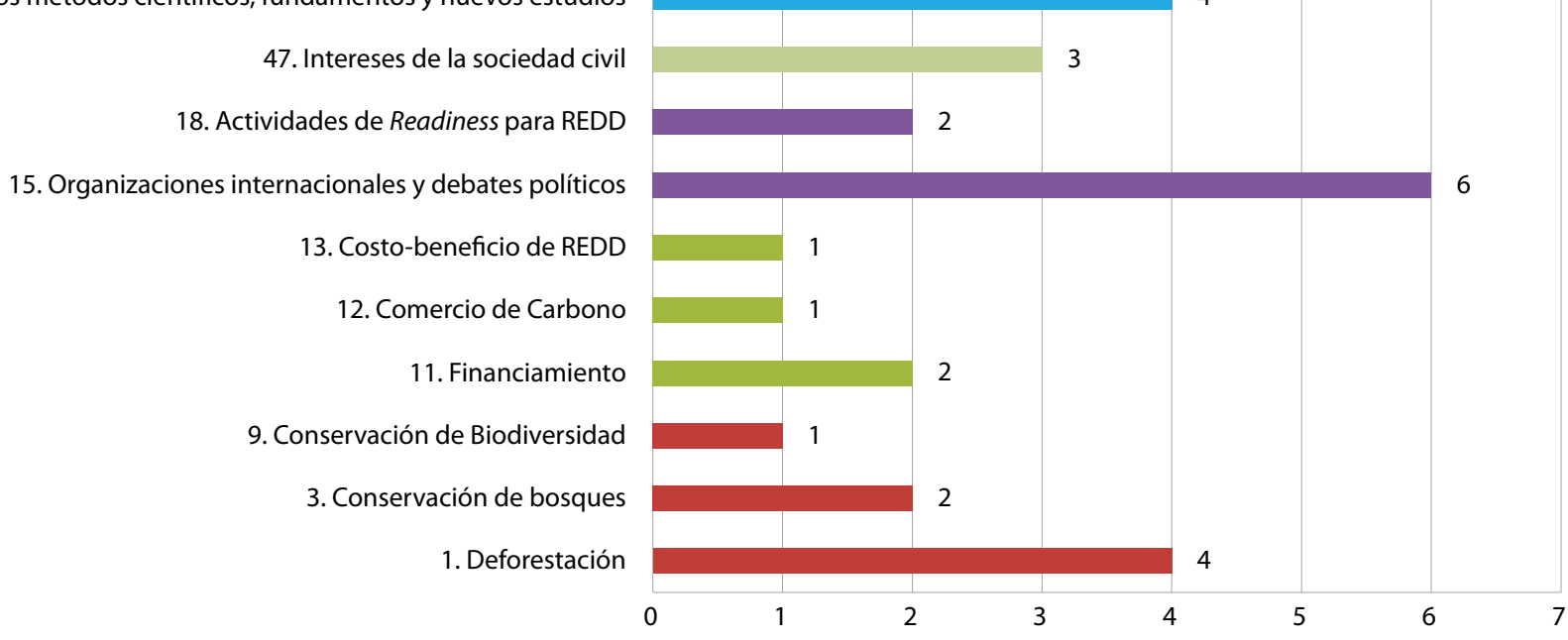

Figura 21. Tópicos identificados para "REDD", "deforestación evitada" y "reducción de emisiones + deforestación" Nota: Los colores son acorde a los colores de los metatópicos de la Figura 13.

la estabilidad jurídica vinculada a los derechos de propiedad y la titulación en los bosques. Dos casos son "Especial. Freno a la deforestación" (2009), cuyo tema central es Políticas y formulación de políticas y "Bonos de carbono financiarán proyectos forestales en Perú" (2008), cuyo tema central es Economía y Mercados. Otro tema tratado ampliamente es el de las invasiones y la falta de presencia del estado en las zonas alejadas, como en "De castańo a oscuro" (2009) que si bien el tema central es Ecología, habla de la falta de una planificación estratégica y una mala planificación social alrededor de la carretera interoceánica, lo que ha traído deforestación y concesiones castañeras invadidas. Se menciona también la burocracia estatal como una traba para el desarrollo de actividades relacionadas, ya que extiende los plazos y encarece los procesos.

Como menciona Alonso Castro de AIDER, para evitar la deforestación y promover REDD, es fundamental educar a las poblaciones locales: "Podrían crear conocimiento sobre el tema entre las poblaciones regionales, evitando en algunos casos que personas mal intencionadas y ajenas a la Amazonia usufructúen de los bosques en desmedro de las poblaciones locales; esto ayudará a la transparencia del proceso REDD".

\subsubsection{Actores}

De las 26 noticias analizadas, solo 19 pasaron al Nivel 3 , ya que cuentan con información sobre actores que participan de alguna manera en las noticias. Todos los actores identificados en las 19 noticias se consideran defensores, ya que son los que presentan la postura relacionada con REDD. Ninguna de las 19 noticias evaluadas cuenta con un adversario, de lo que se desprende que las noticias no llegan a un nivel de profundidad suficiente de análisis del tema tratado, ya que en ninguna noticia se presentan dos versiones o dos posiciones de un argumento vinculado con REDD. Cabe indicar que no significa que los adversarios, para el análisis del presente estudio se oponen a REDD, sino al marco y la posición expresadas por el defensor.

Como se puede apreciar en la figura 22, el grupo más citado en temas REDD es el de Organizaciones No Gubernamentales Ambientales (ONG Ambientales), ya sean internacionales (cinco artículos) o nacionales (solo uno), lo que en total suma seis noticias que equivale al 31,6\% del Nivel 3. Esta incidencia de ONG ambientalistas en las noticias vinculadas con REDD son un claro indicador de quiénes son los que están poniendo las pautas del tema REDD en el país. Algunas de las ONG que aparecen en los artículos son Greenpeace, quien afirmó que la oposición de Colombia para diseñar un mecanismo que reduzca las emisiones de $\mathrm{CO} 2$ provocados por la deforestación de los bosques augura una catástrofe climática ("Colombia deja sin protección a selva" (2009)); y WWF en "Decepción y esperanza" (2010) que habla sobre la falta de acuerdos pactados en Copenhague así como del impacto positivo que puede generar la participación social en la toma de decisiones. 


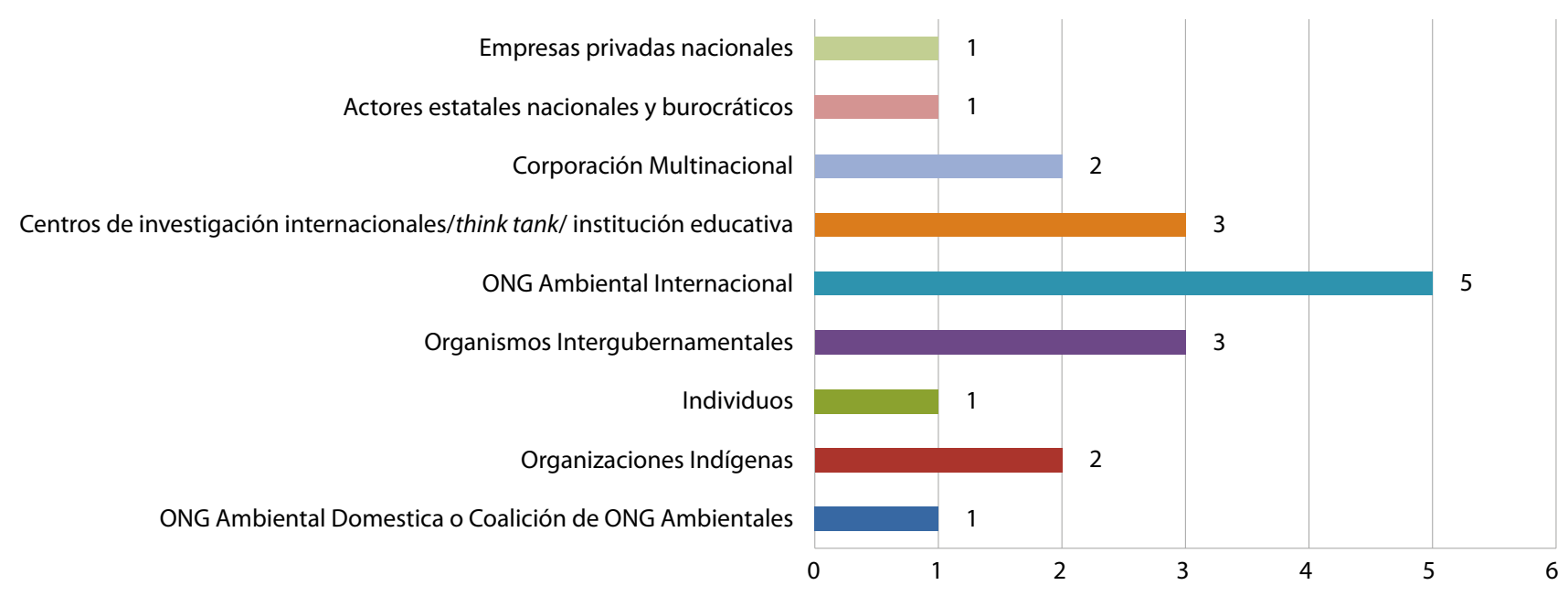

Figura 22. Representación organizacional de los defensores, para "REDD", "deforestación evitada" y"reducción de emisiones + deforestación"

En segundo lugar se encuentran los Centros de Investigación Internacionales y las Organizaciones Intergubernamentales, con tres artículos cada uno. Las Organizaciones Indígenas y las Corporaciones Multinacionales aparecen como defensores de dos noticias cada una; mientras que los Actores Estatales Nacionales y Burocráticos, las Empresas Privadas Nacionales y los Individuos sólo aparecen una vez.

Una apreciación interesante es que ninguno de los actores identificados se repiten en más de una noticia, ni a nivel organizacional ni a nivel personal, lo cual es una clara manifestación de que no hay una persona, o una organización, que haya decidido difundir información sobre REDD en los medios de comunicación, sino que son actores aislados que son citados o entrevistados por los medios de manera ocasional. Como menciona Gonzalo Pajares de Perú 21 , sería una buena idea "tener contacto con las fuentes y ser receptores de información, de tal manera que con un constante flujo de información, nos daríamos cuenta como están funcionando las cosas". Todo esto pone en manifiesto que en la actualidad no hay un contacto entre las fuentes vinculadas a la temática ambiental (mucho menos REDD) y los medios de comunicación.

Dado el bajo número de noticias, una vez más es difícil llegar a formar una idea clara de quiénes son los que están manejando el tema en el país. Es claro que las ONG ambientalistas son un grupo que está moviendo el tema, pero no hay un liderazgo claro y masivo de ninguna organización o individuo. Como menciona Tania García de DAR, no hay continuidad en la cobertura de temas ambientales, siendo las noticias muy esporádicas, y aun cuando se trate de un artículo bien trabajado la poca periodicidad hace que se pierda en el tiempo, y que no cale en el público. Los medios no están reportando en temas concretos ni hay un seguimiento a alguna iniciativa puntual. Esto se refleja en la falta de actores definidos, ya que no hay un movimiento significativo sobre REDD, y no hay una organización, o grupo de actores que esté liderando el discurso. No se percibe una estrategia de parte de ninguno de los diarios evaluados de hablar sobre medio ambiente o REDD, y los artículos analizados son más bien independientes los unos de los otros, oportunistas, captando noticias aisladas. Las únicas noticias que están de alguna manera vinculadas unas con otras son las que se dan o hablan de Copenhague y/o Cancún. La apreciación personal de Bertha Alvarado de la DGFFS del MINAG es que "En el Perú el tema ambiental es ignorado o mal abordado en datos y en muchos de los casos se tergiversan los hechos", y que "La calidad [de la información] es mala y en muy baja cantidad".

\subsubsection{Perspectivas de REDD}

La postura que toma el defensor de un marco puede ilustrar cómo este resalta ciertos aspectos, relegando otros. Los optimistas son quienes consideran que el futuro de REDD tiene más aspectos positivos que negativos, mientras que los pesimistas son aquellos que expresan una visión poco alentadora del futuro de REDD. 
Para el caso de la evaluación en el Perú (ver Figura 23), los actores identificados son, en su mayoría, optimistas sobre el futuro de REDD con 11 de los artículos codificados como "optimista" (58\%). El segundo grupo con mayor número de artículos es el de "neutral" (26\%) con cinco artículos, seguido de "pesimista" (16\%) con solo tres artículos.

Como se puede apreciar en la figura 24, la gran mayoría de actores tiene una visión optimista del futuro de REDD, siendo el grupo de Centros de Investigación Internacionales los que lideran esta tendencia, ya que los tres artículos donde este grupo aparece como defensor han sido codificados como optimistas. Si se evalúa a las ONG como un mismo grupo $^{13}$, tres de los artículos tienen una visión optimista, dos tienen una visión pesimista de REDD y uno tiene una visión neutral.

Las únicas tres posturas pesimistas en cuanto a REDD corresponden a dos artículos que tienen como defensores a ONG ambientalistas internacionales (Global Witness y Greenpeace); y a AIDESEP, una organización indígena. El articulo donde aparece Global Witness como defensor, "Los bosques peruanos están en la mira” (2009), trata sobre los posibles problemas de REDD a raíz de la COP 15 en Copenhague. Laura Furones, de Global Witness, identificada como la defensora en el artículo, menciona que "REDD es como una torta de la que muchas naciones quieren un pedazo", lo cual evidencia la falta de claridad y pautas definidas en los resultados del proceso llevado a cabo en Copenhague. La segunda noticia pesimista, cuyo defensor es Greenpeace, titulada "Colombia deja sin protección a selva” (2009), trata justamente de la falta de compromiso de parte del gobierno colombiano para establecer un mecanismo de REDD. En "Cambio climático: indígenas piden compensación económica” (2009), AIDESEP sostiene que el mecanismo REDD amenaza la diversidad ecológica, y resalta el hecho de que las plantaciones no son bosques.

Vale resaltar la falta de un discurso sobre la relación del mecanismo REDD con pueblos indígenas. Las organizaciones indígenas hacen defensa en 2 artículos mientras que las tierras indígenas cubren 15\% del territorio nacional, la gran mayoría de las cuales se

13 ONG ambientalistas, ya sean internacionales, o nacionales (ONG Ambiental Internacional y ONG Ambiental Doméstica o Coalición de ONG Ambientales).

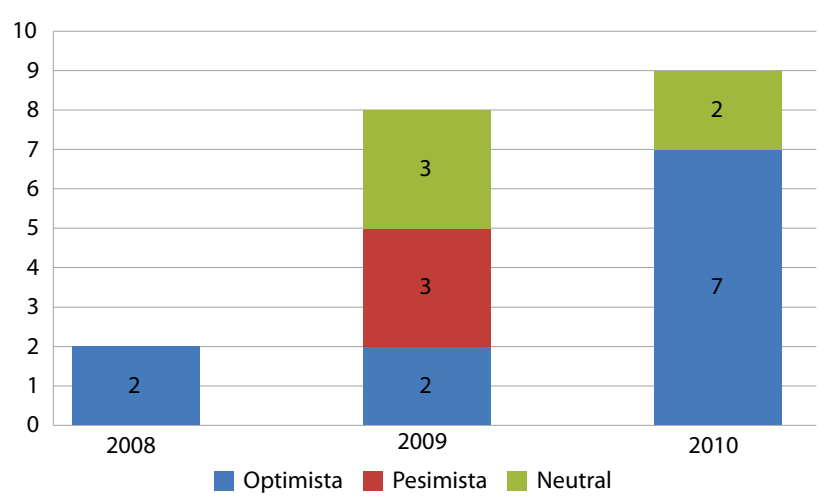

Figura 23. Evaluación del futuro de REDD por parte de defensores, por año, para "REDD", "deforestación evitada" y "reducción de emisiones + deforestación"

ubican en los bosques amazónicos. La Asociación Nacional de Pueblos Indígenas del Perú, AIDESEP, ha sido activa en las discusiones nacionales e internacionales, con un informe presentado durante la COP en Durban en 2011 (AIDESEP y FPP 2011) $y$ han influenciado las fases de readiness para REDD en el Perú (MINAM RPP). Aunque hay participación en el proceso, y REDD y los pueblos indígenas en Perú han recibido cubrimiento por parte de diarios internacionales (Biticombe, 2010; Ranadagan, 2011) y en la televisión (60 Minutes Australia, 2012), no llega a ser una voz dominante en los discursos en los periódicos nacionales ni subnacionales.

Estos resultados demuestran que, en general, los actores perciben las iniciativas del mecanismo REDD como positivas para reducir emisiones y conservar los bosques. No se ha podido establecer la razón del incremento de artículos positivos sobre REDD. Puede deberse a que no hay un patrón definido sobre la cobertura de las noticias, lo que lo hace un hecho totalmente aleatorio. Es necesario considerar que los actores que plantean la temática de REDD de manera positiva probablemente sean los que están tratando de impulsar estudios e investigaciones sobre REDD, tanto a nivel internacional como en el país. Entre ellos se encuentran los Centros de Investigación Internacionales (dentro de los cuales aparece CIFOR como defensor en una de las noticias) y las ONG Ambientalistas, por lo que no es de sorprender que haya una predominancia de puntos de vista optimistas sobre el tema. Posiblemente, ellos consideren que REDD puede llegar a ser un mecanismo interesante en el futuro, sin necesariamente sobredimensionar la oportunidad de REDD, promover la generación de expectativas, 


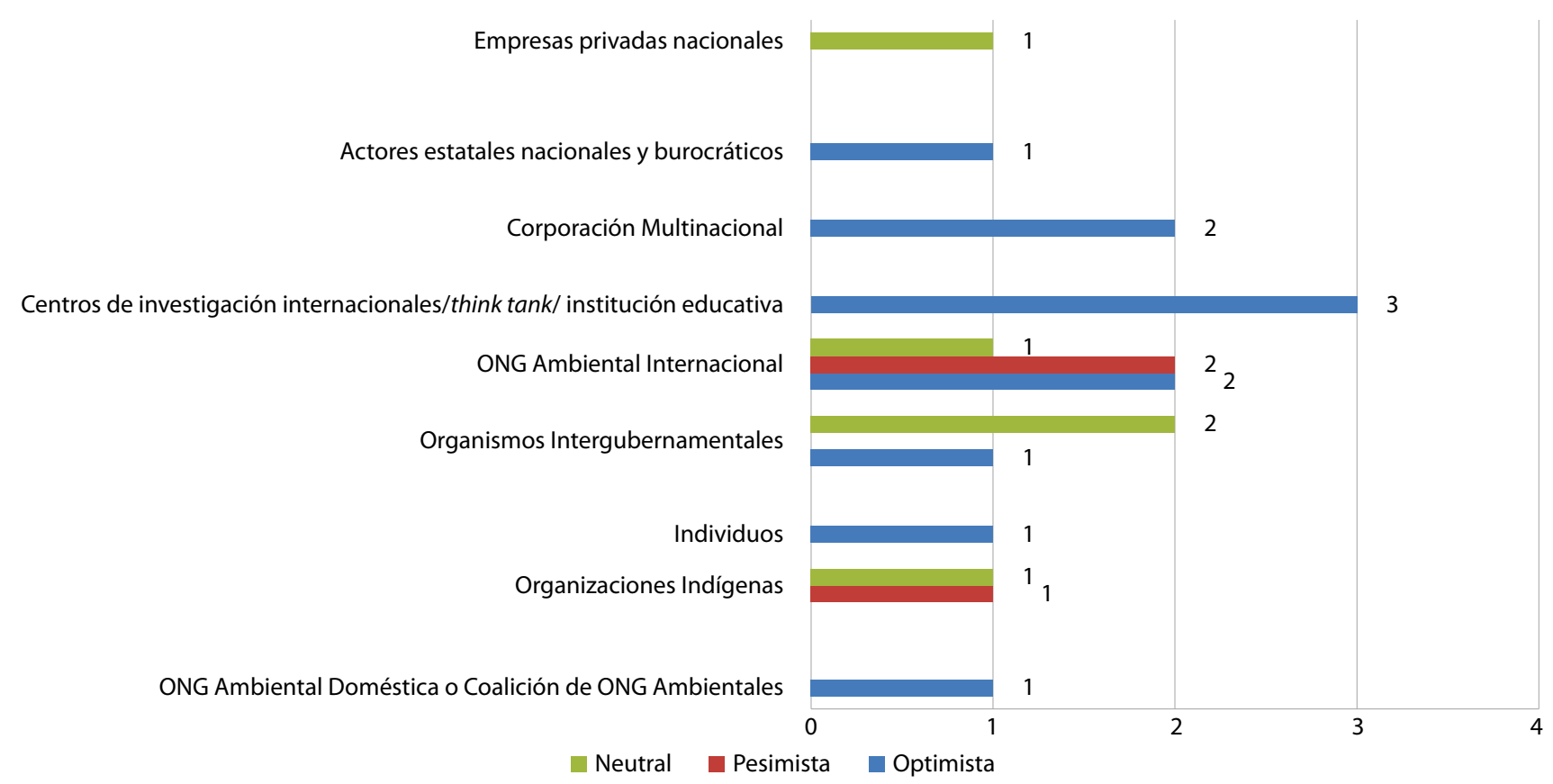

Figura 24. Evaluación del futuro de REDD por parte de los defensores, por organización, para "REDD", "deforestación evitada", y"reducción de emisiones + deforestación"

ni impulsar iniciativas. En general los centros de investigación promueven estudios sobre la realidad y sus potenciales.

\subsubsection{REDD y las 3Es}

La postura de los actores identificados en las 19 noticias de Nivel 3 fue evaluada para determinar si le daban prioridad a alguna de las $3 \mathrm{E}+\mathrm{s}$, efectividad, eficiencia, equidad, y otros cobeneficios (Angelsen y Wertz-Kanounnikouff, 2008). Como se puede ver en la figura 25, el análisis demuestra que no existe un eje que destaque muy por encima del resto, encontrándose la equidad junto con los otros cobeneficios en el primer lugar, con cinco noticias cada uno. En segundo lugar se encuentra la eficiencia del mecanismo REDD, con cuatro noticias, seguido de la efectividad, con tres artículos.

Resalta la importancia que se le da a temas de equidad y de otros cobeneficios, que están más vinculados con un aspecto social y conservacionista, que con el buen desarrollo de los proyectos en sí. Como ejemplo tenemos "Publirreportaje: Conservación y manejo de los bosques amazónicos y el nuevo paradigma de calentamiento y cambio climático global" (2009), que menciona que además de ayudar a la preservación de los bosques tropicales para asegurar el secuestro de carbono, REDD

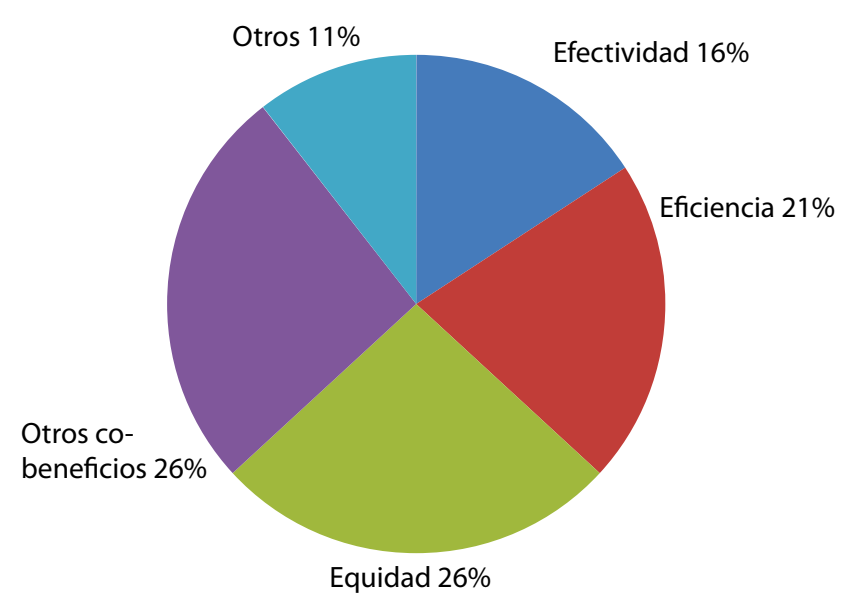

Figura 25. Prioridades de los defensores para resultados de REDD, para "REDD", "deforestación evitada" y "reducción de emisiones + deforestación"

podría también asegurar que los bosques continúen cumpliendo su rol social y económico en beneficio de las poblaciones locales. Cesar Morán, director ejecutivo de ACCA, en el artículo "De castaño a oscuro" (2009) menciona que es fundamental que "el Estado procure dar los beneficios del bosque a quienes ya lo cuidan y mantienen", refiriéndose a los castańeros de Madre de Dios. 
Si se evalúa la prioridad en cuanto a las $3 E$ s que le dan los distintos grupos de actores se puede apreciar que no hay una postura definida. Esto puede estar ligado, nuevamente, al bajo número de noticias halladas, lo que no permite analizar tendencias claras en los contenidos.

De acuerdo con las personas entrevistadas, se necesita crear espacios de disertación, encuentro y debate a partir del conocimiento de la realidad forestal y entendiendo las implicancias de los proyectos REDD. Se debe promover también alianzas estratégicas entre instituciones de investigación, los medios de comunicación y la administración del Estado, de tal manera que haya más información que permita desplegar todo el panorama de lo que implicaría

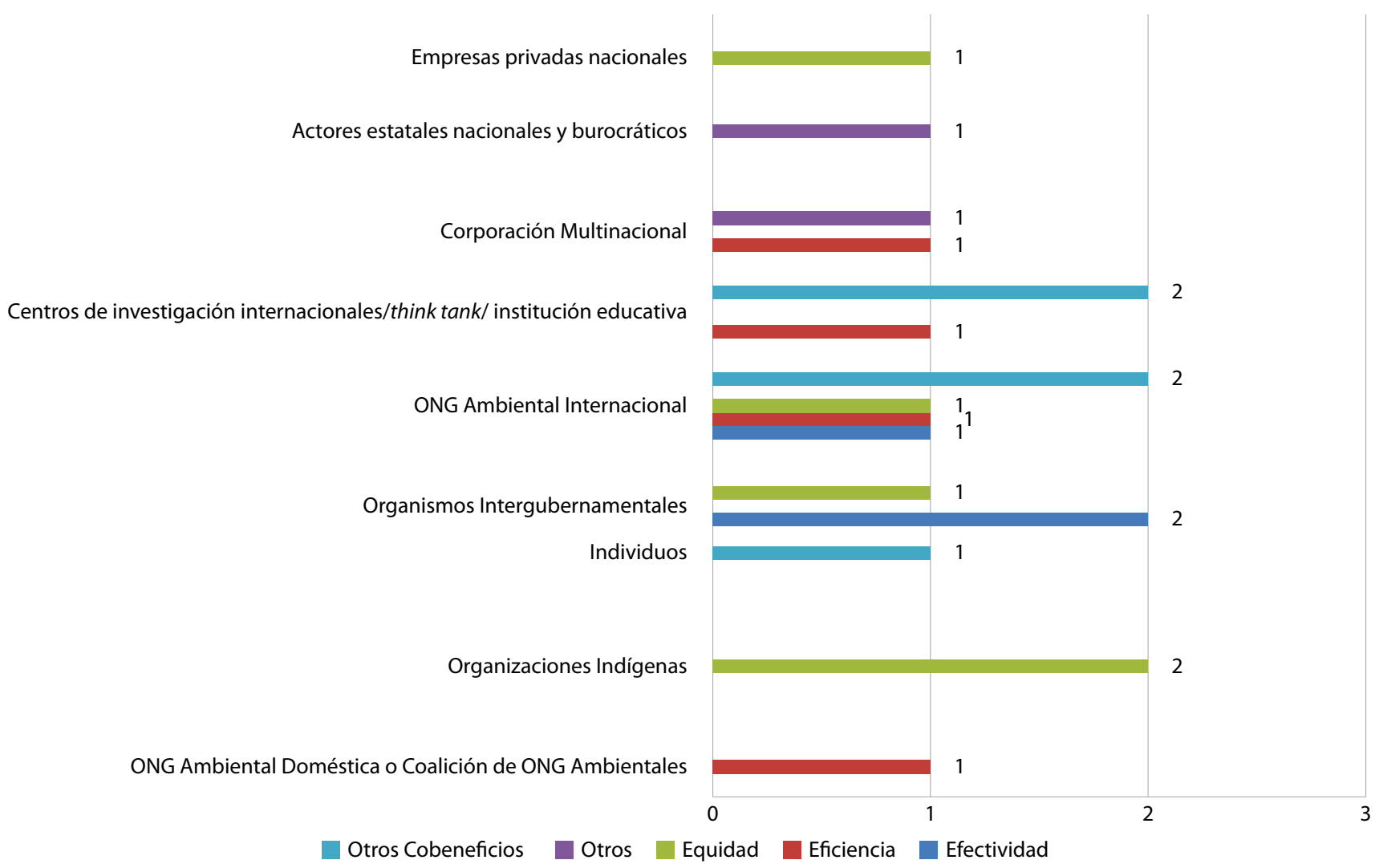

Figura 26. Prioridades de los defensores según la representación organizacional, para "REDD", "deforestación evitada" y "reducción de emisiones + deforestación" insertar el mecanismo REDD en el Perú. Juan José Rodríguez de la ONG The Nature Conservancy menciona que es importante "promover las noticias ambientales, los conceptos de REDD, las ventajas de este mecanismo para los diversos actores, tanto para los que contienen las parcelas, los gobiernos municipales, regionales y las diversas organizaciones, tratando de eliminar las barreras de las autoridades y facilitar los procesos". Lucía Ruíz, Directora Ejecutiva de CIMA menciona que "para entender REDD se tiene que entrar por el tema de cambio climático, adaptación, mitigación y por experiencias concretas que se están llevando a cabo en el país. Con ese tipo de explicaciones se puede entrar luego a hablar de herramientas e instrumentos económicos como REDD". 


\section{Conclusiones y recomendaciones}

Como se ha podido observar a lo largo del análisis, para ambas etapas del estudio el número de noticias que hablan de temas ambientales son muy pocas, siendo REDD un tema que se toca de manera muy escasa, y aún más escasas son las noticias que realizan un análisis más profundo del tema. Existen incluso eventos relevantes que no se han identificado en las noticias halladas. Esto ha dificultado considerablemente el análisis ya que debido al bajo número de artículos es muy difícil plantear conclusiones en ausencia de tendencias claras, salvo en ocasiones donde hay una marcada inclinación hacia una de las variables analizadas. Como menciona Tania García de DAR, no existe continuidad en la cobertura de temas ambientales, siendo las noticias muy esporádicas, y aun cuando se trate de un artículo bien trabajado la poca periodicidad hace que se pierda en el tiempo, y que no cale en el público.

De los 33 artículos hallados en el estudio nacional sobre REDD, solo 26 fueron analizados de manera más detallada ya que los siete restantes no contenían información suficiente. De los diez artículos hallados en el estudio regional, ninguno contaba con información suficiente para ser evaluado a mayor profundidad. De los ocho diarios evaluados en el estudio nacional, El Comercio es el que presentó más noticias del G1 ("REDD”, "deforestación evitada” y "reducción de emisiones + deforestación”), mas no del G2 ("cambio climático + bosques"), en tanto que el diario La República arrojó un número significativamente mayor que el resto. Si se comparan los hallazgos con la percepción de los entrevistados (tanto especialistas en REDD como periodistas), se puede ver que la mayoría considera que El Comercio es el diario que mayor información ambiental publica, lo cual es correcto si se evalúa el total de palabras clave buscadas (G1, G2 y la búsqueda más amplia). Es interesante que todos los entrevistados colocaran al diario Trome en el último puesto, ya que se encontró una noticia del grupo G2 en este diario, mientras que en los diarios Expreso y La Razón no se encontraron noticias para ninguno de los dos grupos de búsqueda. Esto indica que la percepción de las personas en cuanto a los diarios que publican información ambiental no es necesariamente real y se debe tener esto en cuenta al momento de planificar estrategias de propagación de información de temas ambientales, incluyendo REDD.
A raíz del análisis se puede concluir que la prensa ha ido incrementando la cobertura de temas relacionados con el mecanismode REDD, y con cambio climático y bosques, aunque de manera muy gradual y no representativa. Para el caso puntual de la búsqueda de noticias en diarios de alcance nacional relacionadas con REDD (empleando las palabras clave "REDD", "deforestación evitada" y "reducción de emisiones + deforestación"), las primeras noticias aparecen en el año 2008, con tres artículos en total, habiéndose encontrado 12 artículos en el año 2009, y 14 en 2010, lo que demuestra una tendencia creciente. Se debe mencionar que para el año 2011 se encontraron solo cuatro artículos, habiéndose realizado la búsqueda hasta fines de noviembre de 2011, lo que no lo hace comparable con los demás años.

Para el caso del análisis regional, además de ser muy escaso el número de noticias halladas en general, considerando todas las búsquedas, llama la atención la baja incidencia de noticias vinculadas con REDD, ya que se eligieron precisamente las regiones de Madre de Dios y San Martín debido a que se estimó que podrían ser las pioneras en el tema, y sin embargo no se encontró ninguna noticia sobre REDD en Madre de Dios. Se debe tener en cuenta, sin embargo, que aun cuando la incidencia de noticias es bastante baja, REDD sí es un tema que se está moviendo actualmente, existiendo un número significativo de organizaciones que están trabajando en ello. Los medios no se preocupan por transmitir información relacionada al tema, ya que como indica José Antonio Huamaní, conductor de Telepuerto al día, "solamente se habla de medio ambiente cuando hay conflictos sociales, a razón justamente contra el atentado a la Amazonía y la deforestación. Sin embargo, no se habla del ambiente desde un enfoque de concientización, sino más bien, se apunta a vender lo que se destruye, pero no se habla de cómo generar alternativas de solución".

Para el caso del número de artículos relacionados con REDD encontrados en los diarios regionales, se puede apreciar también una tendencia creciente, con solo una noticia en el año 2010 y nueve en 2011, todas halladas en diarios de la región San Martin. Sin embargo se deben tener en cuenta muchos factores 
que dificultaron la búsqueda de noticias para el estudio regional, como el caso de la búsqueda on line, donde los diarios no cuentan con banner de búsqueda confiables; mientras que para la búsqueda física en bibliotecas y hemerotecas, no se cuenta con una sistematización adecuada de los diarios, los cuales se encuentran en muy mal estado.

Del análisis es claro que la mayoría de noticias del estudio nacional están vinculadas con hechos internacionales, como es el caso de los picos que se dan en diciembre de 2009 y 2010, que coinciden con las COP 15 en Copenhague y la COP 16 en Cancún, respectivamente. Esto no quiere decir que no se cubran noticias nacionales o locales, pero sí es evidente que se le da mucho más cobertura a eventos internacionales de gran envergadura que a noticias de pequeña escala, ya sea porque no existen noticias a ser reportadas, o porque la prensa no las considera relevantes.

El tema más tratado en los artículos evaluados es el de Políticas y Formulación de Políticas, sin embargo ninguno de los artículos analizados habla específicamente de políticas concretas o incluso de procesos políticos. Sí se menciona el Protocolo de Kioto en muchos de los artículos de corte internacional, los cuales hacen referencia a Kioto para contextualizar el artículo, o para plantear una posición en cuanto a los avances logrados a partir de la fecha. La única noticia que de alguna manera menciona una política nacional es "Desde hoy se buscará una nueva dinámica ambiental” (2010) que habla del compromiso del Perú de conservar 54 millones de hectáreas de bosques a través del Programa Nacional de Conservación de Bosques.

Un tema recurrente en varias de las noticias del estudio nacional es la falta de estabilidad jurídica, lo que pone en riesgo los derechos de propiedad, y por lo tanto plantea un desafío importante para programas de REDD en el país. Otro desafío que se plantea es la burocracia estatal que en muchos casos dificulta el avance de procesos, creando trabas y elevando los costos de cualquier acción que se quiera realizar.

Las noticias a nivel nacional y subnacional son, en su mayoría, descriptivas y no analíticas, donde la información presentada en muchos casos describe un hecho o un evento, y no analiza a fondo las circunstancias. Se dan noticias ambientales pero difícilmente se explican sus causas históricas, económicas y culturales, lo que reduce el panorama reflexivo del público lector. Como indica Jaime Semizo de ISUR, "son muy pocas las noticias ambientales que se presentan, es decir, salen todas las semanas pero son muy cortas, son básicamente conflictos, denuncias, rebotan noticias de algún medio de Lima, se copia y pega".

La mayoría de los artículos encontrados provienen de agencias internacionales de noticias y son muy pocos los artículos que son escritos por periodistas nacionales. Como mencionan algunos de los entrevistados, es fundamental capacitar a los periodistas actuales y futuros en temas ambientales, que cada vez van a tomar más importancia en los medios y pueden ser aspectos muy sensibles que afectan a la población. Se podría pensar en incluir un curso ambiental en el currículo de las carreras de periodismo y comunicaciones, tal como fue recomendado por alguno de los entrevistados.

Si bien este estudio analiza diarios a nivel nacional y regional, no considera televisión, radio, páginas web ni ningún otro medio de comunicación. Mientras que no fue posible incluir un análisis de la radio en este estudio, por encontrarse fuera del alcance de la metodología y por la falta de búsquedas online de la historia de discusiones en las radios del país, se destaca como un medio de comunicación importante para el país para la diseminación de información y la formación de discursos nacionales. Siendo el Perú un país de bajos recursos, es importante considerar que mucha gente no tiene acceso a diarios y su único medio informativo es la radio, lo cual salió a la luz en varias de las entrevistas regionales, como lo indican Carla Mendoza, Secretaria Técnica de la mesa REDD en San Martín: "La radio, por otro lado, es un elemento de comunicación interesante en la región, bastante fuerte, sobre todo porque la señal televisiva no llega a los caseríos"; y Nelson Kroll, Coordinador del proyecto MADERACRE: "una de las cosas que más usa la gente es la radio, más que los diarios y es además, un elemento que puede llegar a más personas y llegar mejor". Es por ello que si se quiere realizar una campaña de difusión de REDD se deberá pensar en hacerlo a través de diferentes medios, con la finalidad de llegar al mayor número de actores, y la radio es el medio al que la mayor cantidad de personas tiene acceso, incluyendo a la gente de bajos recursos que en muchos de los casos son justamente los beneficiarios de proyectos REDD. 


\section{Bibliografía}

60 Minutes Australia, 2012. The Carbon Cowboy. 6 de julio de 2012. http://sixtyminutes.ninemsn. com.au/stories/8495029/the-carbon-cowboy.

Angelsen, A. y Wertz-Kanounnikoff, S., 2008. What are the key design issues for REDD and the criteria for assessing options? En: Angelsen, A. (ed.) Moving ahead with REDD: issues, options and implications. Centro para la Investigación Forestal Internacional (CIFOR), Bogor, Indonesia.

Bennet (citado en Boykoff 2008). Boykoff, M., 2008. The cultural politics of climate change discourse in UK tabloids.

Boykoff, M. 2008. The cultural politics of climate change discourse in UK tabloids. Political Geography.

Brockhaus, M. y Di Gregorio, M. 2012. A brief overview: Component 1 on national REDD+ policies and processes. Bogor, Indonesia, Centro para la Investigación Forestal Internacional (CIFOR): 4p.

Capellini, M. 2004. La prensa chicha en Perú. Revista Latinoamericana de Comunicación "Chasqui". Disponible en:http://chasqui. comunica.org/content/view/72/57/. [Consulta: 1 de octubre de 2012].

Comunicar, 2011. Movistar TV controla 60\% del mercado de la TV pagada en Perú. Disponible en: http://www.comunicar.info/2011/05/ movistar-tv-controla-60-del-mercado-de.html

Di Gregorio, M., Price, S., Saunders, C. y Brockhaus, M. 2012. Code book for the analysis of media frames in articles on REDD. Centro para la Investigación Forestal Internacional (CIFOR), Bogor, Indonesia.

DePerú, 2011. Directorio de periódicos locales del Perú. Disponible en: http://www.deperu.com/ medios/diarios.htm. [Consulta: 1 de octubre de 2012].

Derecho Ambiente y Recursos Naturales (DAR), 2011. La Situación de REDD en el Perú. Disponible en: http://www.gruporeddperu.net/ images/stories/publicaciones/REDD_peru01_2. pdf. [Consulta: 1 de octubre de 2012].

Fillieule, O. y Jiménez, M. 2006. The methodology of protest event analysis. Oxford University Press, Oxford, Reino Unido.
Grupo de opinión pública de la Universidad de Lima, 2007. Cuadro: confianza en instituciones no estatales. Disponible en: http://www.ulima. edu.pe/webulima.nsf/default/F598031D8994 3F2F05256E630017BD4C/\$file/barometro_ social_oct_2007-p4.pdf. [Consulta: 1 de octubre de 2012].

Gutierrez, C. 2005. La Radio en las Escuelas Rurales Andinas. Asociación Pukllasunchis. Disponible en: http://www.pukllasunchis.org/radio/pdfs/ Ponencia_Florida.pdf.

Inwent, 2009. REDD+ Marco Conceptual y Experiencias Latinoamericanas. Disponible en: http://www.eclac.cl/dmaah/noticias/ noticias/5/36375/REDD+Colombia_memorias_ final_lowres.pdf. [Consulta: 1 de octubre de 2012].

Laumann, E. y Knoke, D. 1987. The organizational state: social choice in national policy domains. University of Wisconsin Press, Madison, WI, EUA.

May, P., Calixto, B. y Gebara, M. 2011. REDD+ politics in the media: a case study from Brazil. Working Paper 55. Centro para la Investigación Forestal Internacional (CIFOR), Bogor, Indonesia.

McCombs, M. 2004. Setting the Agenda. The Mass Media and Public Opinion. Polity Press, Malden, MA, EUA.

Milburn, M. 1991. Persuasion and Politics. The Social Psychology of Public Opinion. Brooks/ Cole Belmont, Cal., EUA.

Ministerio del Ambiente, 2010. Segunda comunicación nacional de cambio climático, Iniciativa Nacional de Conservación de Bosques. Disponible en: http://sinia.minam.gob.pe/index. php?idElementoInformacion $=245$. [Consulta: 1 de octubre de 2012].

Ministerio del Ambiente, 2011. Carta No 055 - 2011 - DVMDERN/MINAM. Carta a la Secretaría Ejecutiva de la Convención Marco de las Naciones Unidas.

Muñoz, C. 2008. La Comunicación y los medios de comunicación como motor de desarrollo e impulso de cambios sociales. Disponible en: http://www.atinachile.cl/content/view/170946/ la-comunicacion-y-los-medios-de-comunicacion- 
como-motor-de-desarrollo-e-impulso-decambios-sociales.html. [Consulta: 1 de octubre de 2012].

OEI, 2011. Medios de Comunicación y cultura. Organización de Estados Iberoamericanos para la Educación, la Ciencia y la Cultura. Disponible en: http://www.oei.es/cultura2/peru/07.htm. [Consulta: 1 de octubre de 2012].

PCM, 2008. Presidencia del Consejo de Ministros y Comisión Interministerial de Asuntos Sociales. Informe del Cumplimiento de los Objetivos de Desarrollo del Milenio Perú 2004-2008.

Perú 21. (24 de febrero de 2012). "La clase media es el 56\% de la población urbana."

Ranganathan, J. 2010. REDD Alert: Lessons from Peru's Camisea Pipeline Project. Huffington Post, 2 de agosto de 2010.

Revista Quehacer, 2007, número 164. "En la radio la política es más sabrosa”. Entrevista a Adrián Menéndez por Abelardo Sánchez León, Lima, Perú.

Sandoval, C. y Al-Ghassani, A. 1990. Inventario de los medios de comunicación en Costa Rica. Escuela de ciencias de la comunicación, UCR, San José, Costa Rica.

SBSTA, 2008. Submission FCCC/SBSTA/2008/ MISC.4. Submission of the Republic of Paraguay on behalf of Argentina, Honduras, Panamá and Peru on methodological issues and criteria for evaluating actions for reducing emissions from deforestation and forest degradation in developing countries.

Sydney Morning Herald, 2011. Carbon Cowboys. 23 de julio de 2011.

Vargas, R. 2010. El poder de los medios de comunicación. En: Perú Económico.com. Portal de noticias económicas en tiempo real. Disponible 1 de octubre de 2012 en: http:// perueconomico.com/ediciones/51-2010-nov/ articulos/858-el-poder-de-los-medios-decomunicacion.

\section{Artículos citados en el documento}

Adaptación al cambio climático. (15 de octubre de 2008). Voces.

AFP. (29 de noviembre de 2010). Desde hoy se buscará una nueva dinámica ambiental. El Peruano.

Benites B., M. (7 de setiembre de 2010). La importancia del cuanto. Gestión.
Blume, J. (2 de febrero del 2004). El hombre: la especie más peligrosa. La República.

Bonos de carbono financiarán proyectos forestales en Perú. (5 de marzo de 2008). Gestión.

Brockhaus, M. y Di Gregorio, M. 2012. A brief overview: Component 1 on national REDD+ policies and processes. Bogor, Indonesia, Centro para la Investigación Forestal Internacional (CIFOR): 4p.

Cambio climático: indígenas piden compensación económica. (11 de diciembre de 2009). La República.

Castillo T., D. y Baker, T. (20 de diciembre de 2009). Publirreportaje: Conservación y manejo de los bosques amazónicos y el nuevo paradigma de calentamiento y cambio climático global. La República.

Colombia deja sin protección a selva. (15 de diciembre de 2009). La República.

Decepción y esperanza. (05 de enero de 2010). Gestión.

Del Águila, H. (18 de octubre de 2010). 29 científicos internacionales evaluaron bosques de Ucayali. Ahora.

EFE. (5 de octubre de 2008). Ecuador: ¿'Medio ambiente o petróleo? La República.

EFE. (30 de noviembre de 2010). Medidas contra la deforestación pueden reducir hasta en $80 \%$ la extinción de especies, según estudio. El Comercio.

Efecto Invernadero. (13 de marzo de 2001). La República.

En San Martín se trabaja en el cumplimiento de compromisos para mitigar daños del efecto invernadero. (8 de agosto de 2011). Voces.

Financiarán primer proyecto para evitar deforestación de bosques (1 de octubre de 2008). Gestión.

Gobierno peruano destinará 12 millones de dólares para la conservación de bosques. 5 de marzo de 2011). Voces.

II Encuentro de nacionalidades indígenas amazónicas. (10 de noviembre de 2011). Voces.

Miró Quesada M., M. (15 de diciembre de 2009). Coalición africana se pone fuerte en reunión mundial. El Comercio.

Presidentes regionales darán a conocer problemática de la selva peruana. (4 de abril de 2011). Voces.

Ráez L., E. (8 de noviembre de 2009). Hermano fuego, hermano bosque. El Comercio. 
Reuters. (2 de diciembre del 2010). El nuevo Google EarthEngine ayudará a evitar la deforestación. El Comercio.

Reuters. (24 de febrero de 2010). Revela un estudio de las Naciones Unidas. El Comercio.

Rocha R., A. (4 de julio de 2009). De castaño a oscuro. El Comercio.

Struyf, E. (5 de diciembre de 2009). Especial: Conferencia de Copenhague. El Comercio

Struyf, E. (11 de octubre de 2009). Especial. Freno a la deforestación. El Comercio

Struyf, E. (15 de diciembre de 2009). Los bosques peruanos están en la mira. El Comercio.
Tejada, J. (16 de setiembre de 2009). Premian a ganadores de concurso de dibujo sobre cambio climático. Voces.

Tejada, J. (28 de octubre de 2008). Resultados de escenarios de cambio climático. Voces.

Thomas, V. y Chomitz, K. (2 de enero de 2010).Los bosques y el clima. La República.

Urrunaga, J.M. (24 de octubre de 2009). Emisión imposible. El Comercio.

Venderán bonos de carbono gracias a los bosques (26 de agosto de 2010). El Comercio. 

Los Documentos de trabajo de CIFOR contienen resultados preliminares o avanzados de investigaciones relativas a problemas de los bosques tropicales, que deben ser publicados de manera oportuna. Son generados para informar y promover el debate. Su contenido ha sido revisado internamente pero no ha pasado el proceso más largo de la revisión externa por pares.

En este estudio, hemos evaluado la cobertura periodística del mecanismo REDD en periódicos nacionales y subnacionales del Perú para entender mejor los mensajes que llegan a los lectores peruanos. A nivel nacional, encontramos tan solo 33 artículos sobre REDD en ocho periódicos nacionales: El Comercio, Perú 21, Gestión, Expreso, La República, La Razón, El Peruano y Trome. Expandiendo la búsqueda a cambio climático y bosques, encontramos 203 noticias. Al encontrar esta baja cobertura en la prensa nacional, elegimos 2 departamentos del país donde se encuentra la mayoría de proyectos REDD y presentan mayores avances en las fases de preparación: San Martín (Voces y Ahora) y Madre de Dios (Don Jaque y El Observador). Pero, de nuevo, encontramos únicamente 10 artículos sobre REDD, y 10 más al ampliar la búsqueda a cambio climático y bosques.

En los periódicos regionales, todos los artículos mencionaron REDD pero no trataron el tema con una profundidad suficiente para poder evaluar los marcos y enfoques temáticos. En los periódicos nacionales, 26 artículos llegaron a discutir REDD con mayor profundidad. La mayoría de ellos son optimistas sobre REDD (58\%). Mientras que se estima que en el país hay 41 proyectos REDD, 74\% de las noticias tratan de temas internacionales. Los temas centrales de los artículos fueron mayormente relacionados con políticas o ecología y los actores principales fueron las ONG ambientales. Los enfoques están distribuidos casi igualmente entre los cobeneficios (26\%), la equidad (26\%), la eficiencia (21\%), y la efectividad (16\%) de REDD. Aunque REDD se creó en base a la premisa de mitigación del cambio climático, para los cuales la eficiencia y efectividad son las preocupaciones más relevantes, la equidad y los cobeneficios son los temas centrales en el Perú: los derechos de los pueblos indígenas, la reducción de la pobreza, y la conservación de la biodiversidad figuran como los temas más relevantes en la cobertura del tema y como prioridades nacionales.

Esta investigación fue realizada por CIFOR como parte del Programa de Investigación del CGIAR'Bosques, árboles y agrosilvicultura: Medios de vida, paisajes y gobernanza'. El objetivo del programa es mejorar el manejo y uso de los bosques, la agroforestería y los recursos genéticos de los árboles a lo largo del el paisaje, desde bosques hasta plantaciones. CIFOR dirige el programa de colaboración en asociación con Bioversity International, el Centro Internacional de Agricultura Tropical y el Centro Mundial de Agroforestería.

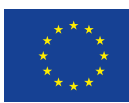

